\title{
Non-canonical odor coding ensures unbreakable mosquito attraction to humans
}

\author{
Meg A. Younger ${ }^{1,2,7^{\star}}$, Margaret Herre ${ }^{1,2,7^{*}}$, Alison R. Ehrlich ${ }^{1,4}$, Zhongyan Gong ${ }^{1,5}$, Zachary \\ N. Gilbert ${ }^{1}$, Saher Rahiel ${ }^{1}$, Benjamin J. Matthews ${ }^{1,3,6}$, Leslie B. Vosshall1,2,3*
}

\section{SUMMARY}

\begin{abstract}
Female Aedes aegypti mosquitoes show strong innate attraction to humans. This chemosensory behavior is critical to species survival because females require a bloodmeal to reproduce. Humans, the preferred host of Ae. aegypti, produce a complex blend of odor cues along with carbon dioxide $\left(\mathrm{CO}_{2}\right)$ that attracts females ready to bite. Mosquitoes detect these cues with heteromeric ligand-gated ion channels encoded by three different chemosensory receptor gene families. A common theme in other species is that olfactory neurons express a single receptor that defines their chemical specificity and that they extend axons that converge upon dedicated glomeruli in the first sensory processing center in the brain. Such an organization permits the brain to segregate olfactory information and monitor activity of individual glomeruli to interpret what smell has been encountered. We have discovered that Ae. aegypti uses an entirely different organizational principle for its olfactory system. Using genetic strains that label subpopulations of olfactory neurons, we found that many neurons co-express multiple members of at least two of the chemosensory receptor families. This unexpected co-expression is functional, as assessed by in vivo calcium imaging showing that a given glomerulus is activated by multiple ligands detected by different receptor families. This has direct functional consequences for mosquito behavior. Mutant mosquitoes that cannot sense $\mathrm{CO}_{2}$ can be behaviorally activated by a volatile amine that stimulates the $\mathrm{CO}_{2}$ glomerulus. This non-canonical olfactory system organization featuring overlapping receptor expression may explain the female mosquito's robust and 'unbreakable' attraction to humans.
\end{abstract}

Key words: Aedes aegypti; mosquito; odor coding; olfaction; GCaMP imaging; behavior

\section{INTRODUCTION}

Increased global travel, a growing world population, and rising temperatures are all combining to increase the emergence and transmission of novel disease-causing pathogens. This includes vector-borne diseases, in which pathogens are spread by "vector" organisms such as mosquitoes, ticks, sandflies, and fleas. Diseases spread by these arthropods collectively account for more than 700,000 deaths every year (WHO, 2020). Female Aedes aegypti mosquitoes spread arboviruses including dengue, Zika, yellow fever, and chikungunya. Only female mosquitoes bite, and they do so because they require a blood-meal for reproduction (Allan et al., 1987). Ae. aegypti prefer to bite human hosts, which contributes to their effectiveness as a disease vector (Brown et al., 2014; Gouck, 1972; McBride et al., 2014). To identify human hosts, mosquitoes rely heavily on chemosensory cues, including carbon dioxide $\left(\mathrm{CO}_{2}\right)$ emitted from breath, and human body odor, which is a mixture of hundreds of different individual odorants including lactic acid and volatile amines such as ammonia (Acree et al., 1968; Bernier et al., 2000; Davis, 1984; Gallagher et al., 2008; Geier et al., 1999; Smallegange et al., 2005; Smith et al., 1970).

Insects detect such chemosensory cues using membrane receptors encoded by three large gene families, Olfactory Receptors (ORs), lonotropic Receptors (IRs), and Gustatory Receptors (GRs). All three gene families encode ionotropic ligand-gated ion channels, in contrast to the metabotropic $G$

\footnotetext{
${ }^{1}$ Laboratory of Neurogenetics and Behavior, The Rockefeller University, New York, NY 10065 USA, ${ }^{2}$ Kavli Neural Systems Institute, New York, NY 10065 USA, ${ }^{3}$ Howard Hughes Medical Institute, New York, NY 10065 USA ${ }^{4}$ Current address: New York University School of Medicine, 550 First Ave, New York, NY $10016{ }^{5}$ Current address: Helen Wills Neuroscience Institute, University of California, Berkeley, Berkeley, CA 94720 USA ${ }^{6}$ Current address: University of British Columbia, Department of Zoology, Vancouver, BC V6S 0K3 Canada ${ }^{7}$ These authors contributed equally ${ }^{*}$ Correspondence: meg.younger@gmail.com (M.A.Y.), margo.herre@gmail.com (M.H.), leslie.vosshall@rockefeller.edu (L.B.V.)
} 
protein-coupled odorant receptors utilized by vertebrates and C. elegans nematodes (Ihara et al., 2013). ORs are odorant-gated ion channels (Butterwick et al., 2018; Sato et al., 2008; Wicher et al., 2008) that are formed by a heteromultimeric complex of the conserved co-receptor Orco and a ligand-sensitive OR (Benton et al., 2006; Larsson et al., 2004; Neuhaus et al., 2005; Sato et al., 2008). IRs are variant ionotropic glutamate receptors that are formed by one or more of three conserved co-receptors, Ir25a, Ir8a, and Ir76b, and ligand-sensitive subunits that determine the selectivity of the receptor complex (Abuin et al., 2011; Benton et al., 2009; Silbering et al., 2011). Although GRs are primarily taste receptors (Clyne et al., 2000; Montell, 2009; Scott et al., 2001), several GRs form a complex that detects carbon dioxide $\left(\mathrm{CO}_{2}\right)$ (Jones et al., 2007; Kwon et al., 2007). $\mathrm{CO}_{2}$ is an important volatile human host cue that activates and attracts mosquitoes (Gillies, 1980). In Ae. aegypti, Gustatory Receptor 3 (Gr3) encodes an essential subunit of the $\mathrm{CO}_{2}$ receptor, and $\mathrm{Gr} 3$ mutant mosquitoes lose all sensitivity to $\mathrm{CO}_{2}$ (McMeniman et al., 2014).

Because mosquitoes specialize on humans and require blood to reproduce, the drive to find humans is strong and innate. Indeed, even mosquitoes genetically engineered to eliminate genes critical for peripheral detection of host sensory cues are able to find and bite people. Animals lacking the olfactory receptor co-receptor (Orco), the obligate co-receptor required for the function of the entire family of ORs, show strong attraction to humans (DeGennaro et al., 2013). Deleting the Ir8a co-receptor reduces but does not eliminate attraction to humans (Raji et al., 2019). Similarly, while mosquitoes lacking the obligate $\mathrm{CO}_{2}$ receptor subunit, Gr3, do not respond to $\mathrm{CO}_{2}$ and show impaired behavioral responses in laboratory assays, they are highly effective in finding humans in a more naturalistic semi-field setting (McMeniman et al., 2014). It is not known how the mosquito olfactory system is seemingly infallible in its ability to detect humans.

The cloning of the first odorant receptors by Buck and Axel in 1991 (Buck and Axel, 1991) led to the subsequent discovery that each olfactory sensory neuron expresses a unique odorant receptor that specifies its functional properties. In the well-studied olfactory systems of Drosophila melanogaster flies (Clyne et al., 1999; Gao and Chess, 1999; Vosshall et al., 1999) and Mus musculus mice (Bashkirova and Lomvardas, 2019; Chess et al., 1994), olfactory sensory neurons are thought to express a single olfactory receptor. In both species, neurons expressing a given receptor project axons to dedicated olfactory glomeruli in the first sensory processing center in the brain, the antennal lobe in insects (Couto et al., 2005; Fishilevich and Vosshall, 2005; Vosshall et al., 2000) and the olfactory bulb in vertebrates (Mombaerts et al., 1996; Ressler et al., 1994; Vassar et al., 1994). This "one-receptor - to - one - neuron - to - one glomerulus" organization is believed to be a widespread motif in both invertebrate and vertebrate olfactory systems, and the convergence onto discrete glomeruli is hypothesized to permit the brain to parse which subpopulation of olfactory neurons is activated by a given odor (Rubin and Katz, 1999; Uchida et al., 2000; Wang et al., 2003).

Consistent with this organization, the number of expressed chemosensory receptors in the OR and IR gene families roughly correlates to the number of olfactory glomeruli. This holds true in Drosophila melanogaster flies ( 60 receptors/ 55 glomeruli) (Benton et al., 2009; Laissue et al., 1999; Robertson et al., 2003), the honey bee Apis mellifera ( 180 receptors/ 160 glomeruli) (Flanagan and Mercer, 1989; Robertson et al., 2010), and the tobacco hornworm Manduca sexta ( 60 receptors/ 70 glomeruli) (Grosse-Wilde et al., 2011). Based on these studies, it is widely thought that merely counting the number of antennal lobe glomeruli in a new species would be reasonably predictive of the number of chemosensory receptors found in its genome. In Ae. aegypti, however, there is a striking mismatch between the number of expressed chemosensory receptors and the number of antennal lobe glomeruli, with at least twice as many receptors as available glomeruli (Bohbot et al., 2007; Ignell et al., 2005; Matthews et al., 2018; Shankar and McMeniman, 2020; Zhao et al., 2020). How is the mosquito olfactory system organized to accommodate so many receptors and does this departure from rules established in other species explain their exquisite ability to locate human hosts?

In this study, we developed a CRISPR-Cas9-based genetic knock-in strategy in Ae. aegypti to generate a suite of genetically-modified mosquito strains that label molecularly distinct populations of olfactory sensory neurons. We used these strains to understand how human odor is encoded in the mosquito olfactory system. Combining anatomical analysis of these lines with extensive RNA in situ expression analysis, we found that the olfactory system of Ae. aegypti does not have the expected "one-receptor-to-one-neuronto-one-glomerulus" organization seen in other organisms. We frequently observed co-expression of multiple chemosensory receptors from at least two of the three receptor gene superfamilies within individual olfactory sensory neurons. Antennal lobe glomeruli were often innervated by olfactory sensory neurons expressing different receptors. We hypothesized that this unconventional organization underlies the robust, seemingly unbreakable, properties of the Ae. aegypti olfactory system in detecting human odor. To test this, we examined a minimal mixture that drives hostseeking behavior, the combination of $\mathrm{CO}_{2}$ and lactic acid. We found that the neurons that sense $\mathrm{CO}_{2}$ express not only the $\mathrm{CO}_{2}$ receptor gene $\mathrm{Gr} 3$, but also members of the IR family of chemosensory receptors that detect acids and amines. Using in vivo functional calcium imaging we found that these $\mathrm{CO}_{2}$ neurons also sense volatile amines, consistent with their co-expression of $\mathrm{Gr} 3$ and IRs. Moreover, triethyl amine can substitute for $\mathrm{CO}_{2}$ to drive attraction to lactic acid in mutants that cannot sense $\mathrm{CO}_{2}$. This sensory organization, in which multiple receptors that respond to very different types of chemosensory stimuli are co-expressed, suggests a redundancy in the code for human odor. We speculate that this design supports the robust human host-seeking seen in this olfactory specialist. 


\section{RESULTS}

Mismatch in chemosensory receptor and olfactory glomerulus number suggests a novel olfactory organization

In the mosquito, olfactory cues are sensed by olfactory sensory neurons in the antenna and the maxillary palp, whose axons project to the ipsilateral antennal lobe of the brain (Distler and Boeckh, 1997; Ignell et al., 2005) (Figure 1A-B, $\mathrm{S} 1 \mathrm{~A}-\mathrm{C})$. The antennal lobe, the insect equivalent of the vertebrate olfactory bulb, is organized into discrete olfactory glomeruli in which axons from peripheral olfactory sensory neurons terminate and synapse with local interneurons and projection neurons that relay olfactory information to the higher brain (Stocker, 1994). Previous studies used morphological criteria to define 50 (Ignell et al., 2005), 60 (Zhao et al., 2020), or 81 (Shankar and McMeniman, 2020) discrete olfactory glomeruli in the female Ae. aegypti antennal lobe. In this study, we define approximately 65 olfactory glomeruli $(64.9 \pm 0.9$, mean \pm SEM), obtained by counting antennal lobe glomeruli in the left hemisphere of 12 female $A e$. aegypti brains stained to reveal synaptic neuropil (Figure $1 \mathrm{~B}, \mathrm{I}, \mathrm{K}, \mathrm{S} 2-5)$. The glomerulus count ranged from 60-72 glomeruli per antennal lobe, indicating a high level of variability in the organization of the antennal lobe (see Methods). We generated 3-D reconstructions of complete antennal lobes and saw considerable variability in the size and shape of the glomeruli (Figure S1). We were able to consistently identify certain landmark glomeruli, most notably the three glomeruli that are innervated by the maxillary palp (Ignell et al., 2005; Shankar and McMeniman, 2020) (Figure S1D-K).

The canonical "one-receptor-to-one-neuron-to-one glomerulus" organization posits that the number of chemosensory receptors should roughly match the number of glomeruli in the antennal lobe (Figure 1D). While there is not yet a clear consensus on the number of olfactory glomeruli in $\mathrm{Ae}$. aegypti, it ranges from 50 to 81 . How does this relate to the number of chemosensory receptors expressed? In the updated Ae. aegypti genome (Matthews et al., 2018), there are 117 OR, 135 IR, and 72 GR genes for a total of 324 structural genes that could function in the olfactory system (Figure $1 \mathrm{E})$. We have reanalyzed published RNA expression data (Matthews et al., 2016) using multiple thresholds to estimate the number of receptors expressed in the antenna and maxillary palp. Even at the conservative threshold of 5 transcripts per million (TPM), the mosquito olfactory system expresses 102 chemosensory receptors, and moving the threshold to 2, 1, or 0.5 TPM increases the number of receptors plausibly expressed to 134,156 , and 178 , respectively (Figure 1F,G, Data File 1). Thus, there are many more chemosensory receptors expressed in the olfactory system than available antennal lobe glomeruli, suggesting that the organization of the Ae. aegypti olfactory system must differ from the canonical scheme. We speculate that the mismatch can be resolved by expressing multiple receptors per neuron or having multiple different types of neurons co-converge on a single glomerulus or both (Figure $1 \mathrm{H}$ ).
To begin to distinguish between these two organizational principles, we generated a collection of CRISPR-Cas9 gene-targeted strains that label subpopulations of olfactory neurons using the Q-system, a binary expression system similar to Gal4/UAS (Brand and Perrimon, 1993) that uses cell type-specific expression of the QF2 transcription factor to induce expression of an effector from the QF2 binding QUAS enhancer (Potter et al., 2010). We introduced an inframe insertion that replaced the stop codon of each of the co-receptors Orco, Ir25a, Ir8a, and Ir76b, as well as the $\mathrm{CO}_{2}$ receptor subunit Gr3 with the transcription factor QF2 (Figure 1I, S2-S6. See Data File 1 for a full description of all genotypes by figure) (Matthews et al., 2019; Potter et al., 2010; Riabinina et al., 2016). These five new gene-sparing knock-in strains were designed to cause minimal disruption to the locus to increase the likelihood that they would faithfully report expression of the endogenous gene. We crossed these QF2 driver lines individually to a QUAS-CD8:GFP reporter to label neuronal membranes and visualized axonal projection patterns in the antennal lobe.

Orco, Ir25a, Ir8a, and Ir76b co-receptor driver lines were expressed in olfactory sensory neurons with distinct projection patterns in the antennal lobe (Figure 1I-K). Unexpectedly, neurons that expressed Ir25a projected to almost all of the glomeruli in the antennal lobe $(89.9 \pm 1.4 \%$, mean \pm SEM, $n$ = 3)(Figure $1 \mathrm{I}-\mathrm{K}, \mathrm{S} 3$ ), and expression overlapped extensively with glomeruli labeled by Orco (Figure 1I-K, S2, S3). While these co-receptor driver lines labeled glomeruli in the same regions from brain to brain, the interindividual expression patterns were not identical, consistent with the variability in glomerular anatomy that we have observed (see Methods). Neurons that detect $\mathrm{CO}_{2}$ are located in the maxillary palp (Grant et al., 1995; Lu et al., 2007; Omer and Gillies, 1971) and we saw that Gr3-expressing neurons projected to a large glomerulus in the posterior antennal lobe, Glomerulus 1 (Figure 1I-K, see Methods for full discussion of glomerulus nomenclature) which is also innervated by Ir25a-expressing neurons. We also noted the presence of a second small glomerulus that was often innervated by Gr3-expressing neurons in the antenna (Figure S6B). These initial findings point to the overlap of $O R$-, IR-, and GR-expressing neurons in the antennal lobe of Ae. aegypti, which are believed to remain segregated in Drosophila melanogaster.

Co-expression and co-convergence of Orco and Ir25a in the mosquito olfactory system

The high degree of overlap between glomeruli labeled by Orco- and Ir25a-expressing olfactory sensory neurons suggests that there is either widespread Orco and Ir25a co-expression within individual sensory neurons or that Orco and Ir25a are expressed in different neurons whose axons coconverge onto individual antennal lobe glomeruli or both (Figure 1H). To distinguish between these possibilities, we adapted the Split-QF2 system (Riabinina et al., 2019) for use in the mosquito. This system "splits" the transcription factor QF2 into two components, the DNA binding domain (QF2$\mathrm{DBD}$ ) and the activation domain (QF2-AD) each tagged with a synthetic leucine zipper (Figure 2A,B). When both the QF2-DBD and QF2-AD are co-expressed in the same cell, 
bioRxiv preprint doi: https://doi.org/10.1101/2020.11.07.368720; this version posted November 8, 2020. The copyright holder for this preprint (which was not certified by peer review) is the author/funder, who has granted bioRxiv a license to display the preprint in perpetuity. It is made available under aCC-BY 4.0 International license.

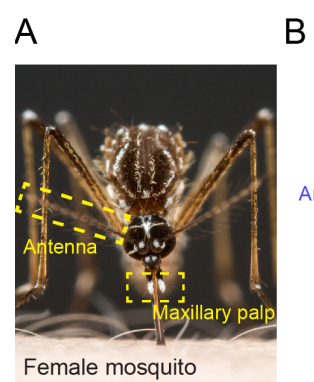

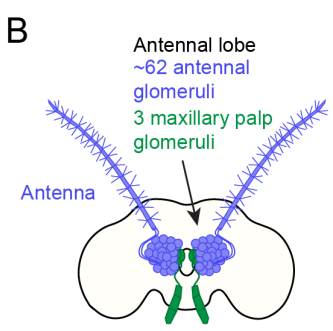

Maxillary palp

C
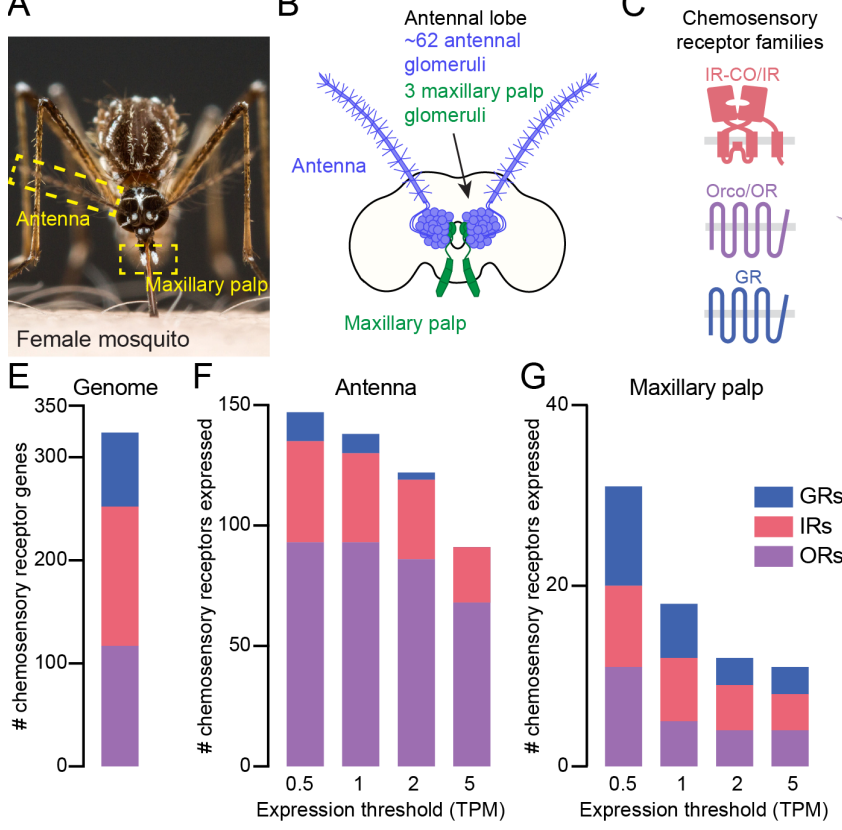

Expression threshold (TPM)

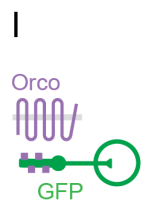

GFP

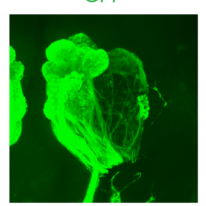

GFP
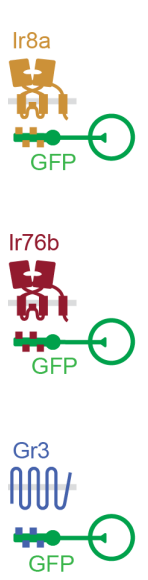
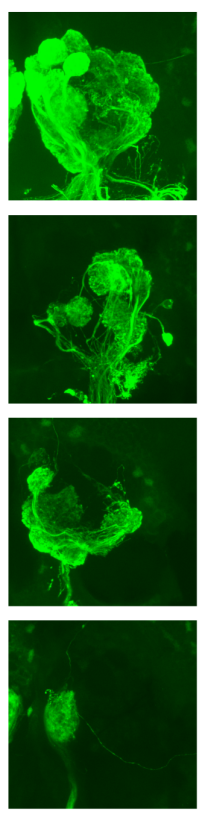

GFP BRP
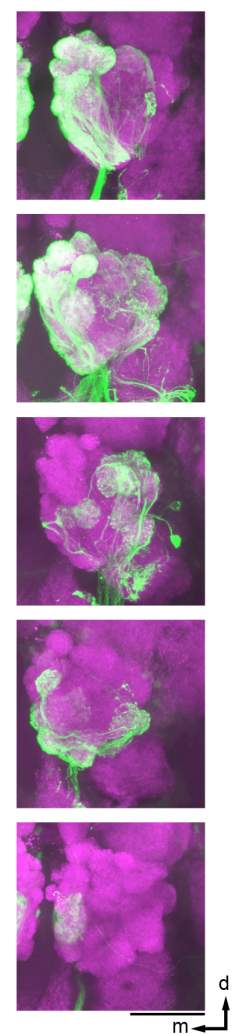

$\mathrm{J}$
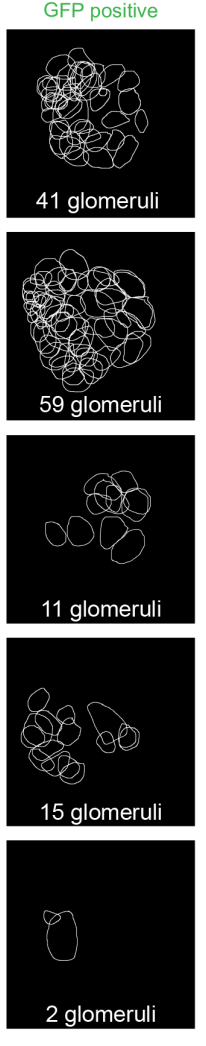

D

Canonical olfactory system organization

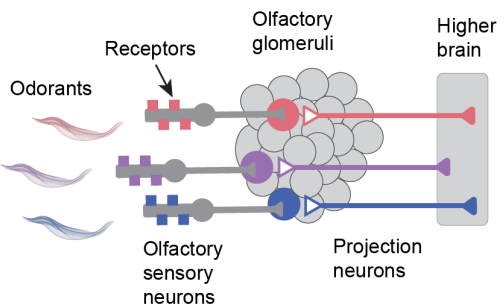

$\mathrm{H}$
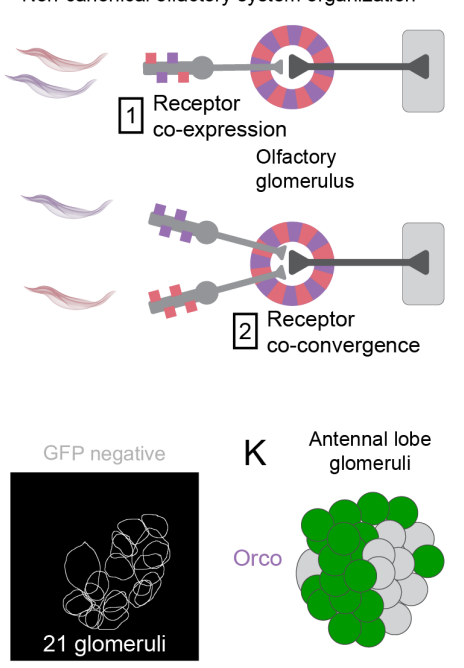

K $\begin{gathered}\text { Antennal lobe } \\ \text { glomeruli }\end{gathered}$
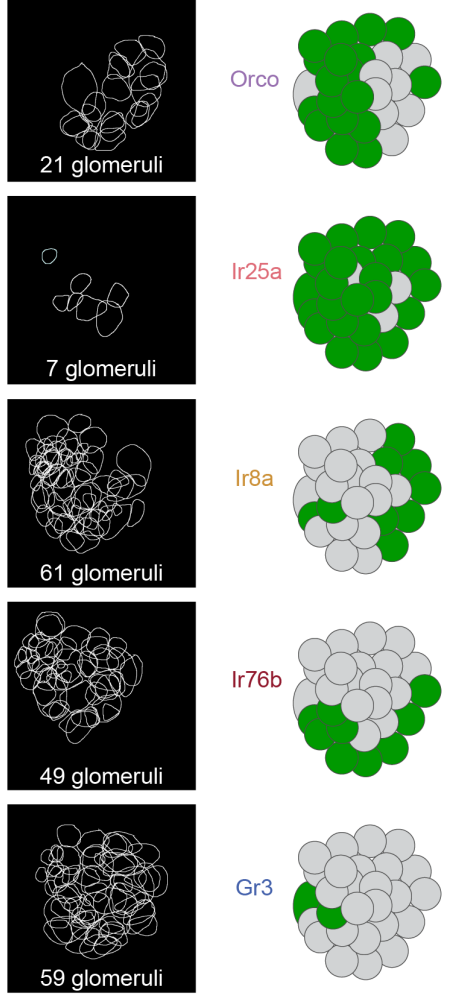

Figure 1: Mismatch in chemosensory receptor and olfactory glomerulus number suggests a novel olfactory organization (A) Ae. aegypti female with sensory structures highlighted in yellow boxes. (B) Approximate number of antennal lobe glomeruli per brain hemisphere innervated by the indicated sensory structure, derived from quantification of the left antennal lobe in 12 brains presented in (I-J) and Figure S2-S5. See also Figure S1. (C) Cartoons of insect chemosensory gene families. (D) Cartoon of canonical olfactory system organization. (E-G) Stacked bar plots of the number of chemosensory genes in the Ae. aegypti genome (E), and the number expressed above the indicated TPM thresholds in the antenna $(F)$ and maxillary palp $(G)$. (H) Two models of olfactory system organization that can account for the observation that there are far more chemosensory receptors than olfactory glomeruli in Ae. aegypti. (I) Maximum-intensity projections of confocal Z-stacks of antennal lobes in the left-brain hemisphere of the indicated genotype with immunofluorescent labeling of GFP (green) and the nc82 monoclonal antibody, which recognizes Brp (magenta). Brp is used throughout this paper as a synaptic

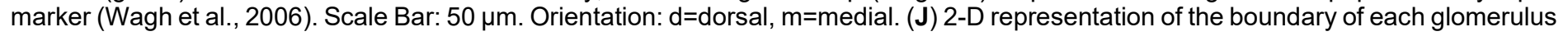
that is GFP positive and GFP negative. See also Figure S2-S6. (K) Cartoon schematic of the glomeruli receiving projections from olfactory sensory neurons expressing the indicated chemosensory receptor. 
the two domains associate via the leucine zipper, reconstitute a functional QF2 protein, initiate transcription at the QUAS enhancer, and drive expression of a reporter gene (Figure 2C).

Using the same stop-codon replacement approach that we used to generate the QF2-lines, we inserted the $Q F 2-A D$ into the Ir25a locus (here referred to as IR25a-QF2-AD) and the $Q F 2-D B D$ into the Orco locus (here referred to as OrcoQF2-DBD). When either IR25a-QF2-AD or Orco-QF2-DBD was used to drive expression of dTomato, we did not see fluorescence in the antenna, maxillary palp, or the antennal lobe (Figure 2D-F, S7). Therefore, neither QF2-DBD nor QF2-AD alone can activate expression from the QUAS enhancer. However, when Orco-QF2-DBD and IR25a-QF2-AD were crossed into the same animal, we saw expression of $d$ Tomato in antennal and maxillary palp neurons, as well as axonal projections in the antennal lobe (Figure 2D-F, S7, S8). Nearly half of the glomeruli in the antennal lobe were labelled with dTomato (Figure 2G-I, S7, S8). This points to widespread Orco and Ir25a co-expression within Ae. aegypti olfactory sensory neurons.

While examining these antennal lobes we consistently noticed that a cluster of anterior dorsal glomeruli was unlabeled when the Orco-QF2-DBD, IR25a-QF2-AD combination was used to drive expression in animals. However, these glomeruli were labelled when either Orco-QF2 or IR25a-QF2 were used to drive expression (Figure $2 \mathrm{~J}, \mathrm{~K}$ ). This observation strongly suggests that separate populations of Orco-positive and Ir25a-positive neurons co-converge onto these glomeruli. Therefore, the mosquito olfactory system shows evidence of both co-expression and co-convergence, motifs that are not typically seen in the conventional model organisms Drosophila melanogaster flies or Mus musculus mice (Figure $2 \mathrm{~L}$ ). It is also possible that a given glomerulus shows both co-convergence of molecularly distinct neurons while also receiving projections from neurons co-expressing multiple chemosensory co-receptors.

Extensive co-expression of chemosensory co-receptors in the antenna

The observation that nearly half of antennal lobe glomeruli receive projections from neurons co-expressing Ir25a and Orco in gene-targeted strains suggested that there is extensive co-expression of the IR and OR chemoreceptor families. To confirm the existence of such co-expressing neurons, we carried out whole mount antennal immunostaining with an antibody to the endogenous Orco protein and GFP expressed from each sensory neuron driver. We observed extensive co-expression of Orco and Ir25a, with substantially fewer cells co-expressing either Orco and Ir8a or Orco and Ir76b (Figure 3A-D), even after accounting for fewer total Ir76b and Ir8a cells (Figure 3B-D, Data File 1).

To confirm and extend these results, we performed RNA in situ hybridization in wild-type antennae with probes designed to target endogenous Orco, Ir76b, and Ir25a transcripts (Figure $3 \mathrm{E}$ ). These experiments replicated patterns of co-expression observed in immunostained antennae
(Figure 3A-D), with almost half of Orco cells co-expressing Ir25a, and few Orco cells co-expressing Ir76b (Figure 3F-H, Data File 1) indicating that widespread co-expression is not an artifact of the genetic reporter lines.

By examining the expression pattern of these three transcripts simultaneously, we were also able to elucidate the relationship between Ir25a and Ir76b expression. In Drosophila melanogaster, Ir76b is co-expressed with Ir25a in olfactory sensory neurons in the antenna and in gustatory neurons in the labellum (Abuin et al., 2011; Lee et al., 2018). In Ae. aegypti, we found that $100 \%$ of Ir76b-expressing neurons in the antenna also express Ir25a (Figure 3F,H). We also observed that in addition to widespread co-receptor coexpression, some mosquito olfactory neurons express just one co-receptor (Figure 3I). Our data demonstrate not only extensive co-expression between Orco and IR co-receptors, but also complexity in the rules that govern receptor expression in antennal olfactory sensory neurons.

\section{Coordinated co-expression of chemosensory receptors} in the maxillary palp

We have documented extensive chemosensory co-receptor co-expression, but to form functional odorant-sensitive IR or OR complexes, olfactory sensory neurons must express both co-receptors and ligand-sensitive receptors (Abuin et al., 2011; Benton et al., 2009; Larsson et al., 2004; Neuhaus et al., 2005). To simultaneously monitor the extent of co-expression of both co-receptors and ligand-sensitive receptors, we carried out multiplexed whole mount RNA in situ hybridization (Choi et al., 2018) in the maxillary palp, the olfactory organ that detects the potent host cue $\mathrm{CO}_{2}$ as well as other host odors (Grant et al., 1995; Lu et al., 2007; McMeniman et al., 2014; Omer and Gillies, 1971) (Figure $4 A, B)$. The maxillary palp expresses many fewer chemosensory receptors genes than the antenna, with 18 receptors detected at the 1 TPM threshold in the maxillary palp compared to 138 in the antenna at the same threshold, simplifying the task of selecting genes for expression analysis (Figure $1 F, G)$. We performed RNA in situ hybridization with probes for 10 of the 18 chemosensory co-receptors and ligand-sensitive receptors that were present in maxillary palp RNA-seq at a threshold of TPM $>1$. This technique visualized gene expression with sufficient sensitivity that even Or71 and $I r 75 g$ (present at 1.93 and 1.67 TPM, respectively) were readily detected (Figure 4C-I, S9).

We found no overlap in expression of Orco and Gr3 in the maxillary palp, but Ir25a was expressed in all Orco and all Gr3 cells (Figure 4D). Previous work in Anopheles gambiae suggested that Orco-expressing neurons in the maxillary palp can be evenly divided into two non-overlapping groups: an Or8 population and an Or49 population (Lu et al., 2007). We show definitively that Or8 and Or49 are in segregated populations of Orco-expressing neurons in Ae. aegypti (Figure $4 \mathrm{E})$, and when combined with the results of the previous experiment (Figure 4D), that these cells are also all Ir25apositive. Additional RNA in situ hybridization experiments revealed that Or8- and Or49-expressing cells also often express Ir76b, with a bias towards expression in Or8- 
bioRxiv preprint doi: https://doi.org/10.1101/2020.11.07.368720; this version posted November 8, 2020. The copyright holder for this preprint (which was not certified by peer review) is the author/funder, who has granted bioRxiv a license to display the preprint in perpetuity. It is made available under aCC-BY 4.0 International license.

A

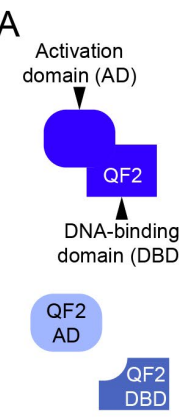

D

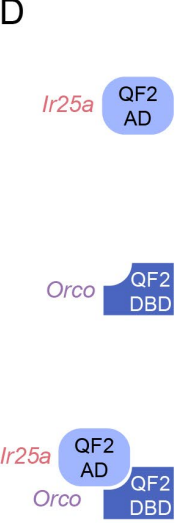

G

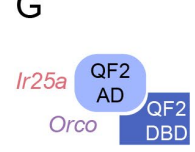

Orco
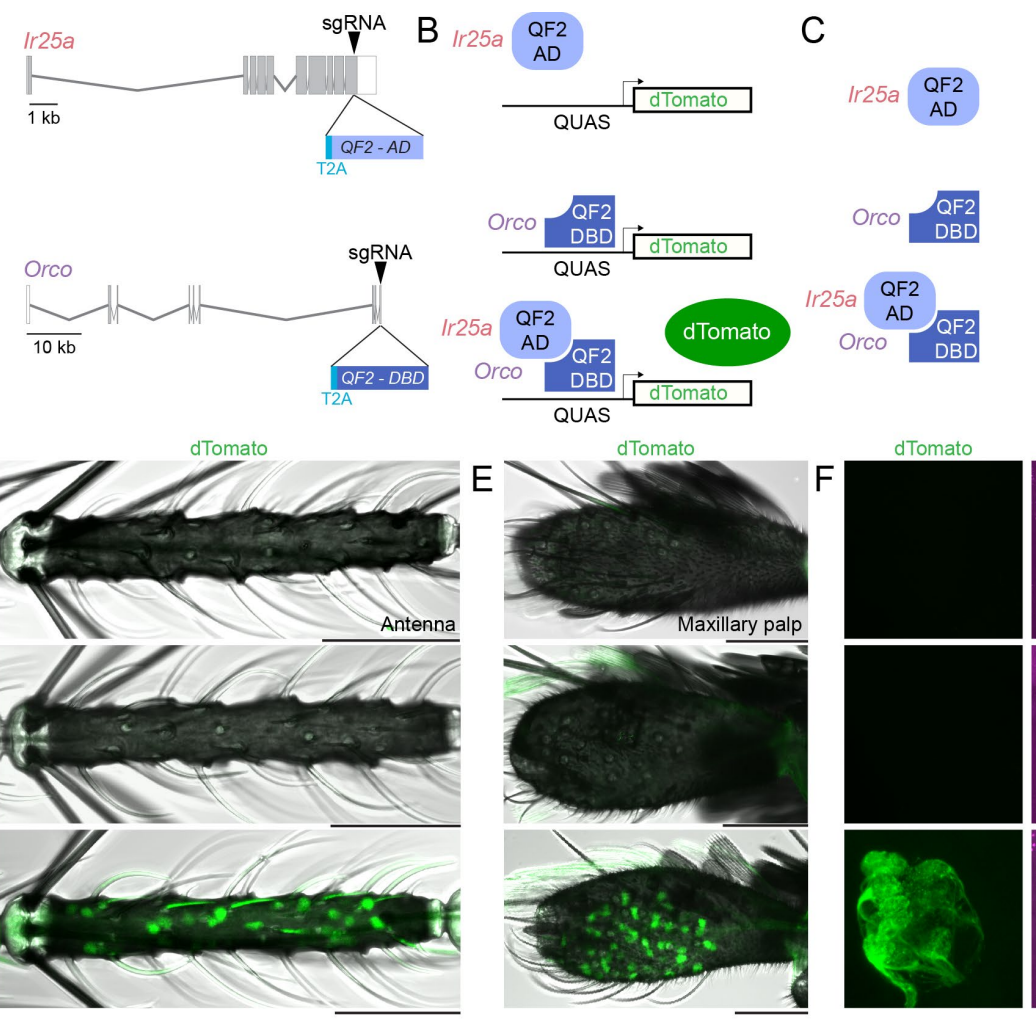

C

dTomato

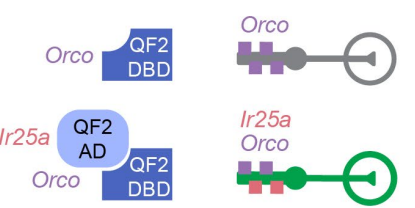

dTomato BRP
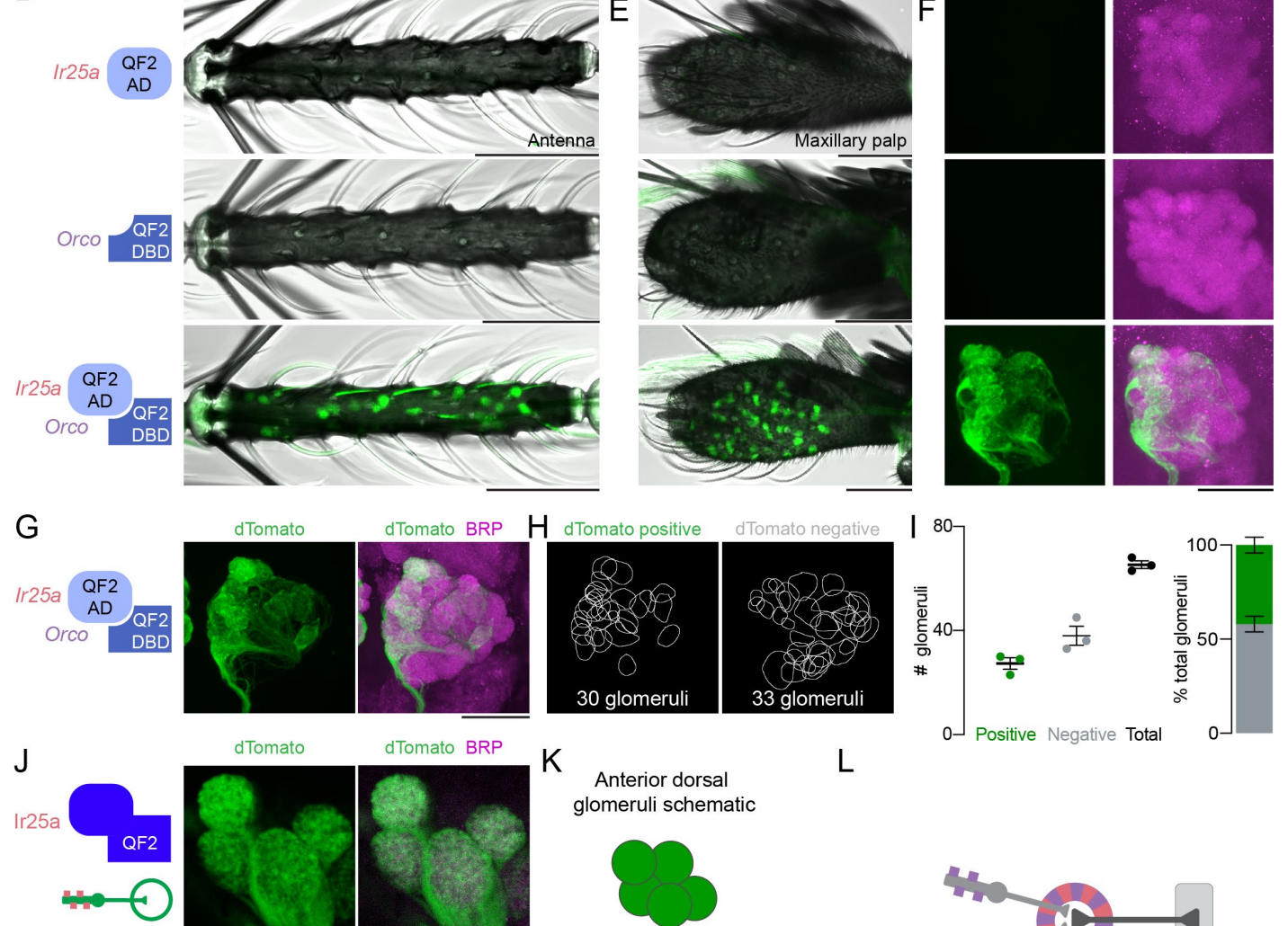

dTomato

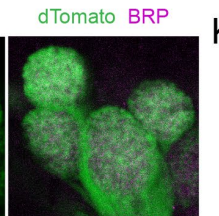

$\mathrm{K}$

Anterior dorsal

glomeruli schematic
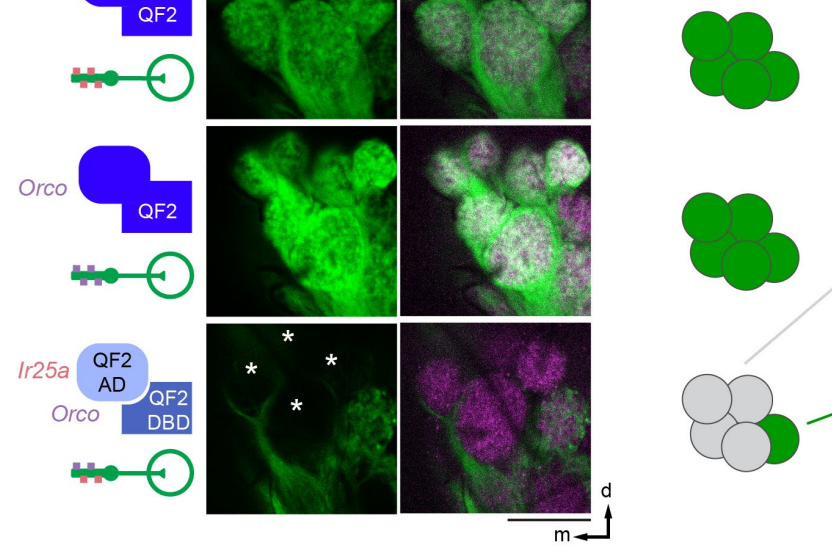

L
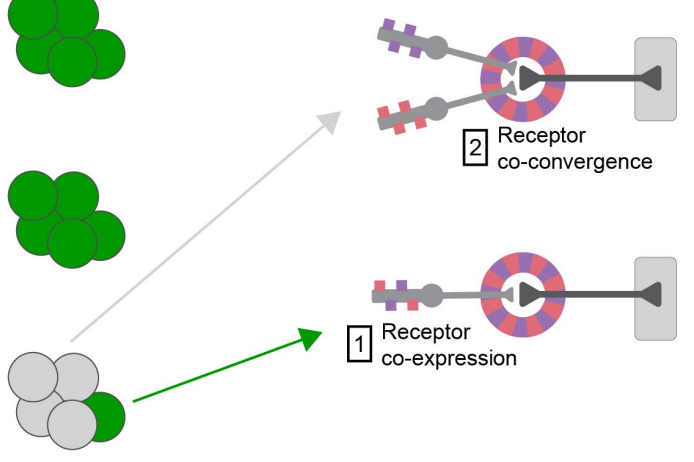

Figure 2. Genetic evidence for widespread Orco and Ir25a co-expression

(A) Schematic of the Split-QF2 system (left) and diagrams of Orco and Ir25a gene loci with exons (grey boxes), introns (grey lines) and CRISPR-Cas9 gRNA site (arrowhead) used to insert T2A-QF2-AD (light blue) and T2A-QF2-DBD (medium blue). AD and DBD gene maps are not to scale. (B-C) Schematic of the Split-QF2 system (B) and outcome of gene expression in olfactory sensory neurons of the indicated genotypes (C). (D-E) Maximum-intensity projections of confocal Z-stacks of antennae (D) and maxillary palp (E) of the indicated genotypes showing intrinsic dTomato fluorescence, with transmitted light overlay. See also Figure S7A,B. (F-G) Maximum-intensity projections of confocal Z-stacks of antennal lobes from the left brain hemisphere of the indicated genotype with immunofluorescent labeling of dTomato (green) and Brp (synaptic marker, magenta). See also Figure S8. (H-I) 2-D representation of the boundary of each glomerulus in (G) that is GFP positive and GFP negative $(H)$ and quantification (I). $n=3$, mean \pm SEM. See also Figure S7C. (J) Single confocal sections of the anterior dorsal region of the antennal lobe in the left-brain hemisphere of the indicated genotype with immunofluorescent labeling of dTomato (green) and Brp (synaptic marker, magenta). (K) Schematic of the 5 glomeruli shown in (J) with GFP positive glomeruli (green). (L) Two models of Ae. aegypti olfactory system organization supported by data in this figure. Scale bars: $50 \mu \mathrm{m}$, except (J): 25 $\mu m$. Orientation: proximal left $(D)$, distal left $(E) ;(F, G, H, J): d=d o r s a l, m=$ medial. 
bioRxiv preprint doi: https://doi.org/10.1101/2020.11.07.368720; this version posted November 8, 2020. The copyright holder for this preprint (which was not certified by peer review) is the author/funder, who has granted bioRxiv a license to display the preprint in perpetuity. It is made available under aCC-BY 4.0 International license.

A Antenna immunostaining
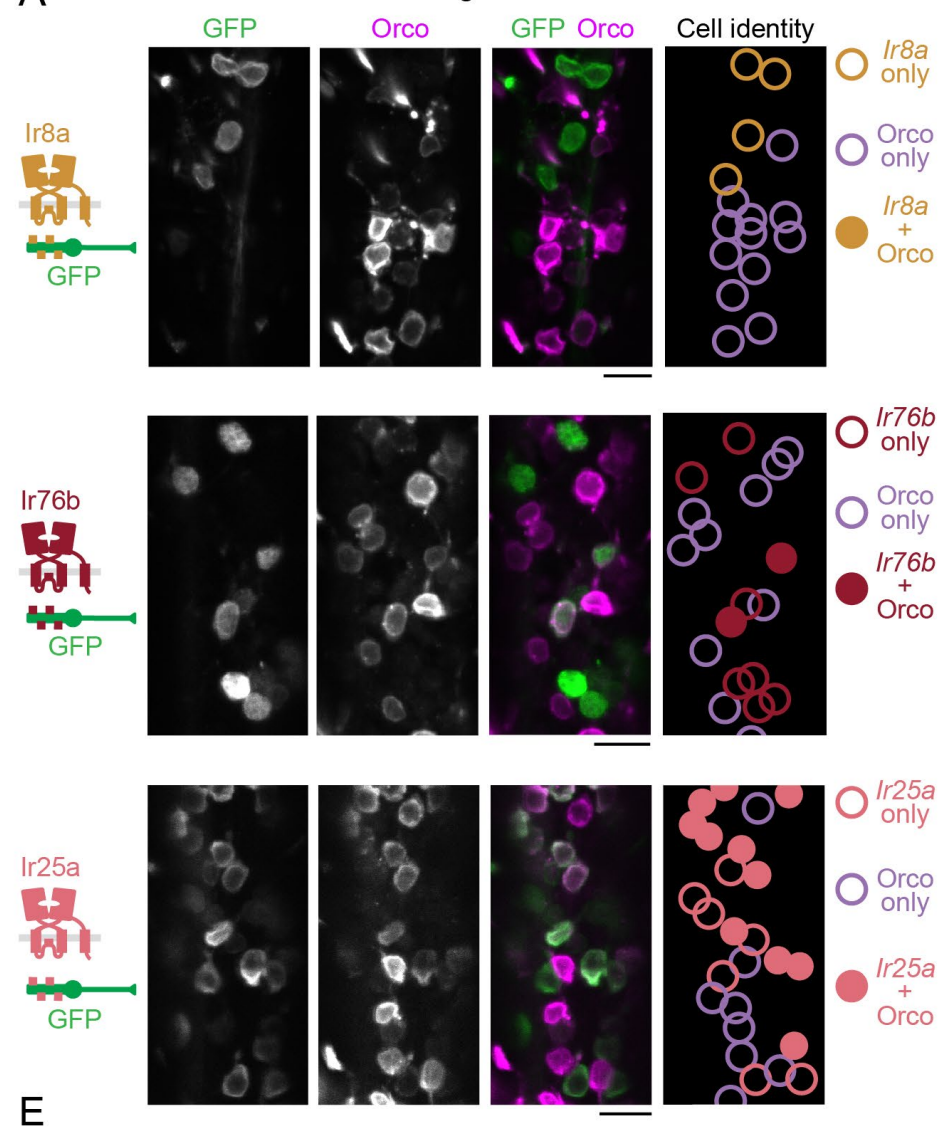

Antenna RNA in situ hybridization
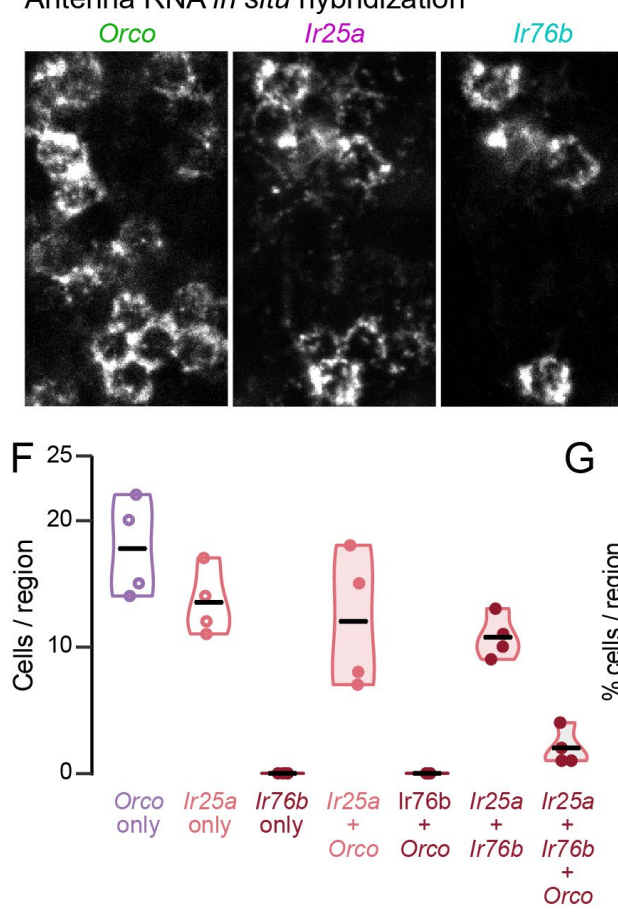
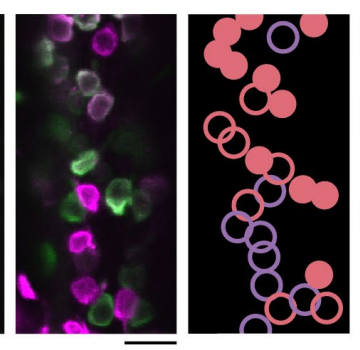
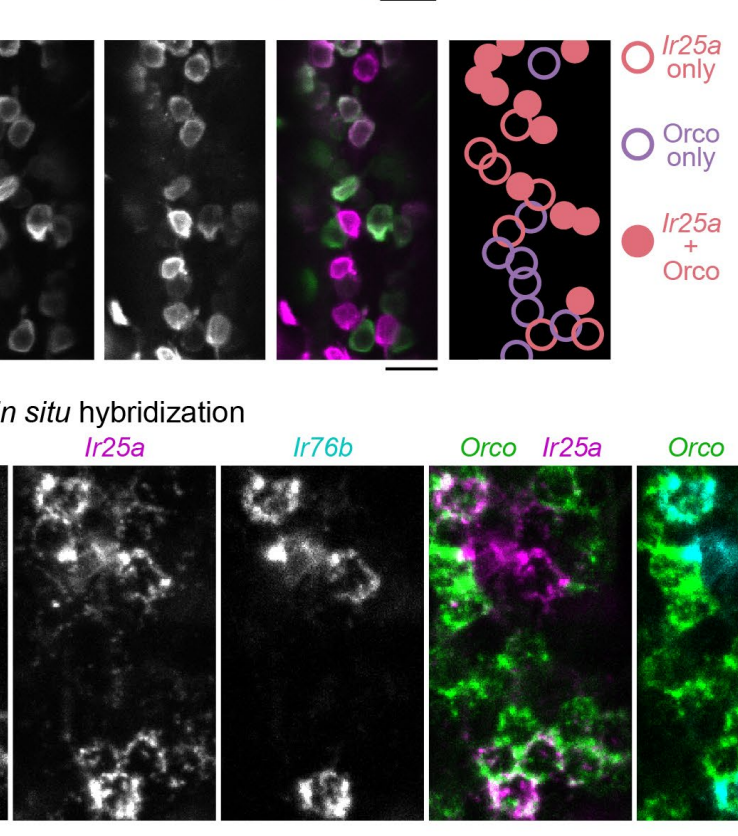

B

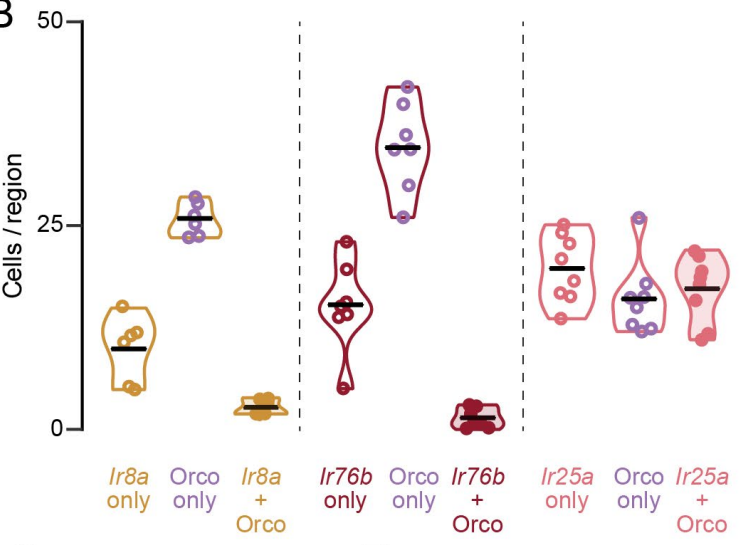

C

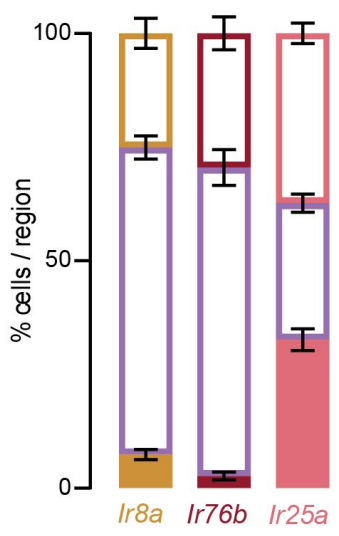

$\mathrm{D}$

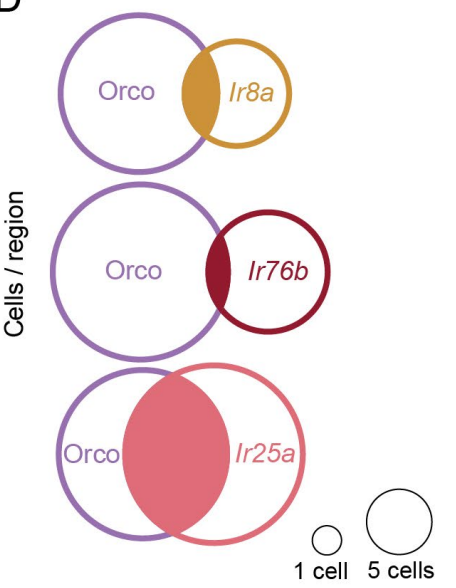

1 cell 5 cells
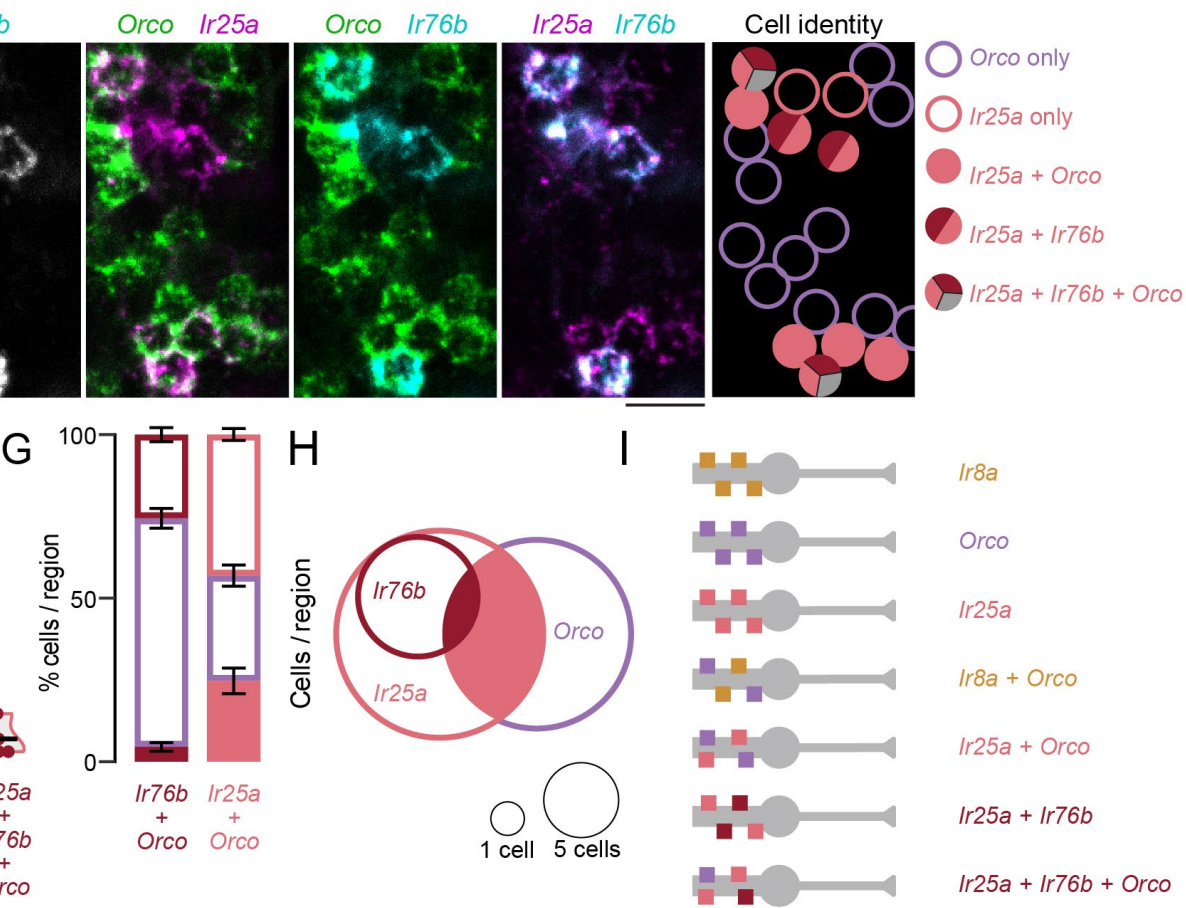

Figure 3. Extensive co-expression of chemosensory co-receptors in the antenna

(A) Orco and GFP immunostaining in antennae of the indicated genotypes with cartoon schematic indicating cell identity. (B-D) Quantification of antennal cells in the indicated genotypes co-expressing Orco protein and GFP presented as violin plots showing raw cell counts $(B)$ (mean with range), stacked bar plots $(C)$ (mean \pm SEM), and Euler diagrams with area scaled to mean cells/region (D). $n=6-8$ antennal segments, 34-68 cells/region. (E) RNA in situ hybridization in wild-type antennae with the indicated probes. (F-H) Quantification of wildtype antennal cells expressing the indicated genes as violin plots showing raw cell counts $(F)$ (mean with range), stacked bar plots $(\mathrm{G})($ mean $\pm \mathrm{SEM})$, and Euler diagrams with area scaled to mean cells/region $(\mathrm{H}) . \mathrm{n}=4$ antennal segments, $45-63$ cells/ region. (I) Cartoon schematic of olfactory neuron populations identified in this figure. Scale bars: $10 \mu \mathrm{m}$. 
expressing cells (Figure 4F, S9, Data File 1). Taken together these data show that olfactory sensory neurons express coreceptors Orco, Ir25a, Ir76b and either of the ligand-sensitive subunits Or49 or Or8.

When we analyzed IR ligand-sensitive subunit expression, we found that Ir100a and Ir93a are also expressed in a subset of Or49-expressing neurons (Figure 4G,H, S9, Data File 1 ), suggesting that these cells can form functional $O R$ and IR complexes with their respective co-receptors in the same neuron. Further, we identified co-expression of Or71 and Or49, demonstrating that more than one ligand-sensitive OR can also be expressed in an olfactory sensory neuron in $A e$. aegypti (Figure S9O). Lastly, we found that $65 \%$ of Gr3-expressing cells also express $1 \mathrm{r} 75 \mathrm{~g}$. Taken together with the finding that Gr3-expressing cells express Ir25a (Figure 4D, $4 \mathrm{I}, \mathrm{S} 9 \mathrm{~N}$, Data File 1) this raises the possibility that a functional IR complex can be found in $\mathrm{CO}_{2}$-sensitive neurons.

\section{Volatile amine sensing by $\mathrm{CO}_{2}$ neurons that lack the $\mathrm{Gr} 3$} $\mathrm{CO}_{2}$ receptor

We set out to investigate the functional relationships of these extensive receptor co-expression patterns by focusing on the maxillary palp, which is both simpler in organization than the antenna and also uniquely important because it is the sensory appendage that detects $\mathrm{CO}_{2}$.

To delineate the organization of maxillary palp projections in the brain, we used our QF2 and Split-QF2 driver lines to examine sensory innervation of antennal lobe glomeruli (Figure $5 \mathrm{~A}-\mathrm{H}$ ). Glomerulus 2 and Glomerulus 3 received input from both Orco-expressing neurons and Ir25a- and Ir76bexpressing neurons (Figure $5 A-G$ ), consistent with data presented in Figure 4. Co-expression of Orco and Ir25a in neurons that project to these two glomeruli was confirmed using the Split-QF2 system (Figure 2). In Orco-QF2-DBD, IR25aQF2-AD animals, Glomerulus 2 and Glomerulus 3 were labeled, but Glomerulus 1 was not (Figure $5 \mathrm{H}$ ). We also discovered that Glomerulus 1 , which is the largest glomerulus in the antennal lobe (Shankar and McMeniman, 2020), received input from Gr3-expressing sensory afferents. Glomerulus 1 was also innervated by Ir25a-expressing sensory neurons (Figure $5 \mathrm{~A}-\mathrm{H}$ ), consistent with the co-expression of Gr3 and Ir25a in olfactory neurons (Figure 4D). This finding raised the possibility that Glomerulus 1 may respond to additional odorant ligands independent of $\mathrm{CO}_{2}$-sensitive Gr3.

Given the extensive receptor co-expression observed in the maxillary palp (Figure 4,5I), we next explored the possibility that functional expression of multiple receptor types would allow maxillary palp $\mathrm{CO}_{2}$-sensitive neurons to respond to additional odorants. We set out to examine odorants detected by maxillary palp neurons by developing an in vivo calcium imaging preparation with the genetically-encoded calcium sensor GCaMP6s (Chen et al., 2013), allowing us to monitor stimulus-evoked activity in the antennal lobe of a mosquito as it was exposed to different odorants or to $\mathrm{CO}_{2}$ (Figure $5 \mathrm{~J}$ ). We imaged the axon terminals of maxillary palp sensory neurons in the antennal lobe with two-photon microscopy using a custom-built olfactometer to deliver odorants and $\mathrm{CO}_{2}$ within a continuous air stream. We expected that Glomerulus 1 would respond to $\mathrm{CO}_{2}$ because it receives projections from Gr3-expressing neurons. Indeed, in preliminary experiments when we imaged GCaMP6s responses in axonal termini of Gr3-expressing neurons in Glomerulus 1, we observed low fluorescence at baseline and concentration-dependent responses to $\mathrm{CO}_{2}$, with no apparent desensitization across trials (data not shown).

To image activity simultaneously in $\mathrm{CO}_{2}$-sensitive Glomerulus 1 and the non- $\mathrm{CO}_{2}$-sensitive Glomerulus 3, we used the Ir25a>GCaMP6s strain, which expresses GCaMP6s in all maxillary palp olfactory neurons (Figure 4). We saw consistent activation of Glomerulus 3 by 1-octen-3-ol and 3-octanone (Figure $5 \mathrm{~K}, \mathrm{~L}$ ), odorants that have been shown in in vitro heterologous expression experiments to activate Or8Orco from both Ae. aegypti and Anopheles gambiae (Bohbot and Dickens, 2009; Lu et al., 2007). Therefore Glomerulus 3 is likely to be innervated by Or8-expressing neurons (Figure 4E). From a panel of candidate odorants, we found that Glomerulus 3 also responded to two volatile amines, hexyl amine and triethyl amine (Figure $5 \mathrm{~K}, \mathrm{~L}$ ). Volatile amines, including polyamines, have been proposed to be IR ligands in Drosophila melanogaster (Geier et al., 1999; Hussain et al., 2016; Min et al., 2013; Silbering et al., 2011). These findings are consistent with the hypothesis that IRs and ORs are functionally co-expressed in maxillary palp neurons and that this co-expression enables these cells to respond to ligands that activate both classes of receptors.

We next turned to the $\mathrm{CO}_{2}$-sensitive Glomerulus 1 (Figure $5 \mathrm{M})$ and imaged stimulus-evoked activity in Gr3 heterozygotes, which have no defects in $\mathrm{CO}_{2}$ sensation, and in $\mathrm{Gr} 3$ homozygous mutants, which lose all physiological and behavioral responses to $\mathrm{CO}_{2}$ (McMeniman et al., 2014). We used $\mathrm{Gr} 3$ heterozygotes as the control genotype in these experiments because this mutation was introduced in a different wild-type strain than our QF2/QUAS reagents and this genetic configuration better controls for genetic background (see Methods). As expected, we saw robust activation of Glomerulus 1 by $\mathrm{CO}_{2}$ in $\mathrm{Gr} 3$ heterozygotes, and a complete loss of response to $\mathrm{CO}_{2}$ in $\mathrm{Gr} 3$ homozygous mutant animals (Figure $5 \mathrm{~N}-\mathrm{P}$ ). $\mathrm{CO}_{2}$-sensing neurons in the maxillary palp respond to multiple odorants in Aedes, Culex, and Anopheles mosquitoes (Lu et al., 2007; Tauxe et al., 2013; Turner et al., 2011) and it has been proposed that Gr3 is a broadlytuned receptor that responds to many odorants. We examined the response to a recently identified $\mathrm{CO}_{2}$-neuron activator, acetone (Ghaninia et al., 2019). This odorant activated Glomerulus 1 in the Gr3 heterozygote but the response to acetone was abolished in the homozygous Gr3 mutant (Figure $5 \mathrm{Q}, \mathrm{R}$ ). This suggests that the $\mathrm{CO}_{2}$ receptor can interact with non- $\mathrm{CO}_{2}$ ligands. We examined the response to volatile amines, and saw consistent responses to hexyl amine and triethyl amine (Figure 5Q,R). The response to both of these volatile amines was unaffected in Gr3 homozygous mutant animals (Figure $5 \mathrm{Q}, \mathrm{R}$ ). We speculate that hexyl amine and triethyl amine are activating the $\mathrm{CO}_{2}$-sensitive neuron by stimulating IRs expressed in this neuron, 
A

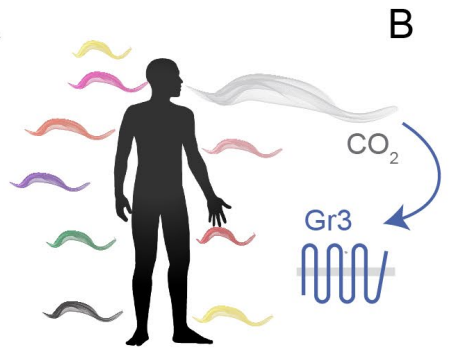

B

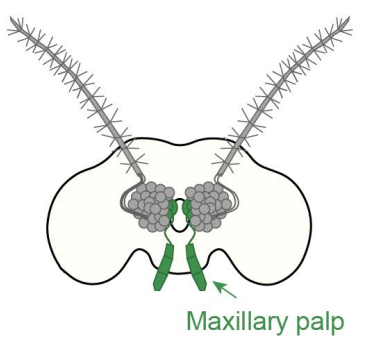

C

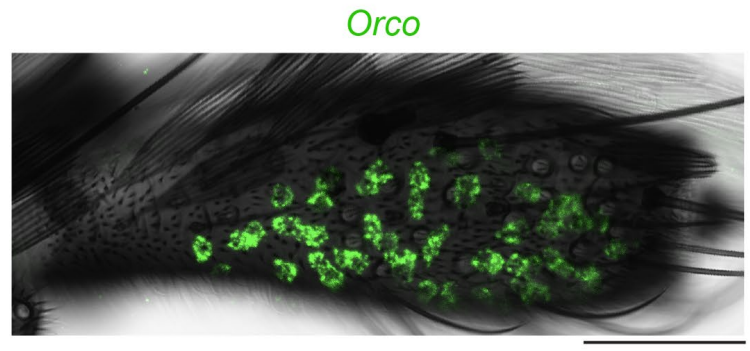

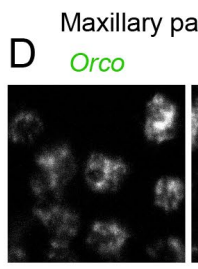
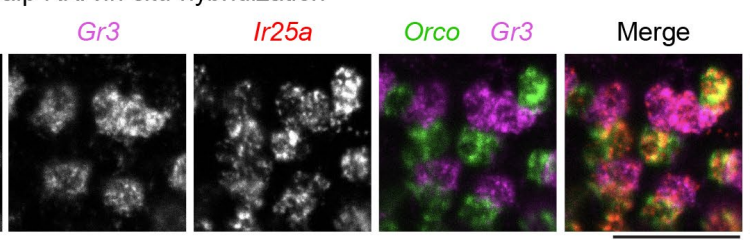

Cell identity

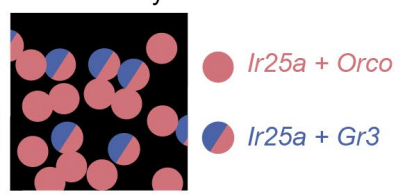

Cells / dorso-lateral palp

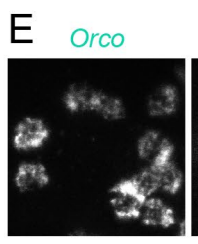

Or49
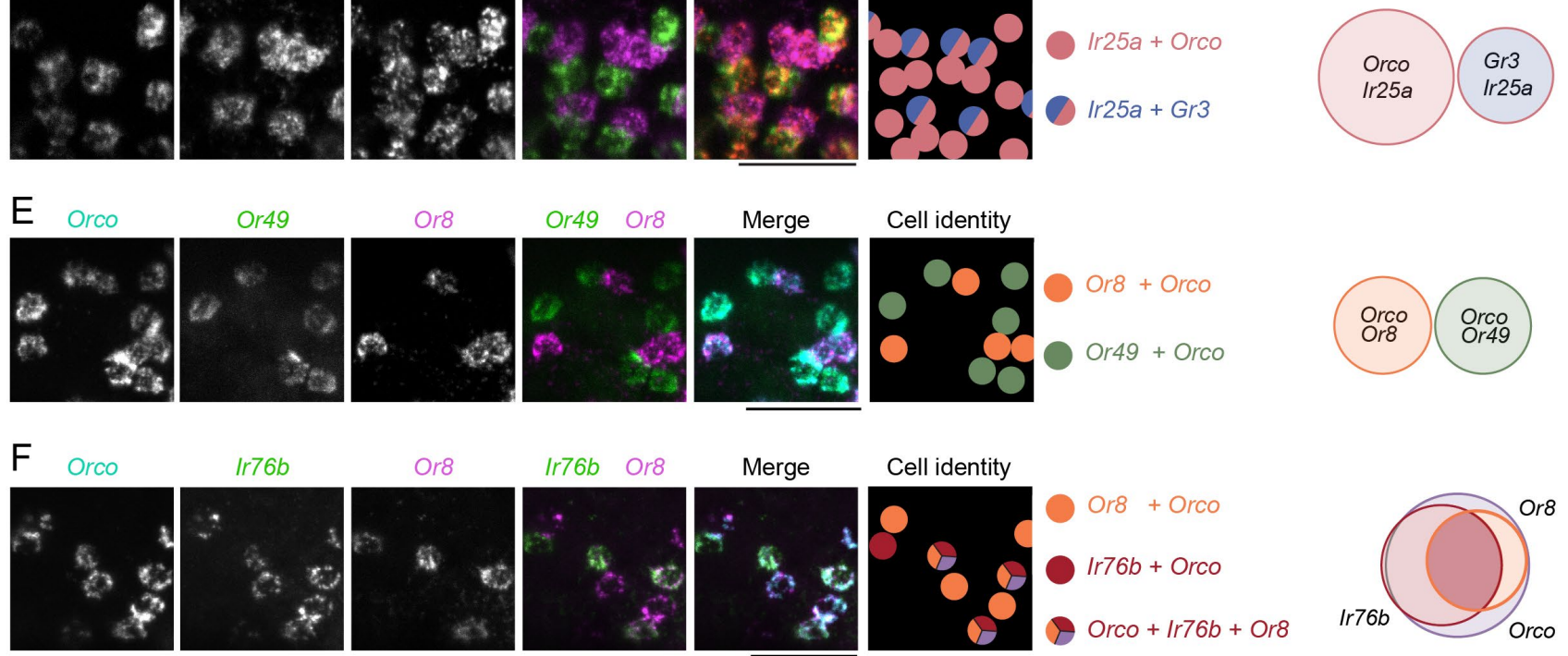

$\operatorname{lr} 76 b$
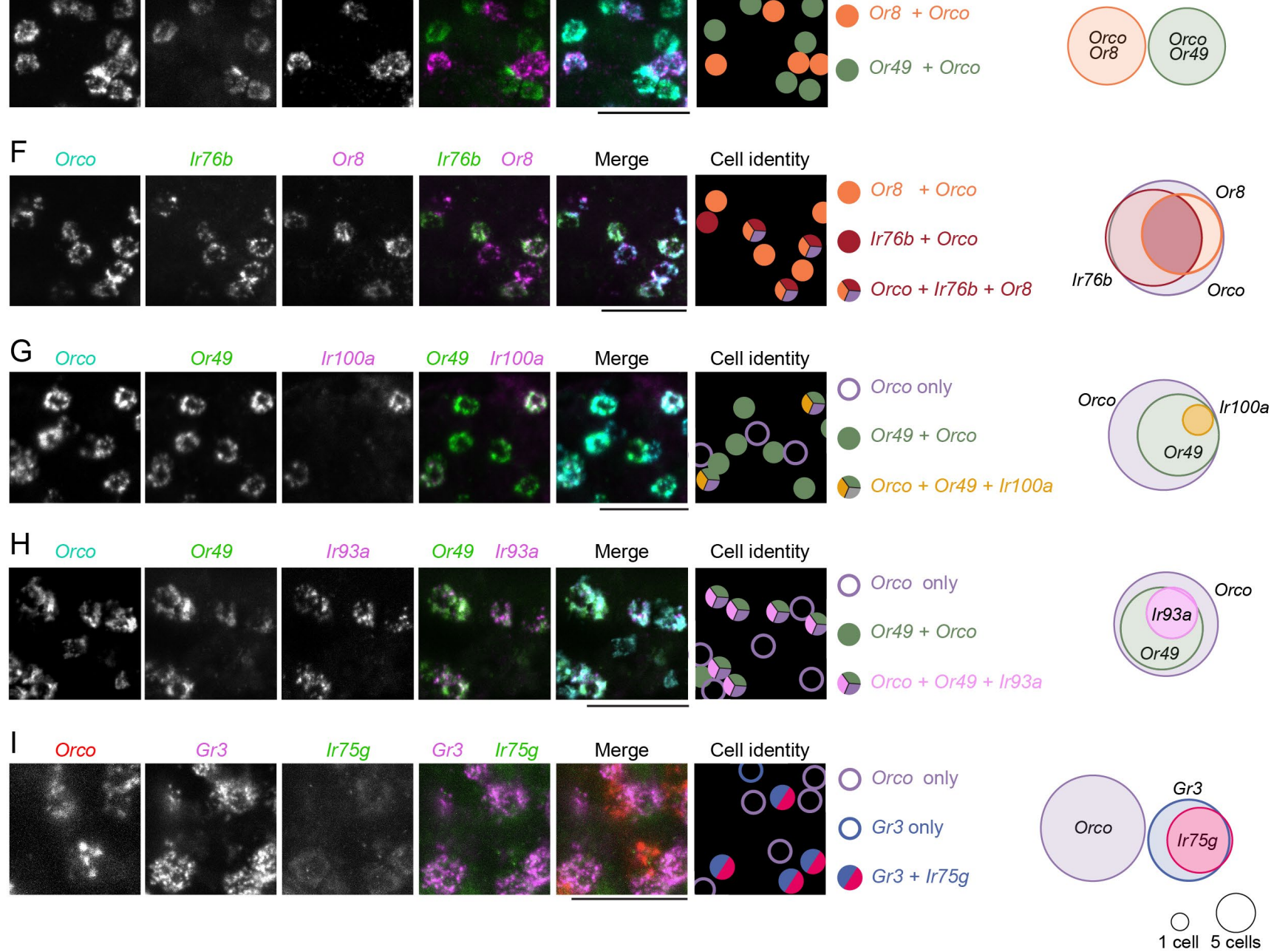

Figure 4. Coordinated co-expression of chemosensory receptors in the maxillary palp

(A) Schematic of human chemosensory cues: $\mathrm{CO}_{2}$ detection requires Gr3. (B) Cartoon indicating maxillary palp (green). (C) Maxillary palp expression of Orco revealed by whole-mount RNA in situ hybridization. Orientation: fourth segment, distal right. (D-I) Whole-mount maxillary palp RNA in situ hybridization with the indicated probes, cartoon schematic indicating cell identity, and quantification of coexpression shown as Euler diagrams, area scaled to mean. $n=5$ maxillary palps, 26-65 cells/dorso-lateral maxillary palp. See also Figure S9. Scale bars: $50 \mu \mathrm{m}(\mathrm{C}), 25 \mu \mathrm{m}(\mathrm{D}-\mathrm{I})$. 
bioRxiv preprint doi: https://doi.org/10.1101/2020.11.07.368720; this version posted November 8, 2020. The copyright holder for this preprint (which was not certified by peer review) is the author/funder, who has granted bioRxiv a license to display the preprint in perpetuity. It is made available under aCC-BY 4.0 International license.
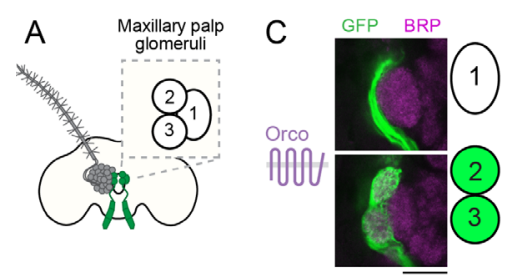

B
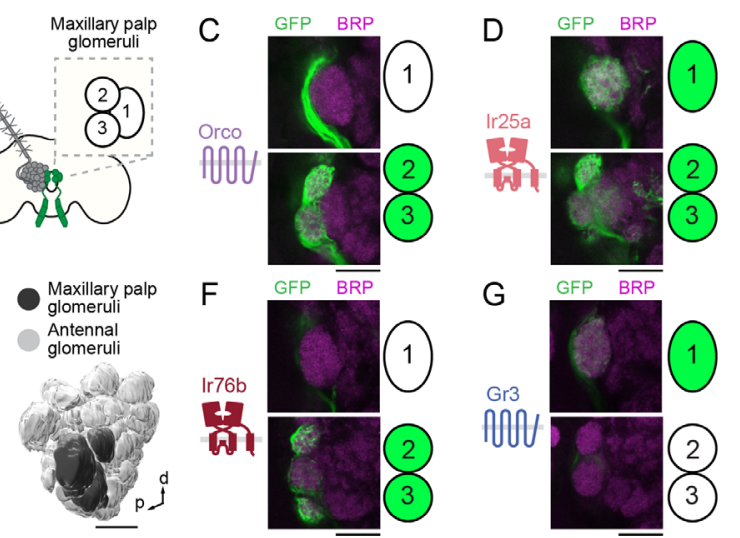

G
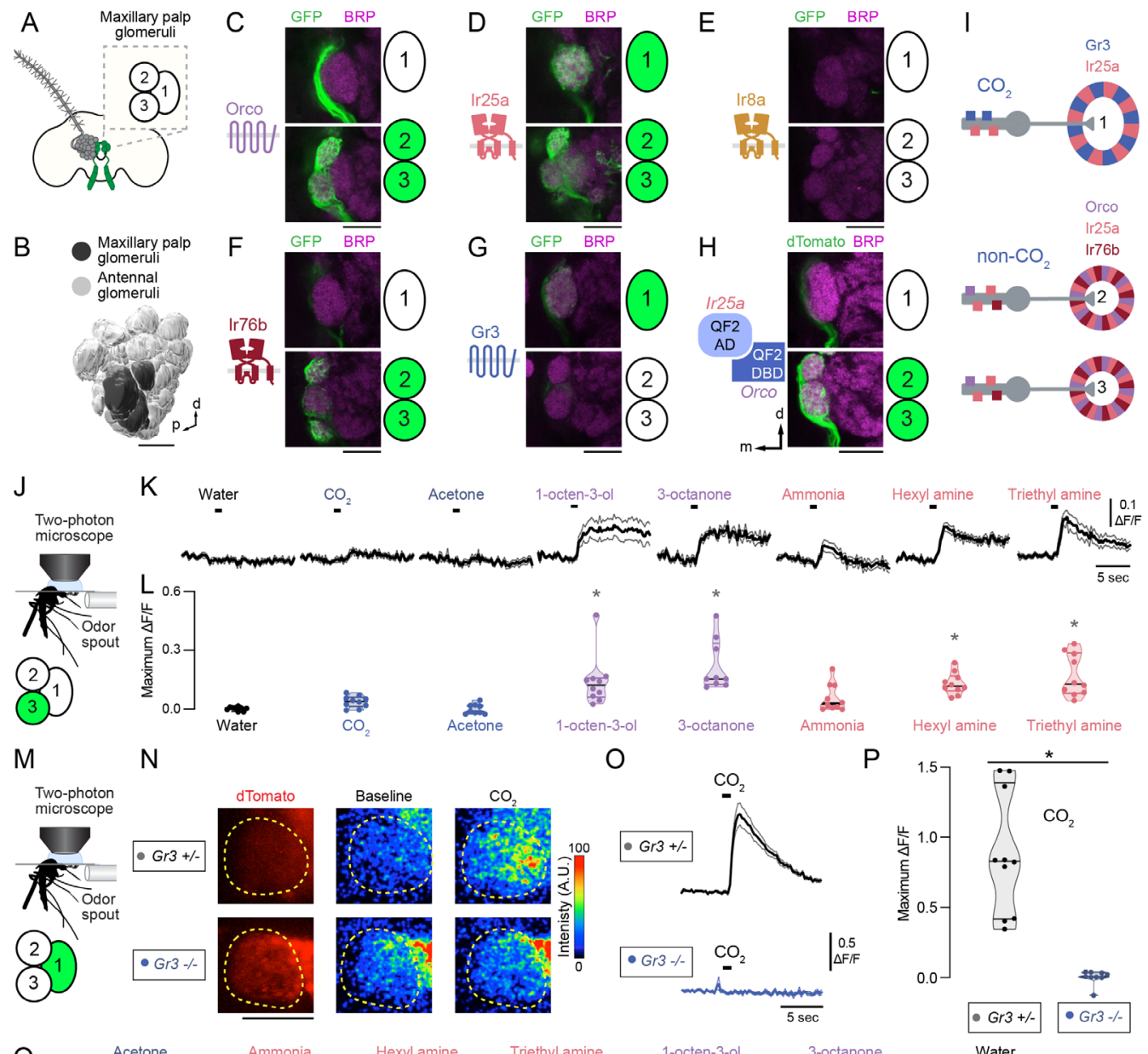

O
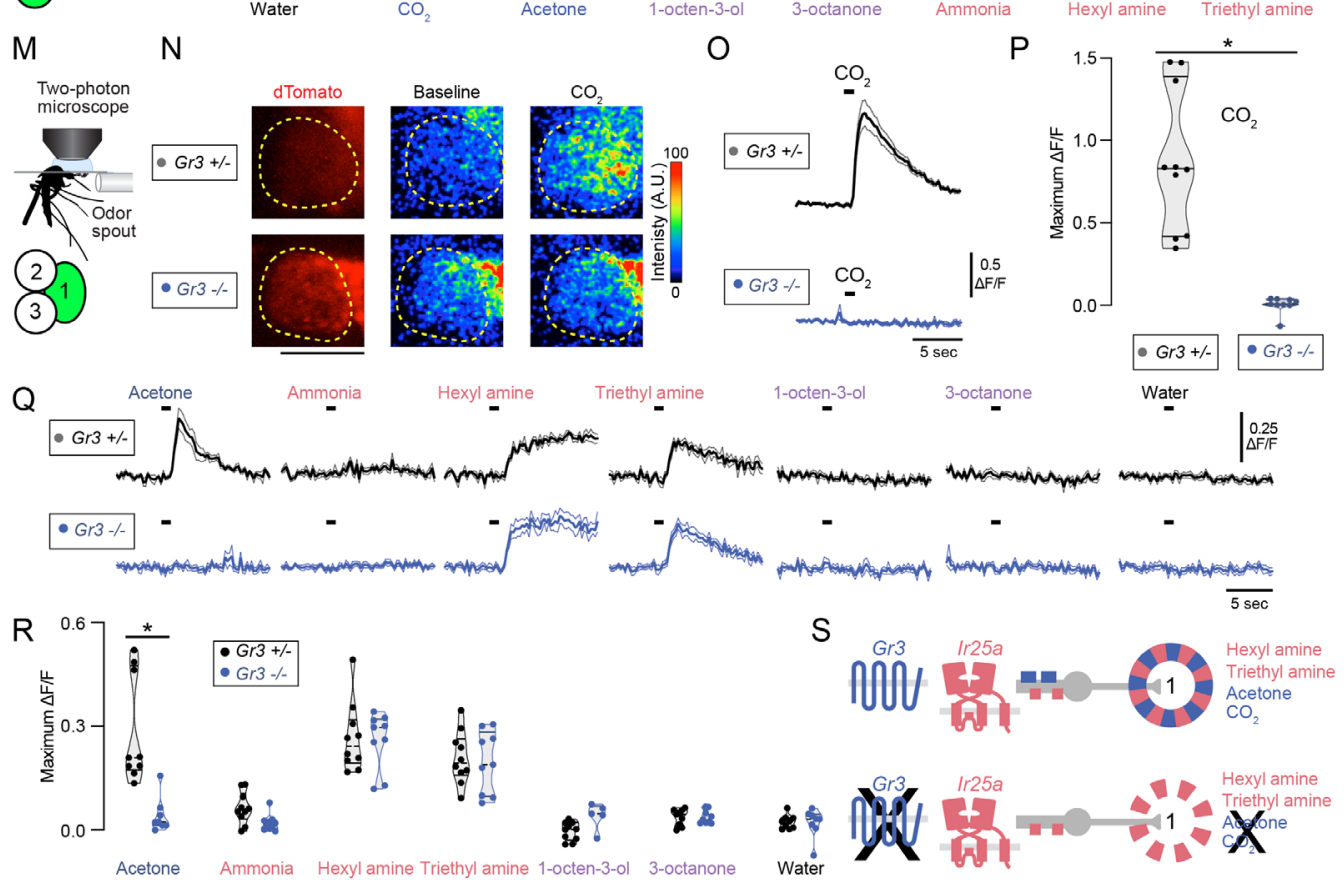

\section{(1)}


which we have shown include at least Ir25a and Ir75g (Figure 4I, 5S).

Volatile amines substitute for $\mathrm{CO}_{2}$ in activating mosquito attraction to humans

Female mosquitoes integrate multiple sensory cues to drive strong attraction to humans. Human odor is a blend of hundreds of volatile odorants, including lactic acid and volatile amines (Acree et al., 1968; Bernier et al., 2000; Dormont et al., 2013). While body heat, $\mathrm{CO}_{2}$ emitted in the breath, and individual odorants produced by human skin individually elicit weak to no mosquito attraction, the combination of multiple sensory cues leads to robust attraction in laboratory behavioral assays (Corfas and Vosshall, 2015; Dekker et al., 2005; McMeniman et al., 2014). Among these cues, $\mathrm{CO}_{2}$ is the most potent synergistic stimulus, sensitizing mosquitoes to gate attraction to both heat and odorants (Dekker et al., 2005; McMeniman et al., 2014). The discovery that triethyl amine and hexyl amine activate Glomerulus 1 in Gr3 homozygous mutants that are unable to detect $\mathrm{CO}_{2}$ led us to hypothesize that volatile amines could substitute for $\mathrm{CO}_{2}$ in sensitizing Gr3 mutant mosquitoes to human body odor (Figure 6A).

To test this, we used a behavioral assay (Basrur et al., 2020) to measure mosquito attraction to various stimuli (Figure $6 \mathrm{~B})$. In control experiments, we baited the assay with either $\mathrm{CO}_{2}$ or lactic acid, a human host volatile, or both $\mathrm{CO}_{2}$ and lactic acid combined, and monitored how many mosquitoes accumulated in the trap. As previously shown, either $\mathrm{CO}_{2}$ or lactic acid alone only weakly attracted mosquitoes, but the combination of lactic acid with $\mathrm{CO}_{2}$ caused potent dose-dependent attraction in two different wild-type strains of $A e$. aegypti (Figure 6C, Data File 1) (Acree et al., 1968; Bernier et al., 2000; Davis, 1984; Geier et al., 1999; Majeed et al., 2014; McMeniman et al., 2014; Smith et al., 1970). Female mosquito attraction to humans is suppressed for 72-96 hours after ingestion of a blood-meal (Davis, 1984; Duvall et al., 2019; Klowden, 1981). We saw the same state-dependent suppression of attraction to $\mathrm{CO}_{2}$ and lactic acid by bloodfed mosquitoes, confirming that these stimuli serve as a proxy for the attraction to human host odor (Figure 6C).

We next tested the hypothesis that activating Glomerulus 1 with volatile amines in $\mathrm{CO}_{2}$-insensitive $\mathrm{Gr} 3$ mutants could sensitize these animals to respond to lactic acid. In control experiments, we observed that neither wild-type nor Gr3 mutants were attracted to $\mathrm{CO}_{2}$ alone, and that only wild-type animals and not Gr3 mutants showed synergistic attraction to $\mathrm{CO}_{2}$ and lactic acid (Figure 6D). As previously observed, both wild-type and $\mathrm{Gr} 3$ mutants showed strong attraction to a live human host in the presence of $\mathrm{CO}_{2}$ (McMeniman et al., 2014). Live human hosts emit many sensory cues, effectively compensating for the inability of $\mathrm{Gr} 3$ mutant mosquitoes to detect $\mathrm{CO}_{2}$ (McMeniman et al., 2014).

Both $\mathrm{CO}_{2}$ and triethyl amine activate Glomerulus 1 in wildtype animals but in Gr3 mutants only triethyl amine and not $\mathrm{CO}_{2}$ activates this glomerulus. We asked if triethyl amine alone or in combination with $\mathrm{CO}_{2}$ was attractive to wild type or Gr3 mutant mosquitoes. Neither wild type nor Gr3 mutant mosquitoes showed any attraction to $\mathrm{CO}_{2}$ alone, triethyl amine alone, or the combination of both (Figure 6E). This was expected because $\mathrm{CO}_{2}$ alone-and by extension the activation of Glomerulus 1 -is insufficient to mediate attraction in this assay. We next asked if triethyl amine can substitute for $\mathrm{CO}_{2}$ in synergizing with lactic acid to attract Gr3 mutant mosquitoes. We tested a range of concentrations of triethyl amine with a single concentration of lactic acid and quantified the number of attracted mosquitoes. Lactic acid alone and both low and high concentrations of triethyl amine were not attractive to Gr3 mutants. However, moderate concentrations of triethyl amine stimulated strong attraction when supplied together with lactic acid (Figure 6F). This sensitization to lactic acid triggered by triethyl amine was not further enhanced by the addition of $\mathrm{CO}_{2}$, a stimulus that $\mathrm{Gr} 3$ mutants do not detect (Figure $6 \mathrm{G}$ ). We speculate that $\mathrm{CO}_{2-}$ insensitive Gr3 mutants rely on a compensatory pathway that uses Ir25a and unknown ligand-sensitive IRs to activate Glomerulus 1 with volatile amines.

To ask if this compensatory pathway is active in wild-type mosquitoes, we repeated these experiments and were surprised to discover that the concentrations of triethyl amine that stimulated Gr3 mutant attraction to lactic acid had no effect on wild-type animals (Figure $6 \mathrm{H}, \mathrm{I}$ ). These results suggest that when mosquitoes lack receptors for potent host cues such as $\mathrm{CO}_{2}$, they rely more heavily on redundant cues detected by the same neurons via the expression of a diverse array of chemosensory receptors to ensure that hostseeking behavior is not compromised (Figure 6J).

\section{DISCUSSION}

A compensatory pathway promotes attraction behavior in the $\mathrm{CO}_{2}$ receptor mutant

It has only recently become possible to generate targeted mutations in chemosensory genes in Ae. aegypti, and a striking finding from studies that generated such mutants is how difficult it is to disrupt human host-seeking. Mutations in the co-receptor Orco (DeGennaro et al., 2013) and the coreceptor Ir8a (Raji et al., 2019) both eliminate entire classes of ligand-specific receptors. In spite of this, Orco mutants show normal attraction to humans and mutations in Ir8a reduce but do not abolish mosquito attraction to humans. Gr3 mutants are completely unable to sense $\mathrm{CO}_{2}$ yet they can also find human hosts, even when released into a large semi-field environment (McMeniman et al., 2014). These findings raise the question: Why is it so difficult to break the mosquito olfactory system and prevent mosquitoes from finding humans? We propose that this is due to redundancy in receptor expression at the periphery. A recent paper (Zhao et al., 2020) examined Ae. aegypti antennal lobe responses of Orco-expressing neurons to physiological concentrations of odor collected from several individual humans, a variety of non-human animals, and floral odors. They identified a glomerulus that responded to odor blends from all human individuals, animals, as well as honey and milkweed odor. It is tempting to speculate that this 

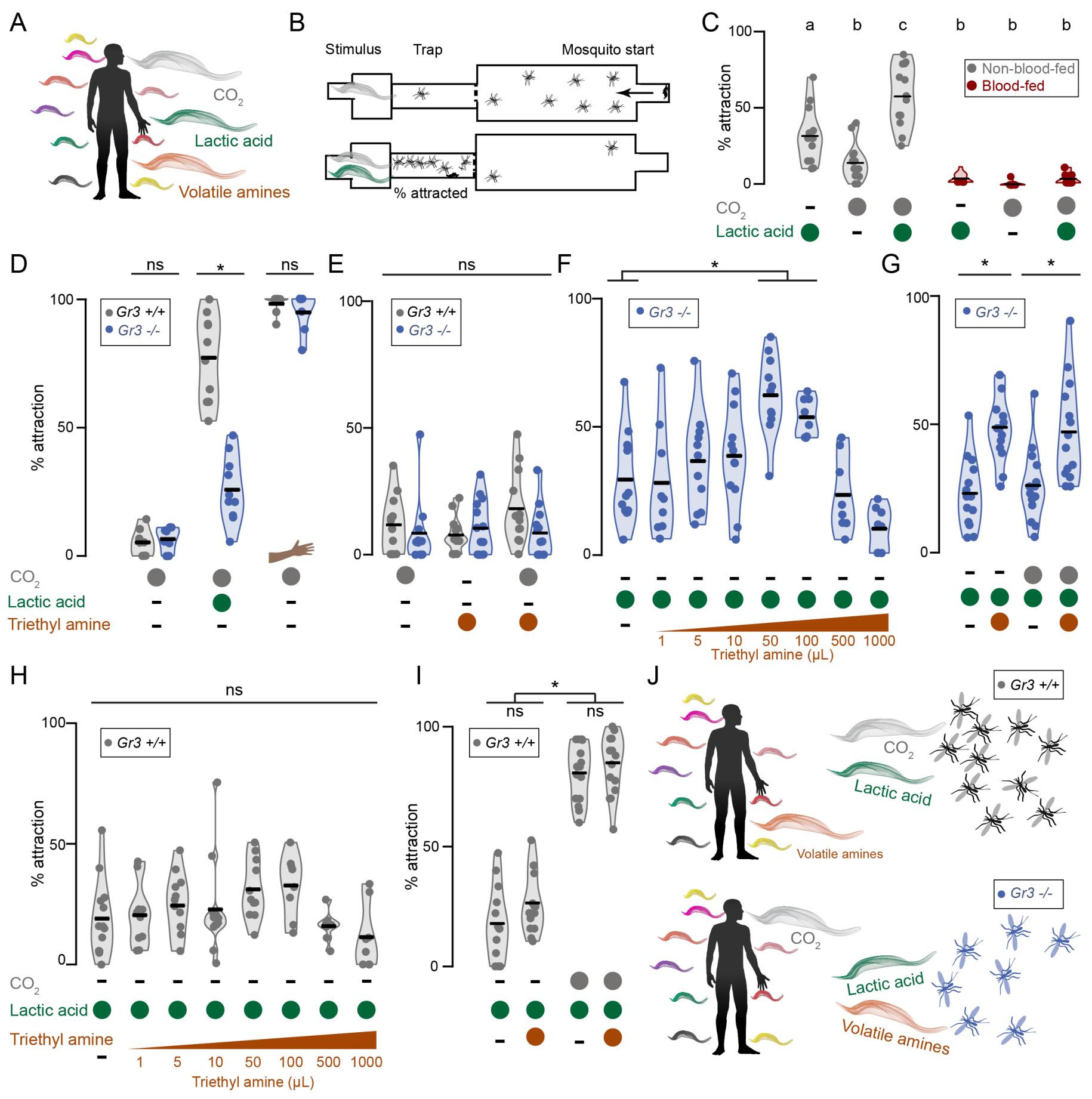

Figure 6: Volatile amines substitute for $\mathrm{CO}_{2}$ in activating mosquito attraction to humans

(A) Humans emit a complex blend of volatile odorants, including $\mathrm{CO}_{2}$, lactic acid, and volatile amines. (B-C) Schematic of behavioral assay (B) and percent wild-type mosquitoes of the indicated blood-feeding status attracted to the indicated stimuli in the assay (C). Lactic acid was supplied at $10 \mu \mathrm{l}$. Mean with range, $n=11-15$ trials, 19-21 mosquitoes/trial, " $p<0.05$, two-way ANOVA followed by Tukey's HSD. (D-I) Attraction of mosquitoes of the indicated genotype to the indicated stimuli. Lactic acid was supplied at $1 \mu \mathrm{l}$ in $\mathrm{D}, \mathrm{F}-\mathrm{I}$. Triethyl amine was presented at the indicated concentration in $\mathrm{F}, \mathrm{H}$ and at $50 \mu \mathrm{l}$ in $\mathrm{E}, \mathrm{G}, \mathrm{I}$. Mean with range, $\mathrm{n}=7-16$ trials, 15-22 mosquitoes/trial. * $\mathrm{p}<0.05$, ns=not significant $\left({ }^{*} p>0.05\right)$, two-way ANOVA followed by Tukey's HSD. (J) Model of the compensatory pathway where volatile amines substitute for $\mathrm{CO}_{2}$ to enable attraction to humans by $\mathrm{CO}_{2}$-insensitive $\mathrm{Gr} 3$ mutants. 
glomerulus is innervated by olfactory sensory neurons that co-express multiple receptors. We have probed IR and GR redundancy in the $\mathrm{CO}_{2}$ system and found that $\mathrm{Gr} 3$ mutant mosquitoes that do not detect $\mathrm{CO}_{2}$ can still detect triethyl amine, and have demonstrated that triethyl amine can act as a behavioral substitute for $\mathrm{CO}_{2}$ in driving attraction to lactic acid in Gr3 mutants. This activation was strongly dependent on the dose of triethyl amine. Although human skin releases a large number of odorants, including volatile amines, we do not know how the concentrations used in our laboratory behavioral assays relate to those produced by human skin.

Surprisingly, this substitution of triethyl amine for $\mathrm{CO}_{2}$ does not drive attraction in wild-type animals. One possible mechanism to explain this finding might be that in the absence of Gr3, the sensitivity of the circuit shifts to enhance the behavioral effect of compounds that activate the IRs co-expressed in the $\mathrm{CO}_{2}$-sensitive neuron. If this were the case, it remains to be seen how the $\mathrm{CO}_{2}$-sensing circuitry is altered, whether it is the sensory neuron or downstream neurons involved in host-seeking, and if changes occur at the level of the receptor, synapse, or the intrinsic firing properties of the sensory neurons themselves (Marder and Goaillard, 2006). $\mathrm{CO}_{2}-$ sensing neurons in the maxillary palp rapidly reset their intrinsic firing to adjust to changes in background levels of $\mathrm{CO}_{2}$ (Majeed et al., 2014) and perhaps the absence of background $\mathrm{CO}_{2}$ sensation in the $\mathrm{Gr} 3$ mutant enhances the signal to noise ratio of other odorants.

\section{Coordinated co-expression between $I R, O R$, and $G R$ lig-} and-sensitive receptors

We identified co-expression of co-receptors and ligand-sensitive receptors belonging to distinct chemosensory families in single neurons in the maxillary palp. This co-expression poses a gene regulatory problem for an olfactory neuron. For ORs and IRs to form functional chemoreceptors, at least one co-receptor and one ligand-sensitive receptor must be expressed in a cell. We have demonstrated that two IRs, Ir93a and Ir100a, are expressed nearly exclusively with Or49 and the co-receptors Orco and Ir25a, whereas Ir75g is co-expressed with the coreceptor Ir25a and the $\mathrm{CO}_{2}$ receptor subunit Gr3. Thus, the transcriptional landscape in Ae. aegypti maxillary palp olfactory neurons is not only permissive to co-expression, but ensures certain receptors are only expressed with others.

How might this complex code of chemosensory receptor coexpression be regulated? In vertebrates, an elaborate epigenetic silencing mechanism ensures that each olfactory neuron expresses only a single allele of a single odorant receptor (Bashkirova and Lomvardas, 2019). In contrast, Drosophila is thought to use a more conventional transcription factor code in which the specification of a neuron and the expression of its chemosensory receptor is tightly regulated (Jafari and Alenius, 2015; Li et al., 2016; Ray et al., 2008). Single-cell sequencing data generated from developing Drosophila melanogaster olfactory neurons demonstrates a complex regulatory landscape wherein dependent on cell type, a set of transcription factors govern receptor expression, axon targeting, or both (Li et al., 2020). Two recent studies (McLaughlin et al., 2020; Task et al., 2020) also document extensive co-expression of receptors in Drosophila melanogaster, calling into question the rules that regulate olfactory organization in this insect. It is yet to be determined if mosquito orthologues of these transcription factors have been co-opted to regulate the co-expression we observe or if this novel olfactory organization demands a distinct transcriptional mechanism.

The maxillary palp has been implicated in responses to $\mathrm{CO}_{2}$ (Acree et al., 1968; Gillies, 1980; Grant et al., 1995), thermosensation (Roth, 1951), mechanosensation (Bohbot et al., 2014), detection of attractive monomolecular odorants such as 1-octen-3-ol (Syed and Leal, 2007; Takken and Kline, 1989; Vythilingam et al., 1992), as well as blends of odorants extracted from human hosts (Tauxe et al., 2013). Maxillary palp transcriptomes offer insights into how these tiny sensory organs detect a broad range of stimuli (Bohbot et al., 2014; Matthews et al., 2018), pointing to a transcriptional landscape that is difficult to reconcile with the prior understanding of neuronal identity in the maxillary palp. It was thought that all basiconic sensilla, which detect volatile odorants, house the sensory dendrites of three neurons that form identical repeating units: one large $\mathrm{CO}_{2}$-sensitive neuron that expresses $\mathrm{Gr} 3$, and two smaller neurons that express either an Orco-Or8 receptor or an Orco-Or49 receptor (Lu et al., 2007; Mclver, 1972). How do these repeating units of just three neurons enable the detection of so many stimuli and accommodate the expression of so many chemosensory genes? We demonstrate through multiplexed RNA in situ hybridization experiments that the receptor composition of these neurons is far more complex, and they can be subdivided into many more than three cell types. We did not evaluate the relationship of every combination of chemosensory genes expressed in the maxillary palp and hypothesize that comprehensive gene expression profiling including the application of single cell RNA-sequencing will reveal even more cell types. The extensive co-expression of IRs, ORs, and GRs documented in this work likely enables maxillary palp neurons to detect volatile odorants belonging to multiple chemical classes and may explain how $\mathrm{CO}_{2}$-sensitive neurons also respond to human skin odor (Dormont et al., 2013; Tauxe et al., 2013), and why mosquitoes unable to detect $\mathrm{CO}_{2}$ can still locate a human host (McMeniman et al., 2014).

Receptor co-expression as a mechanism for redundancy or blend integration

We hypothesize that receptor co-expression is used broadly to detect redundant cues that are present in human odor, a blend that can vary from individual to individual and contains hundreds of different chemicals (Bernier et al., 1999; Bernier et al., 2000). We have not yet explored the role of OR-IR coexpression or the expression of multiple IRs or ORs in single olfactory neurons. It is possible that receptor co-expression is always used to form a highly redundant detection system for different cues that represent the same ecological target: human hosts. This motif has the benefit of limiting the number of neurons needed to detect varied odorants with the same meaning, however, in exchange it may sacrifice the 
ability to distinguish between cues detected by receptors expressed in the same sensory neurons. In Drosophila melanogaster there are rare cases of OR-OR or OR-IR co-expression, which is the exception rather than the rule. Or35a is co-expressed with Ir76b (Silbering et al., 2011), and while these neurons respond to many odorants (Silbering et al., 2011; Yao et al., 2005), the role of co-expression remains unknown. In Drosophila melanogaster, Or49a and Or85f are co-expressed in a specific olfactory sensory neuron population where they play redundant roles in predator avoidance (Ebrahim et al., 2015). Intriguingly, recent data from Drosophila melanogaster also show Orco and Ir25a co-expression in the antenna and maxillary palp (McLaughlin et al., 2020; Task et al., 2020), suggesting that broad co-receptor co-expression may be a conserved motif in insects and upending previous data that suggested strict segregation of OR and IR sensory neuron populations in flies.

While extensive co-expression of different classes of olfactory receptors within olfactory neurons documented in this study is a novel organizational principle, there are counterexamples of receptor co-expression within a single class of chemosensory receptor. Karner et al. have documented polycistronic expression of multiple odorant receptors in Anopheles gambiae sensory neurons (Karner et al., 2015). The nematode $C$. elegans copes with a very large number of chemosensory receptor genes and a very small number of sensory neurons by extensive receptor co-expression (Troemel et al., 1995; Vidal et al., 2018).

What is the functional significance of co-expression of different classes of olfactory receptors, the ORs, IRs, and GRs, in Aedes aegypti? It is possible that co-expression is exploited to integrate the detection of multiple odors in the sensory neuron itself. In Drosophila melanogaster, IRs that form functional complexes can depolarize resting membrane potential in vitro (Ai et al., 2013). If the same phenomenon is occurring in Ae. aegypti neurons that express both IR and OR complexes, it is possible that an IR complex could render a neuron more sensitive to OR ligands. Certain odors repress OR activity relative to baseline in Drosophila melanogaster (Hallem and Carlson, 2006; Yao et al., 2005) and it is possible that multiple receptors housed in a single neuron could be a source of blend-specific repression. Individual odorant molecules found in human odor exist in many blends and this might be a way to limit the attraction to monomolecular components of human odor that are found in aversive blends or are produced by other animals. Recent data in Drosophila show that, in maxillary palp sensilla innervated by Orco neurons, responses to several odorants change in Ir25a mutant flies (Task et al., 2020). The direction of the response is sensilla-specific. In some neurons, responses are higher in Ir25a mutants, in other neurons, responses are lower, suggesting that Ir25a may be implicated in gain control in Orco neurons (Task et al., 2020). These ideas remain to be tested in the mosquito, but it is tempting to speculate that this could be used as a method to detect ratios of odors present in a blend, a key determinant in how attractive many monomolecular compounds are to mosquitoes (Bernier et al., 2007).
We demonstrate that Ae. aegypti mosquitoes employ both receptor co-expression in primary sensory neurons as well as co-convergence of neurons that express distinct classes of chemosensory receptors onto the same glomerulus. Consistent with these data, we also identified olfactory neurons in the antenna that express ORs without IRs, IRs without ORs, and neurons that express both ORs and IRs. What is the functional difference between integrating odorant information in the primary sensory neuron versus at the first synapse in the antennal lobe? Co-convergence of olfactory sensory neurons onto the antennal lobe could allow for the early integration of olfactory cues while still retaining discrete input channels that could be selectively modulated during changes in behavioral state, such as the suppression of host-seeking after a blood meal. The role of co-convergence in this system remains to be tested.

In summary, our study reveals unexpected complexity in the gene expression and functional organization of the mosquito olfactory system. The potential redundancy afforded by a system in which many neurons express receptors that respond to non-overlapping sets of odorant ligands may greatly increase the sensitivity and robustness of the mosquito olfactory system. Future attempts to refine the design of repellents to ward off mosquitoes or attractant traps to lure them will have to reckon with the complexity of this system.

\section{DATA AND RESOURCE AVAILABILITY}

Supplementary Figures S1-S9 accompany the paper. All raw data in the paper are provided in Data File 1. Additional raw data and custom scripts are available at https://github.com/VosshallLab/Younger_Herre_Vosshall2020. Plasmids are available from Addgene (accession \#162520-162526).

\section{ACKNOWLEDGMENTS}

We thank Emily Dennis, Laura Duvall, Itzel Ishida, Philip Kidd, Erica Korb, Carolyn McBride, Christopher Potter, Darya Task, Zhilei Zhao, and members of the Vosshall Lab for comments on the manuscript; Gloria Gordon and Libby Mejia for expert mosquito rearing; Maria Elena (Ellen) de Obaldia for early assistance with the Quattroport olfactometer; Javier Marquina-Solis for antennal lobe tracing assistance; Christina Pyrgaki, Carlos Rico, Katarzyna (Kate) Cialowicz, and Alison North at the Rockefeller Bio-Imaging Resource Center for assistance with confocal imaging; Daniel Gross, James Petrillo, and Peer Strogies at the Rockefeller Precision Instrumental Technologies (PIT) resource center for advice and fabrication of the olfactometer and other imaging components used in the GCaMP imaging experiments; Olena Riabinina and Christopher Potter for providing advice and unpublished Q-system reagents; Carolyn McBride, Matthew DeGennaro and members of the Aedes Toolkit Group for advice and discussion; Caroline Jiang for advice on statistical analysis; Nipun Basrur, Priya Rajasethupathy, Andrea Terceros, Harry Choi and Molecular Instruments for advice on RNA in situ hybridization experiments; Rob A Harrell II at the Insect Transgenesis Facility at the University of Maryland for embryo injections; Cory Root, Raphael Cohn, Ari Zolin, Gaby Maimon, and Vanessa Ruta for advice on calcium imaging and data analysis; Alan Grant and Greg Suh for advice on $\mathrm{CO}_{2}$ delivery; Frances Weis-Garcia and the members of the MSKCC Antibody and Bioresource Core Facility for preparation of the nc82/Brp monoclonal antibody. 


\section{FUNDING}

This work was supported in part by grant \# UL1 TR000043 from the National Center for Advancing Translational Sciences (NCATS, National Institutes of Health (NIH) Clinical and Translational Science Award (CTSA) program. Funding for this study was provided by Jane Coffin Childs Postdoctoral Fellowships (M.A.Y. and B.J.M), The Grass Foundation (M.A.Y.), a Leon Levy Neuroscience Fellowship (M.A.Y.), and by a pilot grant and postdoctoral fellowship from the Kavli Neural Systems Institute (M.A.Y.), a predoctoral fellowship from the Kavli Neural Systems Institute (M.H.), NIH NIDCD grant F30DC017658 (M.H.). B.J.M. received support from National Sciences and Engineering Research Council (NSERC), award RGPIN-2020-05423. M.H. is supported by a Medical Scientist Training Program grant from the National Institute of General Medical Sciences of the NIH under award number T32GM007739 to the Weill Cornell/Rockefeller/Sloan Kettering Tri-Institutional MD-PhD Program. Antibody purification carried out at the MSKCC Antibody and Bioresource Core Facility was supported by a Cancer Center Core Grant 5 P30 CA008748-54. L.B.V. is an investigator of the Howard Hughes Medical Institute.

\section{AUTHOR CONTRIBUTIONS}

M.A.Y. carried out all antennal lobe immunostaining and conducted and analyzed all calcium imaging experiments. M.H. carried out all peripheral tissue immunostaining and RNA in situ hybridization experiments. M.A.Y. and M.H. together conducted and analyzed all behavior data, except those in Figure 6C, which were carried out by A.R.E. B.J.M. provided gene and transcript analysis in Figure 1. Z.G. cloned and isolated Split-QF2 lines with M.H. Z.N.G. cloned and isolated QF2 stop codon replacement lines with B.J.M. and M.A.Y.S.R. worked with M.H. to generate RNA in situ hybridization data. M.A.Y., M.H., and L.B.V. together conceived the study, designed the figures, and wrote the paper with input from all authors.

\section{DECLARATION OF INTERESTS}

The authors declare no competing interests.

\section{REFERENCES}

Abuin, L., Bargeton, B., Ulbrich, M.H., Isacoff, E.Y., Kellenberger, S., and Benton, R. (2011). Functional architecture of olfactory ionotropic glutamate receptors. Neuron 69 , 44-60.

Acree, F., Jr., Turner, R.B., Gouck, H.K., Beroza, M., and Smith, N. (1968). L-Lactic acid: a mosquito attractant isolated from humans. Science 161, 1346-1347.

Ai, M., Blais, S., Park, J.Y., Min, S., Neubert, T.A., and Suh, G.S. (2013). Ionotropic glutamate receptors IR64a and IR8a form a functional odorant receptor complex in vivo in Drosophila. J Neurosci 33, 10741-10749.

Allan, S.A., Day, J.F., and Edman, J.D. (1987). Visual ecology of biting flies. Annu Rev Entomol 32, 297-316.

Bashkirova, E., and Lomvardas, S. (2019). Olfactory receptor genes make the case for inter-chromosomal interactions. Curr Opin Genet Dev 55, 106-113.

Basrur, N.S., De Obaldia, M.E., Morita, T., Herre, M., von Heynitz, R.K., Tsitohay, Y.N., and Vosshall, L.B. (2020). fruitless mutant male mosquitoes gain attraction to human odor. bioRxiv 10.1101/2020.09.04.282434.
Benton, R., Sachse, S., Michnick, S.W., and Vosshall, L.B. (2006). Atypical membrane topology and heteromeric function of Drosophila odorant receptors in vivo. PLoS Biol 4, e20.

Benton, R., Vannice, K.S., Gomez-Diaz, C., and Vosshall, L.B. (2009). Variant ionotropic glutamate receptors as chemosensory receptors in Drosophila. Cell 136, 149-162.

Bernier, U.R., Booth, M.M., and Yost, R.A. (1999). Analysis of human skin emanations by gas chromatography/mass spectrometry. 1. Thermal desorption of attractants for the yellow fever mosquito (Aedes aegypti) from handled glass beads. Anal Chem 71, 1-7.

Bernier, U.R., Kline, D.L., Allan, S.A., and Barnard, D.R. (2007). Laboratory comparison of Aedes aegypti attraction to human odors and to synthetic human odor compounds and blends. J Am Mosq Control Assoc 23, 288-293.

Bernier, U.R., Kline, D.L., Barnard, D.R., Schreck, C.E., and Yost, R.A. (2000). Analysis of human skin emanations by gas chromatography/mass spectrometry. 2. Identification of volatile compounds that are candidate attractants for the yellow fever mosquito (Aedes aegypti). Anal Chem 72, 747-756.

Bohbot, J., Pitts, R.J., Kwon, H.W., Rutzler, M., Robertson, H.M., and Zwiebel, L.J. (2007). Molecular characterization of the Aedes aegypti odorant receptor gene family. Insect Mol Biol 16, 525-537.

Bohbot, J.D., and Dickens, J.C. (2009). Characterization of an enantioselective odorant receptor in the yellow fever mosquito Aedes aegypti. PLoS One 4, e7032.

Bohbot, J.D., Sparks, J.T., and Dickens, J.C. (2014). The maxillary palp of Aedes aegypti, a model of multisensory integration. Insect Biochem Mol Biol 48, 29-39.

Brand, A.H., and Perrimon, N. (1993). Targeted gene expression as a means of altering cell fates and generating dominant phenotypes. Development 118, 401-415.

Brown, J.E., Evans, B.R., Zheng, W., Obas, V., Barrera-Martinez, L., Egizi, A., Zhao, H., Caccone, A., and Powell, J.R. (2014). Human impacts have shaped historical and recent evolution in Aedes aegypti, the dengue and yellow fever mosquito. Evolution $68,514-525$.

Buck, L., and Axel, R. (1991). A novel multigene family may encode odorant receptors: a molecular basis for odor recognition. Cell 65, 175-187.

Butterwick, J.A., Del Marmol, J., Kim, K.H., Kahlson, M.A., Rogow, J.A., Walz, T., and Ruta, V. (2018). Cryo-EM structure of the insect olfactory receptor Orco. Nature 560, 447-452.

Chen, T.W., Wardill, T.J., Sun, Y., Pulver, S.R., Renninger, S.L., Baohan, A., Schreiter, E.R., Kerr, R.A., Orger, M.B., Jayaraman, V., et al. (2013). Ultrasensitive fluorescent proteins for imaging neuronal activity. Nature 499, 295-300.

Chess, A., Simon, I., Cedar, H., and Axel, R. (1994). Allelic inactivation regulates olfactory receptor gene expression. Cell 78, 823-834. 
Choi, H.M.T., Schwarzkopf, M., Fornace, M.E., Acharya, A., Artavanis, G., Stegmaier, J., Cunha, A., and Pierce, N.A. (2018). Third-generation in situ hybridization chain reaction: multiplexed, quantitative, sensitive, versatile, robust. Development 145, 10.1242/dev.165753.

Clyne, P.J., Warr, C.G., and Carlson, J.R. (2000). Candidate taste receptors in Drosophila. Science 287, 1830-1834.

Clyne, P.J., Warr, C.G., Freeman, M.R., Lessing, D., Kim, J., and Carlson, J.R. (1999). A novel family of divergent seventransmembrane proteins: candidate odorant receptors in Drosophila. Neuron 22, 327-338.

Cohn, R., Morantte, I., and Ruta, V. (2015). Coordinated and compartmentalized neuromodulation shapes sensory processing in Drosophila. Cell 163, 1742-1755.

Corfas, R.A., and Vosshall, L.B. (2015). The cation channel TRPA1 tunes mosquito thermotaxis to host temperatures. Elife 4, 10.7554/eLife.11750.

Couto, A., Alenius, M., and Dickson, B.J. (2005). Molecular, anatomical, and functional organization of the Drosophila olfactory system. Curr Biol 15, 1535-1547.

Davis, E.E. (1984). Regulation of sensitivity in the peripheral chemoreceptor systems for host-seeking behavior by a haemolymph-borne factor in Aedes aegypti. J Insect Physiol 30, 179-183.

DeGennaro, M., McBride, C.S., Seeholzer, L., Nakagawa, T., Dennis, E.J., Goldman, C., Jasinskiene, N., James, A.A., and Vosshall, L.B. (2013). orco mutant mosquitoes lose strong preference for humans and are not repelled by volatile DEET. Nature 498, 487-491.

Dekker, T., Geier, M., and Carde, R.T. (2005). Carbon dioxide instantly sensitizes female yellow fever mosquitoes to human skin odours. J Exp Biol 208, 2963-2972.

Distler, P., and Boeckh, J. (1997). Central projections of the maxillary and antennal nerves in the mosquito Aedes aegypti. J Exp Biol 200, 1873-1879.

Dormont, L., Bessiere, J.M., McKey, D., and Cohuet, A. (2013). New methods for field collection of human skin volatiles and perspectives for their application in the chemical ecology of human-pathogen-vector interactions. J Exp Biol 216, 2783-2788.

Duvall, L.B., Ramos-Espiritu, L., Barsoum, K.E., Glickman, J.F., and Vosshall, L.B. (2019). Small-molecule agonists of Ae. aegypti neuropeptide $\mathrm{Y}$ receptor block mosquito biting. Cell 176, 687-701.

Ebrahim, S.A., Dweck, H.K., Stokl, J., Hofferberth, J.E., Trona, F., Weniger, K., Rybak, J., Seki, Y., Stensmyr, M.C., Sachse, S., et al. (2015). Drosophila avoids parasitoids by sensing their semiochemicals via a dedicated olfactory circuit. PLoS Biol 13, e1002318.

Fişek, M., and Wilson, R.I. (2014). Stereotyped connectivity and computations in higher-order olfactory neurons. Nat Neurosci 17, 280-288.
Fishilevich, E., and Vosshall, L.B. (2005). Genetic and functional subdivision of the Drosophila antennal lobe. Curr Biol 15, 15481553.

Flanagan, D., and Mercer, A.R. (1989). An atlas and 3-D reconstruction of the antennal lobes in the worker honey bee, Apis mellifera L. (Hymenoptera : Apidae). Int J Insect Morphol \& Embryol 18, 145-159.

Gallagher, M., Wysocki, C.J., Leyden, J.J., Spielman, A.I., Sun, X., and Preti, G. (2008). Analyses of volatile organic compounds from human skin. Br J Dermatol 159, 780-791.

Gao, Q., and Chess, A. (1999). Identification of candidate Drosophila olfactory receptors from genomic DNA sequence. Genomics 60, 31-39.

Geier, M., Bosch, O.J., and Boeckh, J. (1999). Ammonia as an attractive component of host odour for the yellow fever mosquito, Aedes aegypti. Chem Senses 24, 647-653.

Ghaninia, M., Majeed, S., Dekker, T., Hill, S.R., and Ignell, R. (2019). Hold your breath - Differential behavioral and sensory acuity of mosquitoes to acetone and carbon dioxide. PLoS One 14 , e0226815.

Gillies, M.T. (1980). The role of carbon dioxide in host-finding in mosquitoes (Diptera:Culicidae): a review. Bull Entomol Res 70, 525-532.

Gouck, H.K. (1972). Host preferences of various strains of Aedes aegypti and Aedes simpsoni as determined by an olfactometer. Bull World Health Org 47, 680-683.

Grabe, V., Strutz, A., Baschwitz, A., Hansson, B.S., and Sachse, S. (2015). Digital in vivo 3D atlas of the antennal lobe of Drosophila melanogaster. J Comp Neurol 523, 530-544.

Grant, A.J., Wigton, B.E., Aghajanian, J.G., and O'Connell, R.J. (1995). Electrophysiological responses of receptor neurons in mosquito maxillary palp sensilla to carbon dioxide. J Comp Physiol [A] 177, 389-396.

Grosse-Wilde, E., Kuebler, L.S., Bucks, S., Vogel, H., Wicher, D., and Hansson, B.S. (2011). Antennal transcriptome of Manduca sexta. Proc Natl Acad Sci U S A 108, 7449-7454.

Hallem, E.A., and Carlson, J.R. (2006). Coding of odors by a receptor repertoire. Cell 125, 143-160.

Hussain, A., Zhang, M., Üçpunar, H.K., Svensson, T., Quillery, E., Gompel, N., Ignell, R., and Grunwald Kadow, I.C. (2016). Ionotropic chemosensory receptors mediate the taste and smell of polyamines. PLoS Biol 14, e1002454.

Ignell, R., Dekker, T., Ghaninia, M., and Hansson, B.S. (2005). Neuronal architecture of the mosquito deutocerebrum. J Comp Neurol 493, 207-240.

Ihara, S., Yoshikawa, K., and Touhara, K. (2013). Chemosensory signals and their receptors in the olfactory neural system. Neuroscience 254, 45-60. 
Ito, K., Shinomiya, K., Ito, M., Armstrong, J.D., Boyan, G., Hartenstein, V., Harzsch, S., Heisenberg, M., Homberg, U., Jenett, A., et al. (2014). A systematic nomenclature for the insect brain. Neuron $81,755-765$.

Jafari, S., and Alenius, M. (2015). Cis-regulatory mechanisms for robust olfactory sensory neuron class-restricted odorant receptor gene expression in Drosophila. PLoS Genet 11, e1005051.

Jones, W.D., Cayirlioglu, P., Kadow, I.G., and Vosshall, L.B. (2007). Two chemosensory receptors together mediate carbon dioxide detection in Drosophila. Nature 445, 86-90.

Jové, V., Gong, Z., Hol, F.J.H., Zhao, Z., Sorrells, T.R., Carroll, T.S., Prakash, M., McBride, C.S., and Vosshall, L.B. (2020). Sensory discrimination of blood and floral nectar by Aedes aegypti mosquitoes. Neuron 10.1016/j.neuron.2020.09.019.

Karner, T., Kellner, I., Schultze, A., Breer, H., and Krieger, J. (2015). Co-expression of six tightly clustered odorant receptor genes in the antenna of the malaria mosquito Anopheles gambiae. Front Ecol Evol 3, 10.3389/fevo.2015.00026.

Kistler, K.E., Vosshall, L.B., and Matthews, B.J. (2015). Genome engineering with CRISPR-Cas9 in the mosquito Aedes aegypti. Cell Rep 11, 51-60.

Klowden, M. (1981). Initiation and termination of host-seeking inhibition in Aedes aegypti during oöcyte maturation. J Insect Physiol 27, 799-803.

Kwon, H.W., Lu, T., Rutzler, M., and Zwiebel, L.J. (2006). Olfactory responses in a gustatory organ of the malaria vector mosquito Anopheles gambiae. Proc Natl Acad Sci U S A 103, 13526-13531.

Kwon, J.Y., Dahanukar, A., Weiss, L.A., and Carlson, J.R. (2007). The molecular basis of $\mathrm{CO}_{2}$ reception in Drosophila. Proc Natl Acad Sci U S A 104, 3574-3578.

Laissue, P.P., Reiter, C., Hiesinger, P.R., Halter, S., Fischbach, K.F., and Stocker, R.F. (1999). Three-dimensional reconstruction of the antennal lobe in Drosophila melanogaster. J Comp Neurol $405,543-552$.

Larsson, M.C., Domingos, A.I., Jones, W.D., Chiappe, M.E., Amrein, H., and Vosshall, L.B. (2004). Or83b encodes a broadly expressed odorant receptor essential for Drosophila olfaction. Neuron 43, 703-714.

Lee, Y., Poudel, S., Kim, Y., Thakur, D., and Montell, C. (2018). Calcium taste avoidance in Drosophila. Neuron 97, 67-74 e64.

Li, H., Li, T., Horns, F., Li, J., Xie, Q., Xu, C., Wu, B., Kebschull, J.M., McLaughlin, C.N., Kolluru, S.S., et al. (2020). Single-cell transcriptomes reveal diverse regulatory strategies for olfactory receptor expression and axon targeting. Curr Biol 30, 11891198.e1185.

Li, Q., Barish, S., Okuwa, S., Maciejewski, A., Brandt, A.T., Reinhold, D., Jones, C.D., and Volkan, P.C. (2016). A functionally conserved gene regulatory network module governing olfactory neuron diversity. PLoS Genet 12, e1005780.
Lu, T., Qiu, Y.T., Wang, G., Kwon, J.Y., Rutzler, M., Kwon, H.W., Pitts, R.J., van Loon, J.J., Takken, W., Carlson, J.R., et al. (2007). Odor coding in the maxillary palp of the malaria vector mosquito Anopheles gambiae. Curr Biol 17, 1533-1544.

Majeed, S., Hill, S.R., and Ignell, R. (2014). Impact of elevated $\mathrm{CO}_{2}$ background levels on the host-seeking behaviour of Aedes aegypti. J Exp Biol 217, 598-604.

Manning, L., and Doe, C.Q. (2017). Immunofluorescent antibody staining of intact Drosophila larvae. Nat Protoc 12, 1-14.

Marder, E., and Goaillard, J.M. (2006). Variability, compensation and homeostasis in neuron and network function. Nat Rev Neurosci 7, 563-574.

Matthews, B.J., Dudchenko, O., Kingan, S.B., Koren, S., Antoshechkin, I., Crawford, J.E., Glassford, W.J., Herre, M., Redmond, S.N., Rose, N.H., et al. (2018). Improved reference genome of Aedes aegypti informs arbovirus vector control. Nature 563, 501-507.

Matthews, B.J., McBride, C.S., DeGennaro, M., Despo, O., and Vosshall, L.B. (2016). The neurotranscriptome of the Aedes aegypti mosquito. BMC Genomics 17, 32.

Matthews, B.J., Younger, M.A., and Vosshall, L.B. (2019). The ion channel ppk301 controls freshwater egg-laying in the mosquito Aedes aegypti. Elife 8, e43963.

McBride, C.S., Baier, F., Omondi, A.B., Spitzer, S.A., Lutomiah, J., Sang, R., Ignell, R., and Vosshall, L.B. (2014). Evolution of mosquito preference for humans linked to an odorant receptor. Nature 515, 222-227.

Mclver, S.B. (1972). Fine structure of pegs on the palps of female culicine mosquitoes. Can J Zool 50, 571-576.

McLaughlin, C.N., Brbić, M., Xie, Q., Li, T., Horns, F., Kolluru, S.S., Kebschull, J.M., Vacek, D., Xie, A., Li, J., et al. (2020). Single-cell transcriptomes of developing and adult olfactory receptor neurons in Drosophila. bioRxiv 10.1101/2020.10.08.332130.

McMeniman, C.J., Corfas, R.A., Matthews, B.J., Ritchie, S.A., and Vosshall, L.B. (2014). Multimodal integration of carbon dioxide and other sensory cues drives mosquito attraction to humans. Cell 156, 1060-1071.

Min, S., Ai, M., Shin, S.A., and Suh, G.S. (2013). Dedicated olfactory neurons mediating attraction behavior to ammonia and amines in Drosophila. Proc Natl Acad Sci U S A 110, E13211329.

Mombaerts, P., Wang, F., Dulac, C., Chao, S.K., Nemes, A., Mendelsohn, M., Edmondson, J., and Axel, R. (1996). Visualizing an olfactory sensory map. Cell $87,675-686$.

Montell, C. (2009). A taste of the Drosophila gustatory receptors. Curr Opin Neurobiol 19, 345-353.

Neuhaus, E.M., Gisselmann, G., Zhang, W., Dooley, R., Stortkuhl, K., and Hatt, H. (2005). Odorant receptor heterodimerization in the olfactory system of Drosophila melanogaster. Nat Neurosci 8, 15-17. 
Omer, S.M., and Gillies, M.T. (1971). Loss of response to carbon dioxide in palpectomized female mosquitoes. Ent Exp \& Appl 14, 251-252.

Potter, C.J., Tasic, B., Russler, E.V., Liang, L., and Luo, L. (2010). The $Q$ system: a repressible binary system for transgene expression, lineage tracing, and mosaic analysis. Cell 141, 536548.

Prieto-Godino, L.L., Rytz, R., Cruchet, S., Bargeton, B., Abuin, L., Silbering, A.F., Ruta, V., Dal Peraro, M., and Benton, R. (2017). Evolution of acid-sensing olfactory circuits in Drosophilids. Neuron 93, 661-676.e666.

Raji, J.I., Melo, N., Castillo, J.S., Gonzalez, S., Saldana, V., Stensmyr, M.C., and DeGennaro, M. (2019). Aedes aegypti mosquitoes detect acidic volatiles found in human odor using the IR8a pathway. Curr Biol 29, 1253-1262 e1257.

Ray, A., van der Goes van Naters, W., and Carlson, J.R. (2008). A regulatory code for neuron-specific odor receptor expression. PLoS Biol 6, e125.

Ressler, K.J., Sullivan, S.L., and Buck, L.B. (1994). Information coding in the olfactory system: evidence for a stereotyped and highly organized epitope map in the olfactory bulb. Cell 79, 12451255.

Riabinina, O., Task, D., Marr, E., Lin, C.C., Alford, R., O'Brochta, D.A., and Potter, C.J. (2016). Organization of olfactory centres in the malaria mosquito Anopheles gambiae. Nat Commun 7, 13010.

Riabinina, O., Vernon, S.W., Dickson, B.J., and Baines, R.A. (2019). Split-QF system for fine-tuned transgene expression in Drosophila. Genetics 212, 53-63.

Robertson, H.M., Gadau, J., and Wanner, K.W. (2010). The insect chemoreceptor superfamily of the parasitoid jewel wasp Nasonia vitripennis. Insect Mol Biol 19 Suppl 1, 121-136.

Robertson, H.M., Warr, C.G., and Carlson, J.R. (2003). Molecular evolution of the insect chemoreceptor gene superfamily in Drosophila melanogaster. Proc Natl Acad Sci U S A 100 Suppl 2, 14537-14542.

Roth, L.M. (1951). Loci of sensory end-organs used by mosquitoes (Aedes aegypti (L.) and Anopheles quadrimaculatus say) in receiving host stimuli. Ann Entomol Soc Am 44, 59-74.

Rubin, B.D., and Katz, L.C. (1999). Optical imaging of odorant representations in the mammalian olfactory bulb. Neuron $23,499-$ 511.

Sato, K., Pellegrino, M., Nakagawa, T., Nakagawa, T., Vosshall, L.B., and Touhara, K. (2008). Insect olfactory receptors are heteromeric ligand-gated ion channels. Nature 452, 1002-1006.

Schaefer, M.L., Finger, T.E., and Restrepo, D. (2001). Variability of position of the P2 glomerulus within a map of the mouse olfactory bulb. J Comp Neurol 436, 351-362.

Scott, K., Brady, R., Jr., Cravchik, A., Morozov, P., Rzhetsky, A., Zuker, C., and Axel, R. (2001). A chemosensory gene family encoding candidate gustatory and olfactory receptors in Drosophila. Cell 104, 661-673.

Shankar, S., and McMeniman, C.J. (2020). An updated antennal lobe atlas for the yellow fever mosquito Aedes aegypti. PLoS Negl Trop Dis 14, e0008729.

Silbering, A.F., Rytz, R., Grosjean, Y., Abuin, L., Ramdya, P., Jefferis, G.S., and Benton, R. (2011). Complementary function and integrated wiring of the evolutionarily distinct Drosophila olfactory subsystems. J Neurosci 31, 13357-13375.

Smallegange, R.C., Qiu, Y.T., van Loon, J.J., and Takken, W. (2005). Synergism between ammonia, lactic acid and carboxylic acids as kairomones in the host-seeking behaviour of the malaria mosquito Anopheles gambiae sensu stricto (Diptera: Culicidae). Chem Senses 30, 145-152.

Smith, C.N., Smith, N., Gouck, H.K., Weidhaas, D.E., Gilbert, I.H., Mayer, M.S., Smittle, B.J., and Hofbauer, A. (1970). L-lactic acid as a factor in the attraction of Aedes aegypti (Diptera: Culicidae) to human hosts. Ann Entomol Soc Am 63, 760-770.

Stocker, R.F. (1994). The organization of the chemosensory system in Drosophila melanogaster. a review. Cell Tissue Res 275, 3-26.

Stocker, R.F., Lienhard, M.C., Borst, A., and Fischbach, K.F. (1990). Neuronal architecture of the antennal lobe in Drosophila melanogaster. Cell Tissue Res 262, 9-34.

Strotmann, J., Conzelmann, S., Beck, A., Feinstein, P., Breer, H., and Mombaerts, P. (2000). Local permutations in the glomerular array of the mouse olfactory bulb. J Neurosci 20, 6927-6938.

Syed, Z., and Leal, W.S. (2007). Maxillary palps are broad spectrum odorant detectors in Culex quinquefasciatus. Chem Senses 32, 727-738.

Takken, W., and Kline, D.L. (1989). Carbon dioxide and 1-octen3-ol as mosquito attractants. J Am Mosq Control Assoc 5, 311316.

Tanaka, N.K., Endo, K., and Ito, K. (2012). Organization of antennal lobe-associated neurons in adult Drosophila melanogaster brain. J Comp Neurol 520, 4067-4130.

Task, D., Lin, C.C., Afify, A., Li, H., Vulpe, A., Menuz, K., and Potter, C.J. (2020). Widespread polymodal odorant receptor expression in Drosophila olfactory neurons. bioRxiv in press.

Tauxe, G.M., MacWilliam, D., Boyle, S.M., Guda, T., and Ray, A. (2013). Targeting a dual detector of skin and $\mathrm{CO}_{2}$ to modify mosquito host seeking. Cell 155, 1365-1379.

Troemel, E.R., Chou, J.H., Dwyer, N.D., Colbert, H.A., and Bargmann, C.I. (1995). Divergent seven transmembrane receptors are candidate chemosensory receptors in $C$. elegans. Cell 83, 207-218.

Turner, S.L., Li, N., Guda, T., Githure, J., Carde, R.T., and Ray, A. (2011). Ultra-prolonged activation of $\mathrm{CO}_{2}$-sensing neurons disorients mosquitoes. Nature 474, 87-91. 
Uchida, N., Takahashi, Y.K., Tanifuji, M., and Mori, K. (2000). Odor maps in the mammalian olfactory bulb: domain organization and odorant structural features. Nat Neurosci 3, 1035-1043.

Vassar, R., Chao, S.K., Sitcheran, R., Nunez, J.M., Vosshall, L.B., and Axel, R. (1994). Topographic organization of sensory projections to the olfactory bulb. Cell 79, 981-991.

Vidal, B., U. Aghayeva, H. Sun, C. Wang, L. Glenwinkel, E. A. Bayer, and Hobert, O. (2018). An atlas of Caenorhabditis elegans chemoreceptor expression. PLoS Biol 16, e2004218.

Vosshall, L.B., Amrein, H., Morozov, P.S., Rzhetsky, A., and Axel, R. (1999). A spatial map of olfactory receptor expression in the Drosophila antenna. Cell 96, 725-736.

Vosshall, L.B., Wong, A.M., and Axel, R. (2000). An olfactory sensory map in the fly brain. Cell 102, 147-159.

Vythilingam, I., Chiang, G.L., and Chan, S.T. (1992). Evaluation of carbon dioxide and 1-octen-3-ol as mosquito attractants. Southeast Asian J Trop Med Public Health 23, 328-331.

Wagh, D.A., Rasse, T.M., Asan, E., Hofbauer, A., Schwenkert, I., Dürrbeck, H., Buchner, S., Dabauvalle, M.C., Schmidt, M., Qin, G., et al. (2006). Bruchpilot, a protein with homology to ELKS/CAST, is required for structural integrity and function of synaptic active zones in Drosophila. Neuron 49, 833-844.

Wang, J.W., Wong, A.M., Flores, J., Vosshall, L.B., and Axel, R. (2003). Two-photon calcium imaging reveals an odor-evoked map of activity in the fly brain. Cell 112, 271-282.

WHO (2020). Vector-borne diseases. World Health Organization, Geneva http://www.who.int/mediacentre/factsheets/fs387/en/.

Wicher, D., Schafer, R., Bauernfeind, R., Stensmyr, M.C., Heller, R., Heinemann, S.H., and Hansson, B.S. (2008). Drosophila odorant receptors are both ligand-gated and cyclic-nucleotideactivated cation channels. Nature 452, 1007-1011.

Yao, C.A., Ignell, R., and Carlson, J.R. (2005). Chemosensory coding by neurons in the coeloconic sensilla of the Drosophila antenna. J Neurosci 25, 8359-8367.

Zhao, Z., Zung, J.L., Kriete, A.L., Iqbal, A., Younger, M.A., Matthews, B.J., Merhof, D., Thiberge, S., Strauch, M., and McBride, C.S. (2020). Chemical signatures of human odour generate a unique neural code in the brain of Aedes aegypti mosquitoes. bioRxiv 10.1101/2020.11.01.363861.

Zou, D.J., Chesler, A., and Firestein, S. (2009). How the olfactory bulb got its glomeruli: a just so story? Nat Rev Neurosci 10, 611618.

\section{MATERIALS AND METHODS}

Human and animal ethics statement:

Blood-feeding procedures and behavioral experiments with live hosts were approved and monitored by The Rockefeller University Institutional Animal Care and Use Committee (IACUC protocol 17018) and Institutional Review Board (IRB protocol LV-0652), respectively. Human volunteers gave their written informed consent to participate.
Mosquito rearing and maintenance

Aedes aegypti wild-type laboratory strains (Liverpool and Orlando), CRISPR-Cas9 knock-in, and piggyBAC QUAS transgenic strains were maintained and reared at $25-28^{\circ} \mathrm{C}, 70-80 \%$ relative humidity with a photoperiod of $14 \mathrm{hr}$ light: $10 \mathrm{hr}$ dark as previously described (DeGennaro et al., 2013). Adult mosquitoes were provided constant access to $10 \%$ sucrose. For routine strain maintenance, animals were primarily blood-fed on live mice and occasionally on live human volunteers. Newly generated strains were blood-fed on human volunteers until they were established. All experiments were conducted on female mosquitoes. Detailed genotypes used in each figure, and the use of Liverpool or Orlando as the wild-type strain in a given figure can be found in Data File 1.

Generation of chemosensory receptor QF2 and Split-QF2 knock-in strains

T2A-QF2 gene-sparing stop codon replacement lines were generated using the strategy outlined in Matthews et al. (Matthews et al., 2019). sgRNAs were placed as close to the stop codon as possible and donor constructs were designed to remove the stop codon and replace it with an in-frame cassette containing the $T 2 A$ ribosomal skipping sequence and the QF2 transcription factor or Split-QF2 domains, comprising the QF2 activation domain $Q F 2-A D$, or the QF2 DNA-binding domain QF2-DBD. This strategy spares the function of the gene at the locus being targeted, expresses QF2 or Split-QF2 domains in the cells specified by enhancers at the locus. Insertions were marked by the $3 \times P 3$ enhancer expressing a fluorescent protein.

To identify effective sgRNAs, 5 candidate sgRNAs per gene were first injected into separate pools of 500 Liverpool embryos and CRISPR-Cas9-mediated cut rate was evaluated as previously described (Kistler et al., 2015). Either a single sgRNA or 2 sgRNAs with the highest cut rates were then chosen to be injected with donor plasmids to target chemosensory gene loci using homologydirected repair. sgRNAs targeted the respective gene near the stop codon, target sequence with protospacer adjacent motif (PAM) underlined:

Ir25a: GTTTGTGTGCGTGTCCGTA TGG

Ir76b: GTATTACACTTATCTAAATA TGG

Ir8a: GTCACGCTTGTTGTACAGGG $\underline{\underline{C G G}}$,

GAACAATTTGAACAAGGTCG TGG

Gr3: GTTAGTGATGCATAATATGA CGG

Orco: GTCACCTACTTCATGGTGT TGG

sgRNA DNA template was prepared by annealing oligonucleotides as described (Kistler et al., 2015). In vitro transcription was performed using HiScribe Quick T7 kit (NEB E2050S) following the manufacturer's directions. Following transcription and DNAse treatment for $15 \mathrm{~min}$ at $37^{\circ} \mathrm{C}$, sgRNA was purified using RNAsefree SPRI beads (Ampure RNAclean, Beckman-Coulter A63987), and eluted in Ultrapure water (Invitrogen, 10977-015). Donor plasmids were constructed by Gibson assembly using the following fragments for QF2 lines:

1) pUC19 digested with $\mathrm{Xbal}$ and BamHI

2) Left and right homology arms: Gr3 (left: $1.9 \mathrm{~kb}$, right: $1.6 \mathrm{~kb}$ ), Ir25a (left: $1.8 \mathrm{~kb}$, right: $1.6 \mathrm{~kb}$ ), Ir76b (left: $1.2 \mathrm{~kb}$, right: $2.2 \mathrm{~kb}$ ), Ir8a (left: $1.7 \mathrm{~kb}$, right: $1.7 \mathrm{~kb}$ ), Orco (left: $1.2 \mathrm{~kb}$, right: $1.3 \mathrm{~kb}$ ) generated by polymerase chain reaction (PCR) using Liverpool genomic DNA as a template

3) A $2.6 \mathrm{~kb}$ fragment containing T2A-QF2-SV40, 3xP3-dsRed, PCR-amplified from a previously assembled vector (ppk10779T2A-QF2-SV4O, 3xP3-dsRed, Addgene accession \#130667)

For Split-QF2 lines, donor plasmids were constructed by generating fragments using PCR from the indicated template with indicated primers in Data File 1 and assembled using NEBuilder HiFi DNA Assembly (NEB E5520S):

Ir25a-T2A-QFAD::Zip+-SV40-3xP3-eYFP-SV40 was composed of: 
1. Plasmid backbone with Ir25 homology arms from Ir25a-T2A-QF2 plasmid $(6 \mathrm{~kb})$

2. T2A-QFAD::Zip+-SV40 sequence from (Riabinina et al., 2019), fragment synthesized by Genewiz, sequence in Data File $1(1.5 \mathrm{~kb})$ 3. 3xP3-EYFP-SV40 from PDSAY (Addgene, \#62291) (1.2 kb) Orco-T2A-Zip-::QFDBD-SV40-3xP3-dsRED-SV40 was composed of:

1. Plasmid backbone with Orco homology arms and $3 x P 3-d s R E D$ $S V 40$ from Orco-T2A-QF2 plasmid (6.3 kb)

2. T2A-Zip-::QFDBD-SV40 synthesized by Genewiz, sequence in Data File $1(1.5 \mathrm{~kb})$

For all QF2 and Split-QF2 constructs, the stop codon of the endogenous gene was removed and the PAM sequences corresponding to the sgRNAs used for injection were modified by PCR mutagenesis during Gibson assembly by introducing synonymous codon substitutions to protect the sequence from Cas9 cleavage while retaining the amino acid identity. Plasmids were isolated using an endotoxin-free plasmid midiprep kit (Macherey-Nagel) for QF2 lines and NucleoBond Xtra Midi Endotoxin-Free plasmid kit (Clontech 740420.50) for Split-QF2 lines and eluted in ultrapure water prior to injection. Donor plasmids are available at Addgene (accession numbers \#162520-162526).

Approximately 2000 wild-type Liverpool strain Ae. aegypti embryos were injected with a mix containing recombinant Cas9 protein (PNA Bio, CP01) at $300 \mathrm{ng} / \mu \mathrm{L}$, sgRNAs at $40 \mathrm{ng} / \mu \mathrm{L}$ and donor DNA plasmid (300 ng/ $\mu \mathrm{L}$ for QF2 lines, $600 \mathrm{ng} / \mu \mathrm{L}$ for Split-QF2 lines) at the Insect Transformation Facility at the University of Maryland Institute for Bioscience \& Biotechnology Research. Embryos were hatched and surviving G0 males and females were crossed to wild-type Liverpool mosquitoes and their G1 offspring were screened for fluorescence indicating positive stable germ line transformants.

For QF2 lines, the fidelity of insertion was verified by PCR and Sanger sequencing. One representative line for each chemosensory receptor QF2 knock-in was selected for further study. QF2driven expression patterns were examined by crossing to QUASCD8:GFP-3xP3-ECFP and/or QUAS-dTomato-T2A-GCaMP6s$3 x P 3-E C F P$. All lines were outcrossed to wild-type Liverpool mosquitoes for at least 3 generations prior to being used in experiments.

For Split-QF2 lines, a single family with the correct insertion was confirmed by PCR and Sanger sequencing for Ir25a-QF2-AD and Orco-QF2-DBD. To propagate these lines, a male founder was chosen to cross to wild-type Liverpool females. Animals were then back-crossed to Liverpool for at least 2 additional generations. To evaluate if the Split-QF2 system was functional in Ae. aegypti, Ir25a-QF2-AD was crossed to QUAS-dTomato-T2A-GCaMP6s. The resulting Ir25a-QF2-AD, QUAS-dTomato-T2A-GCaMP6s animals were then crossed to Orco-QF2-AD. Expression of the dTomato reporter was observed in larval antennae and subsequently confirmed in adult antennae and brains.

QUAS transgenic strains

QUAS-CD8:GFP-3xP3-ECFP and QUAS-dTomato-T2AGCaMP6s-3xP3-ECFP transgenic strains were described previously (Matthews et al., 2019). Two independent insertions of the QUAS-dTomato-T2A-GCaMP6s-3xP3-ECFP reporter line (Jové et al., 2020; Matthews et al., 2019) were used in this study. These are located on different chromosomes and were used according to the crossing scheme needed for a given experiment. See Data File 1 for details.

Transcript abundance estimates of Ae. aegypti OR, IR, and GR genes

Expression values for adult sugar-fed, non-blood-fed female sensory tissues were retrieved from the Ae. aegypti L5 genome GitHub repository (https://github.com/VosshallLab/AGWG-AaegL5) at this link: https://github.com/VosshallLab/AGWG-AaegL5/raw/master/AGWG\%20AaegL5\%20Chemoreceptor\%20TPM.xIsx. These expression values reflect libraries from a previous transcriptome study (Matthews et al., 2016) that had been aligned to the Ae. aegypti genome (AaegL5) and chemoreceptor geneset annotation reported in units of Transcripts Per Million (TPM) (Matthews et al., 2018). The number of genes from each of three gene families (ORs, IRs, and GRs) with expression values above the indicated threshold were plotted in Figure 1F, G and are available in Data File 1.

Whole brain fixation and immunostaining

Dissection of adult brains and immunostaining was done as previously described (Matthews et al., 2019). 6-14 day-old mosquitoes were anesthetized on ice. Heads were carefully removed from the body by pinching at the neck with sharp forceps. Heads were placed in a $1.5 \mathrm{~mL}$ tube for fixation with $4 \%$ paraformaldehyde, 0.1 M Millonig's Phosphate Buffer (pH 7.4), 0.25\% Triton X-100, and nutated for $3 \mathrm{hr}$. Brains were then dissected out of the head capsule in ice-cold $\mathrm{Ca}^{+2}-, \mathrm{Mg}^{+2}$-free phosphate buffered saline (PBS, Lonza 17-517Q) and transferred to a 24-well plate. All subsequent steps were done on a low-speed orbital shaker. Brains were washed in PBS containing $0.25 \%$ Triton X-100 (PBT) at room temperature 6 times for 15 min. Brains were permeabilized with PBS, $4 \%$ Triton $X-100,2 \%$ normal goat serum (Jackson ImmunoResearch \#005-000-121) for $\sim 48 \mathrm{hr}$ (2 nights) at $4^{\circ} \mathrm{C}$. Brains were rinsed once and then washed with $\mathrm{PBT}$ at room temperature 6 times for $15 \mathrm{~min}$. Primary antibodies were diluted in PBS, $0.25 \%$ Triton $\mathrm{X}-100,2 \%$ normal goat serum for $\sim 48 \mathrm{hr}(2 \mathrm{nights})$ at $4{ }^{\circ} \mathrm{C}$. Brains were rinsed once then washed in PBT at room temperature 6 times for $15 \mathrm{~min}$. Secondary antibodies were diluted in PBS, $0.25 \%$ Triton X-100, $2 \%$ normal goat serum for $\sim 48 \mathrm{hr}$ (2 nights) at $4^{\circ} \mathrm{C}$. Brains were rinsed once then washed in PBT at room temperature 6 times for $15 \mathrm{~min}$. Brains were equilibrated overnight in Vectashield (Vector Laboratories $\mathrm{H}-1000$ ) and were mounted in Vectashield.

The following primary antibodies were used: anti-Brp/nc82 (mouse; 1:50, Developmental Studies Hybridoma Bank - see below) and/or anti-GFP (rabbit: 1:10,000; Life Technologies A11122).

The secondary antibodies used in all experiments except Figure S1 and Figure S6 were anti-mouse-Cy5 (1:250; Life Technologies A-10524) and anti-rabbit-Alexa Fluor 488 (1:500; Life Technologies A-11034). In Figure S1, the secondary antibody was anti-mouseAlexa Fluor 488 (1:500; Life Technologies A-11001) and in Figure $\mathrm{S} 6$, the secondary antibodies were anti-mouse-Alexa Fluor 594 (1:500; Life Technologies A-11005) and anti-rabbit-Alexa Fluor 488 (1:500; Life Technologies A-11034).

Purification of nc82/Brp monoclonal antibody

Hybridoma cells expressing monoclonal antibody nc82 (Antibody Registry ID: AB_2314866), which recognizes the Drosophila melanogaster Brp protein (Wagh et al., 2006)

developed by Erich Buchner were obtained from the Developmental Studies Hybridoma Bank, created by the NICHD of the NIH and maintained at The University of lowa, Department of Biology, lowa City, IA 52242. Frances Weis-Garcia and the members of the MSKCC Antibody and Bioresource Core Facility subsequently used these hybridoma cells to purify this monoclonal antibody. The hybridoma was adapted to Gibco ${ }^{\mathrm{TM}}$ Hybridoma-SFM (Cat \# 12045084 ) and $1 \%$ fetal bovine serum prescreened for ultra-low levels of bovine Ig. Antibody expression was confirmed and the adapted hybridoma was inoculated into the cell compartment of the Corning ${ }^{\mathrm{TM}}$ CELLine Disposable Bioreactor (Cat \# 353137) in $15 \mathrm{ml}$ of Hybridoma-SFM $+0.5 \%$ fetal bovine serum (production media) at 3 million viable cells / $\mathrm{ml}$. The media compartment of the flask contained $350 \mathrm{ml}$ of production media. The bioreactor was incubated at $37^{\circ} \mathrm{C}$ with $7 \% \mathrm{CO}_{2}$ for 3 days, at which time the cells and media containing nc82 were harvested. 30 million viable cells from the harvest were re-inoculated back into the cell compartment in $30 \mathrm{ml}$ fresh production media. The media in the media compartment was replaced the following day with $650 \mathrm{ml}$ production media. 
Three days later, the media in the media compartment was replaced with $1,000 \mathrm{ml}$ production media, with the next harvest 3 days later ( 7 days after the previous harvest). Cells were harvested weekly and fed bi-weekly until the desired amount of monoclonal antibody was reached. After the first harvest, each one contained about $3 \mathrm{mg}$ of monoclonal antibody $\mathrm{nc} 82 / \mathrm{ml}$ production media. The harvests to be purified were pooled, centrifuged at $12,855 \times \mathrm{g}$ for $15 \mathrm{~min} .6 .5 \mathrm{mg} / \mathrm{run}$ were loaded onto a Cytiva (formerly GE Life Sciences) $1 \mathrm{ml} \mathrm{HiTrap}$ Protein G HP antibody purification column (Cat \# 29048581) at $1 \mathrm{ml} / \mathrm{min}$. The column was then washed with $0.02 \mathrm{M}$ Sodium Phosphate $(\mathrm{pH} 7.0)$ before the monoclonal antibody was eluted with $0.1 \mathrm{M}$ Glycine- $\mathrm{HCl}(\mathrm{pH} 2.7)$. One $\mathrm{ml}$ fractions were collected and immediately neutralized with $60 \mathrm{ml}$ of $1.0 \mathrm{M}$ Tris- $\mathrm{HCl}(\mathrm{pH} \mathrm{9.0)}$. The harvest, flow through and fractions from the peak were run on an a 10\% SDS-PAGE (Bio-Rad Cat \# 345-0010) to confirm purity and determine which should be pooled. The pooled fractions of monoclonal antibody were dialyzed into PBS overnight using dialysis tubing (Spectrum ${ }^{\mathrm{TM}} 132544$ ) with a $50 \mathrm{kDa}$ MWCO. Another $10 \%$ SDS-PAGE was run and the concentration determined using the absorbance at 280 using an extinction coefficient of 1.43 .

Antennal lobe confocal imaging

All brains were imaged using a Zeiss Inverted LSM 880 laser scanning confocal microscope with a 25x / 0.8 NA immersion-corrected objective unless otherwise noted. Glycerol was used as the immersion medium to most closely match the refractive index of the mounting medium Vectashield. Antennal lobes in Figure 1, 2, 5, S2-S8 were imaged at either $1024 \times 1024$ or $2048 \times 2048$ pixel resolution in $X$ and $Y$ with $0.5 \mu \mathrm{m}$ Z-steps for a final voxel size of either $0.0615 \times 0.0615 \times 0.5 \mu \mathrm{m}^{3}$ or $0.1230 \times 0.1230 \times 0.5 \mu \mathrm{m}^{3}$. Both conditions oversampled relative to the objective resolution and no differences were noted between imaging conditions. The laser intensity and gain were adjusted along the Z-axis to account for a loss of intensity due to depth and care was taken to avoid saturation and ensure that the deepest glomeruli were visible for segmentation.

$3 x P 3$ was used as a promoter to express fluorescent proteins as markers for the knock-ins and QUAS transgenes used in this study, and care was taken to distinguish expression derived from the $3 X P 3$ promoter from the expression of the QF2 driver and QUAS effector lines under investigation. 3xP3 drives expression in the optic lobes, as well as some cells in the dorsal brain. Neither area overlaps with the antennal lobes, and as reported previously (Matthews et al., 2019), we saw no 3xP3-driven expression in the antennal lobes in the reporter lines alone (data not shown). Representative antennal lobe images presented in the figures were cropped to remove $3 x P 3$-driven expression elsewhere in the brain. Antennal lobe glomerulus quantification

Confocal images of the antennal lobes in Figure 1, 2, 5, S2-S8 were processed in ImageJ/FIJI (NIH). The number of glomeruli was quantified as follows: a single region of interest (ROI) was manually drawn around each glomerulus at a section approximately central along the Z-axis. Every glomerulus was outlined and an ROI set was collected that contained the outlines of all glomeruli. Glomeruli were then separated into two groups, GFP-positive and GFP-negative glomeruli. A count of each was made to determine the number of glomeruli labeled by each line as well as the total number of glomeruli. The ROIs were flattened along the Z-axis to enable representation of the data in two dimensions in Figure 1, 2, S2-S5, S7. The left antennal lobe in 3 brains was analyzed for each genotype in Figure 1 except for Gr3, for which the left antennal lobe was analyzed in 1 brain, and both left and right antennal lobes were analyzed in an additional 4 brains in Figure S6.

Although we were able to recognize general regions of the antennal lobe, the interindividual variability made it impossible to identify most glomeruli by anatomy alone. We therefore have not attempted to name and number every glomerulus in Ae. aegypti as has been done in previous studies (Ignell et al., 2005; Shankar and McMeniman, 2020). As noted by Ito et al. (Ito et al., 2014), there is considerable confusion about the use of coordinate axes in the brains of animals in general and insects in particular. The glomeruli in the antennal lobe of $A e$. aegypti were originally named by Ignell et al. (Ignell et al., 2005) using a set of coordinate axes that differ from those consistently used in Drosophila melanogaster (Couto et al., 2005; Fishilevich and Vosshall, 2005; Grabe et al., 2015; Laissue et al., 1999; Stocker et al., 1990). A recent study of the antennal lobe of $A e$. aegypti renamed glomeruli to account for this discrepancy in coordinate axes (Shankar and McMeniman, 2020), and throughout this paper we use the same coordinate axes they have implemented. While Shankar and McMeniman renamed most antennal lobe regions and glomeruli, they chose not to rename the MD (Medio-Dorsal) cluster of glomeruli comprising MD1, MD2, and MD3 whose sensory input derives from the maxillary palp. We have observed in our study that the MD glomeruli are medial, but they are not notably dorsal, and therefore refer to them as Glomerulus 1 , Glomerulus 2, and Glomerulus 3 in this paper for simplicity. While there is utility in naming glomeruli, we suspect that the Ae. aegypti mosquito antennal lobe atlas will be refined in the future with the advent of new genetic tools that will unambiguously allow the field to distinguish and name genetically identifiable glomeruli. We found that the size, shape, and number of antennal lobe glomeruli in Ae. aegypti was variable from animal to animal. It is possible that the boundaries between glomeruli are not easily distinguished by synaptic staining and that specific glomeruli will become identifiable once there are genetic tools available that label smaller populations of olfactory sensory neurons. The anatomical variability we see is consistent with both the original map that identified 50 glomeruli (Ignell et al., 2005), which divided glomeruli into 3 classes based on their variability in location, as well as a recent study that looked specifically at the size and shape of glomeruli across animals (Shankar and McMeniman, 2020) and revised the original map to a count of $\sim 80$ glomeruli. Shankar and McMeniman named and numbered these glomeruli across animals, but they noted that they were only able to consistently identify 63 glomeruli. This is similar to the $\sim 65$ glomeruli we observed in our work. While there is not yet a clear consensus on the exact number of antennal lobe glomeruli in Ae. aegypti, the number of chemosensory receptors expressed in the antenna and maxillary palp is at least twice as large as any of the estimates of glomerulus number.

The variability in antennal lobe structure appears at first to contrast with Drosophila melanogaster, where each glomerulus can be clearly identified and named. However, we note that the antennal lobe map in Drosophila melanogaster has been refined with the advent of new genetic techniques, starting with 35 glomeruli in the original atlas (Stocker et al., 1990), then modified to 40 glomeruli (Laissue et al., 1999), and further refined in numerous studies (Couto et al., 2005; Fishilevich and Vosshall, 2005; Tanaka et al., 2012) including a recent count of 54 (Grabe et al., 2015) and 58 (Task et al., 2020) glomeruli. We have refrained from naming glomeruli in Ae. aegypti at this time because we believe that a more stereotyped anatomy will emerge as new genetic lines are generated that allow cell-type-specific labelling.

A recent study in the mosquito Anopheles gambiae using mosquitoes that label Orco-expressing olfactory neurons also noted that the antennal lobe was variable between animals relative to Drosophila melanogaster (Riabinina et al., 2016). It is therefore possible that mosquito antennal lobes are more variable than Drosophilids (Grabe et al., 2015; Prieto-Godino et al., 2017). Variability in olfactory bulb structure is seen even in the mouse, Mus musculus, where the principles of olfactory organization were first established (Schaefer et al., 2001; Strotmann et al., 2000; Zou et al., 2009). The exact size and location of glomeruli can vary between animals more than initially appreciated and appears to be determined by both genetic factors and activity in olfactory sensory 
neurons during the early life of the animal. In Drosophila melanogaster, glomerulus size is highly genetically determined and correlates strongly with the number of olfactory sensory neurons that innervates each glomerulus (Grabe et al., 2015). Whether the variability in glomerulus size in the mosquito is due to activity-dependent changes in structure or other factors remains to be seen.

Additional technical notes on expression and projection patterns of chemosensory receptor knock-in strains

Orco-QF2>QUAS-mCD8:GFP: We noted that the intensity of GFP varies between glomeruli in this driver line, with some bright and others comparably dim. We speculate that this is due to a combination of the variability in Orco expression levels in individual neurons and variability in the density of innervation in individual glomeruli. A large region of the anterior ventral antennal lobe was previously referred to as the Johnston's organ center and was thought to comprise a single large glomerulus (Ignell et al., 2005). In other insect species, Johnston's organ mediates detection of auditory cues. Consistent with a recent study (Shankar and McMeniman, 2020), we segmented this region into multiple glomeruli based on anatomical boundaries revealed with Brp immunofluorescence. Glomeruli in this region are innervated by Orco-expressing neurons, calling into doubt the original report that these glomeruli process auditory stimuli and suggesting instead that they serve an olfactory function. In support of this hypothesis, the analogous area of the Anopheles coluzzii antennal lobe has been shown to receive projections from Orco-expressing olfactory sensory neurons (Riabinina et al., 2016). We also observed GFP projections into the subesophageal zone in Orco-QF2>QUAS-mCD8:GFP animals, which appear to derive from expression in the proboscis, the primary taste organ in insects. This is consistent with similar expression in Anopheles coluzzii (Riabinina et al., 2016) and functional data in Anopheles gambiae showing that olfactory responses are detected in this gustatory organ (Kwon et al., 2006).

Ir25a-QF2>QUAS-mCD8:GFP: The intensity of GFP projections varies between glomeruli in this driver line, with some bright and other comparably dim, as noted for Orco-QF2. The brightest glomeruli are primarily medial and anterior. We see the dimmest innervation in the area previously described as Johnston's organ center as well as in the central antennal lobe. Labeling was also seen in other areas of the brain, most notably the subesophageal zone and anterior mechanosensory motor center.

Ir8a-QF2>QUAS-mCD8:GFP: Depending on the brain being analyzed there were either 2 or 3 medial glomeruli labelled in this line. In the cases where there were 3 medial glomeruli, this third medial glomerulus was innervated by a few large-diameter axons. These were larger and sparser than the smaller axons that densely innervated most other glomeruli in this line. We also note that there are 2-3 cell bodies that express GFP located in the cell body rind lateral to the antennal lobe (rALI). We are unable to definitively describe where these cells project without genetic reagents that selectively label these cells, but they appear to send bilateral processes that cross the midline within what appears to be the saddle to innervate the anterior mechanosensory motor center outside the antennal lobe. All naming is in accordance with the new insect brain nomenclature presented in Ito et al. (Ito et al., 2014).

Ir76b-QF2>QUAS-mCD8:GFP: In addition to projections to the antennal lobe, this line shows innervation of the subesophageal zone of the brain.

Gr3-QF2>QUAS-mCD8:GFP: All antennal lobes in this line show innervation of a single glomerulus (also referred to as "MD1" and here referred to as "Glomerulus 1"; (Ignell et al., 2005; Shankar and McMeniman, 2020). In several brains, we saw a second small medial glomerulus that derives its innervation from the antenna and is in a small medial cluster of landmark glomeruli midway down the anterior-posterior axis closest to the center of the brain. Innervation appears to come from only a few axons.
This low and variable reporter expression is consistent with the low level of expression of $\mathrm{Gr} 3$ in the antennal transcriptome (Matthews et al., 2016). Because this line only shows innervation of these 1-2 glomeruli, we analyzed all glomeruli only in the single brain in Figure $1 \mathrm{I}$, and additionally analyzed 8 more antennal lobes in 4 brains for the presence or absence of labelling in these two glomeruli.

We analyzed both left and right antennal lobes from 4 brains and found that in 3 of the 4 brains there was a second glomerulus in one or both antennal lobes (Figure S6). The presence of the second glomerulus was not specific within a single animal as we found all variations of presence and absence of this glomerulus across both antennal lobes in these 4 animals. In some Gr3-QF2>QUAS$m C D 8: G F P$ animals, we detected a small number of processes that extended beyond the antennal lobe and into the higher brain, although the exact termination site varied. We never saw $\mathrm{CO}_{2}-$ evoked activity in the variable second glomerulus or these projections outside the antennal lobe. Images in Figure S6 were taken as described above with the following changes: Secondary antibodies used were anti-mouse-Alexa Fluor 594 (1:500; Life Technologies A-11005) and anti-Rabbit-Alexa Fluor 488 (1:500; Life Technologies A-11034). Images were taken using a Zeiss Inverted LSM 880 laser scanning confocal microscope with a Plan-Apochromat $40 x / 1.4$ Oil DIC objective. Images were taken at $1024 \times 1024$ in XY to generate images with a final voxel size of $0.1384 \times 0.1384 \times 0.5$ $\mu \mathrm{m}^{3}$. Images were scored as containing GFP in one or two glomeruli.

Additional technical notes on expression and projection patterns of Split-QF2 strains

Ir25a-QF2-AD, Orco-QF2-DBD > QUAS-dTomato-T2A-GCaMP6s: All antennal lobe immunostaining in Figure 2, 5, S7, S8 was carried out as described above with slight modifications to utilize the 15xQUAS-dTomato-T2A-GCaMP6s effector line. The same primary antibodies were used because of the structural similarity between GCaMP6s and GFP. Intrinsic dTomato was detected without antibody amplification, as it retained fluorescence throughout fixation and staining. Brp (Cy5), dTomato, and GCaMP6s (Alexa Fluor 488) were imaged as three separate confocal channels as described above. Glomeruli labelled by dTomato completely overlapped with those labelled by GCaMP6s immunofluorescence, so both channels were used during the quantification of positive and negative glomeruli. dTomato labeling was used to generate sample images. There was no staining in the antennal lobes of the individual split effector lines crossed to 15xQUAS-dTomato-T2AGCaMP6s (n=3 / genotype, Figure 2, S7).

Due to an initial observation that certain glomeruli were consistently unlabeled in the Ir25a-AD;Orco-DBD line but were labelled in the Orco-QF2 and IR25a-QF2 lines, particularly in an anterior region of the brain, we conducted a second experiment to compare glomeruli labelled by the Orco-QF2, IR25a-QF2 and IR25a$A D$;Orco- $D B D$ drivers side-by-side. All drivers were crossed to the 15xQUAS-dTomato-T2A-GCaMP6s effector (Figure 2J). 3 brains per genotype were immunostained and imaged as described above.

Antennal lobe anterograde dye fill

For images in Figure S1, mosquitoes were anesthetized on ice until immobile and then transferred to a cold dissection dish. A single antenna or maxillary palp was loaded with Texas-red conjugated dextran (Molecular Probes D3328) diluted $10 \mathrm{mg}$ in $100 \mu \mathrm{L}$ external saline (103 mM NaCl, $3 \mathrm{mM} \mathrm{KCl,} 5 \mathrm{mM}$ 2-[Tris(hydroxymethyl)methyl]-2-aminoethanesulfonic acid (TES), $1.5 \mathrm{mM} \mathrm{CaCl}_{2}, 4 \mathrm{mM}$ $\mathrm{MgCl}_{2}, 26 \mathrm{mM} \mathrm{NaHCO}_{3}, 1 \mathrm{mM} \mathrm{NaH} \mathrm{PO}_{4}, 10 \mathrm{mM}$ trehalose, $10 \mathrm{mM}$ glucose, $\mathrm{pH} 7.3$, osmolality adjusted to $275 \mathrm{mOsm} / \mathrm{kg}$ ). To load the dye a small drop (approximately $0.5-1 \mu \mathrm{L}$ ) of dye was placed onto the surface of the dish and the animal was moved such that the intended cut-site on a single antenna or maxillary palp was placed in the drop of dye. The antenna or maxillary palp was then removed with sharp forceps and a fine scalpel (F.S.T 10315-12) while it was 
submerged in the dye. Care was taken to remove the maxillary palp proximal to the $4^{\text {th }}$ segment, to include all the basiconic sensilla, and to remove the antenna near the base but to leave the antennal pedicel completely intact. The animal remained immobile on ice with the antenna or maxillary palp submerged and the dye was loaded for 2-5 min. After this time the animal was placed in a small soup cup with access to $10 \%$ sucrose and returned to standard rearing conditions overnight to give the dye time to diffuse throughout the neurons and fill the length of the axon. The next morning dissection of adult brains and immunostaining was carried out as described above.

Antennal lobe 3-D reconstructions

In an attempt to develop a map of the Ae. aegypti antennal lobe, 3 brains from the Liverpool strain were immunolabeled with Brp to identify the boundaries between antennal lobe glomeruli. The left antennal lobe in each brain was independently reconstructed from confocal sections taken with a Plan-Apochromat $63 x / 1$.40NA oil immersion objective, at $1024 \times 1024$ pixel resolution in $X$ and $Y$ with $0.5 \mu \mathrm{m}$ Z-steps for a final voxel size of either $0.1318 \times 0.1318 \times 0.5$ $\mu^{3}$ using the software Imaris (Bitplane). Although the area previously termed Johnston's organ center was considered a single glomerulus in a previous study (Ignell et al., 2005), we noted anatomical boundaries in this region, suggesting that it contains multiple glomeruli. This observation is consistent with recently published work (Shankar and McMeniman, 2020) and this area was segmented by an individual researcher to generate the final reconstructions. Two of these are shown in Figure S1. Each glomerulus was manually segmented into an individual surface using Surpass View. We were consistently able to identify the three glomeruli innervated by the maxillary palp, previously termed MD1, MD2 and MD3 (Ignell et al., 2005) which we refer to in this study as Glomerulus 1, Glomerulus 2, and Glomerulus 3 (Figure 1, Figure 5). The overall structure of the antennal lobe varied considerably from animal to animal and although we were able to identify certain regions and certain landmark glomeruli including those that are targeted by the maxillary palp, we were unable to assign an unambiguous identity to every glomerulus, as is possible in Drosophila melanogaster (Couto et al., 2005; Fishilevich and Vosshall, 2005). This variability makes it essentially impossible to identify a given glomerulus between animals and we therefore have decided to avoid referring to glomeruli by previous naming schemes, including MD1, MD2, MD3. An authoritative atlas of the Ae. aegypti antennal lobe awaits genetic reagents that label subpopulations of sensory neurons that will permit the field to refer to glomeruli by their molecular identity. Antennal whole mount immunofluorescence

Whole-mount immunostaining of adult antennae was performed as described (Riabinina et al., 2016) with modifications. 7-11 day-old Liverpool mosquitoes were immobilized on ice, decapitated and heads and placed in $1 \mathrm{~mL} \mathrm{ZnFA}$ fixative solution $\left(0.25 \% \mathrm{ZnCl}_{2}, 2 \%\right.$ paraformaldehyde, $135 \mathrm{mM} \mathrm{NaCl}, 1.2 \%$ sucrose and $0.03 \%$ Triton $\mathrm{X}-100$ ) for $20-24 \mathrm{~h}$ at room temperature in the dark. Next, the heads were washed three times for 30 min each with HBS buffer $(150 \mathrm{mM} \mathrm{NaCl}, 5 \mathrm{mM} \mathrm{KCl}, 25 \mathrm{mM}$ sucrose, $10 \mathrm{mM}$ HEPES, $5 \mathrm{mM}$ $\mathrm{CaCl}_{2}$ and $0.03 \%$ Triton $\mathrm{X}-100$ ). Antennae were carefully removed in HBS on ice and placed in $400 \mu \mathrm{L}$ HBS in $0.5 \mathrm{~mL}$ Eppendorf tubes. After a brief wash in HBS, the tissue was incubated in 400 $\mu \mathrm{L} 80 \%$ methanol/20\% dimethyl sulfoxide (DMSO) solution for $1 \mathrm{~h}$ at room temperature, washed for $5 \mathrm{~min}$ in $400 \mu \mathrm{L} 0.1 \mathrm{M} \mathrm{Tris} \mathrm{pH} 7.4$, $0.03 \%$ Triton $\mathrm{X}-100$ solution and incubated in $400 \mu \mathrm{L}$ blocking solution (PBS, 5\% normal goat serum (Jackson 005-000-121), 1\% DMSO and $0.3 \%$ Triton $\mathrm{X}-100$ ) for at least $3 \mathrm{~h}$ at room temperature or overnight at $4^{\circ} \mathrm{C}$. Next, the tissue was placed in a $0.5 \mathrm{~mL}$ Eppendorf tubes containing $400 \mu \mathrm{L}$ blocking solution with primary antibodies [rabbit anti-Orco EC2 (Larsson et al., 2004), 1:50, Vosshall lab; chicken anti-GFP, 1:200, Aves GFP-1020] and submerged and held in a water bath sonicator (Branson m1800) for $30 \mathrm{sec}$ at the high setting. Next, the tubes were placed on a rotator for 2 days at $4^{\circ} \mathrm{C}$ in the dark, after which the sonication procedure was repeated The tubes were placed on a rotator for 2 additional days (for a total of 4 days) at $4^{\circ} \mathrm{C}$ in the dark. Next, the tissue was washed $5 \times 30$ min each at room temperature in PBS, $1 \%$ DMSO and $0.3 \%$ Triton $\mathrm{X}-100$. Secondary antibodies (anti-rabbit Alexa Fluor 555 Plus, 1:200, Thermo Fisher A32732, anti-chicken Alexa Fluor 488, 1:200, Thermo Fisher A-11039) and nuclear dye (TO PRO 3 lodide, 1:400, Thermo Fisher T3605) were added to the blocking solution, and tubes were sonicated as described above and incubated for 4 days at $4^{\circ} \mathrm{C}$ in the dark with the sonication repeated after 2 days of incubation. The tissue was then washed $5 \times 30 \mathrm{~min}$ at room temperature in PBS, $1 \%$ DMSO and $0.3 \%$ Triton $X-100$, rinsed in PBS and mounted in Slow Fade Diamond for confocal imaging.

Whole mount antennal and maxillary palp RNA in situ hybridization

RNA was detected in whole mount antenna and maxillary palp using the hybridization chain reaction (HCR) technique as previously described (Choi et al., 2018) with modifications. Probes, amplifiers, Probe Hybridization Buffer, Amplification Buffer, and Probe Wash Buffer were purchased from Molecular Instruments. Full list of probe lot numbers can be found in Date File 1. 5-8 day-old Liverpool mosquitoes were cold anesthetized, manually decapitated with forceps, and heads with antennae and the proboscis were digested in a chitinase-chymotrypsin solution (119 mM NaCl, $48 \mathrm{mM}$ $\mathrm{KCl}, 2 \mathrm{mM} \mathrm{CaCl} 2,2 \mathrm{mM} \mathrm{MgCl}$, $25 \mathrm{mM}$ HEPES, $5 \mathrm{U} / \mathrm{mL}$ chitinase (Sigma-Aldrich C6137-50UN), $100 \mathrm{U} / \mathrm{mL}$ alpha-chymotrypsin (Sigma-Aldrich CHY5S-10VL), 2\% DMSO) (Manning and Doe, 2017 ) at $37^{\circ} \mathrm{C}$ for 30 min (antennae) or $1 \mathrm{hr}$ (maxillary palps) in a Fisher Isotemp oven and subsequently fixed in $4 \%$ paraformaldehyde, $1 \mathrm{X}$ PBS, $0.03 \%$ Triton $\mathrm{X}-100$ on a rotator at $4^{\circ} \mathrm{C}$ overnight. Heads were washed 4 times on ice for 10 min each in $0.1 \%$ PBSTween-20. Antennae or maxillary palps were dissected in $0.1 \%$ PBS-Tween-20 on ice and dehydrated with a graded series of methanol/0.1\% PBS-Tween: $25 \%$ methanol in 0.1\% PBS-Tween20 for 10 min on ice, $50 \%$ methanol in $0.1 \%$ PBS-Tween-20 for 10 min on ice, $75 \%$ methanol in $0.1 \%$ PBS-Tween-20 for 10 min on ice, and two washes of $100 \%$ methanol for $10 \mathrm{~min}$ on ice. Tissues were incubated overnight in $100 \%$ methanol at $-20^{\circ} \mathrm{C}$ and were subsequently rehydrated with a series of graded methanol $/ 0.1 \%$ PBS-Tween-20: 75\% methanol in 0.1\% PBS-Tween-20 for $10 \mathrm{~min}$ on ice, $50 \%$ methanol in $0.1 \%$ PBS-Tween-20 for 10 min on ice, $25 \%$ methanol in $0.1 \%$ PBS-Tween-20 for $10 \mathrm{~min}$ on ice, and two washes of $0.1 \%$ PBS-Tween-20 for 10 min each on ice. Tissue was digested in $20 \mu \mathrm{g} / \mathrm{mL}$ Proteinase-K (Thermo Fisher AM2548) in $0.1 \%$ PBS-Tween for $30 \mathrm{~min}$ at room temperature and washed twice with $0.1 \%$ PBS-Tween-20 for 10 min each at room temperature. Tissue was fixed in $4 \%$ paraformaldehyde in $0.1 \%$ PBSTween-20 for $20 \mathrm{~min}$ at room temperature and washed 3 times for 10 min each in $0.1 \%$ PBS-Tween-20 at room temperature.

Tissue was incubated in Probe Hybridization Buffer at room temperature for $5 \mathrm{~min}$ and then in $37^{\circ} \mathrm{C}$ pre-warmed Probe Hybridization Buffer rotating in a hybridization oven for $30 \mathrm{~min} .8 \mathrm{pmol}$ of each probe set was prepared in $37^{\circ} \mathrm{C}$ pre-warmed Probe Hybridization Buffer and tissue was incubated in probe solution at $37^{\circ} \mathrm{C}$ in a hybridization oven for 2 nights. Tissues were washed in $37^{\circ} \mathrm{C}$ prewarmed Probe Wash Buffer 5 times for $10 \mathrm{~min}$ each at $37^{\circ} \mathrm{C}$. Tissues were washed twice in 5 X SSC $0.1 \%$ Tween-20 at room temperature for 10 min each. Tissues were pre-amplified in room temperature Amplification Buffer for $10 \mathrm{~min} .18 \mathrm{pmol}$ hairpins were separately prepared by heating $6 \mu \mathrm{l}$ of $3 \mu \mathrm{M}$ stock of hairpins $\mathrm{H} 1$ and $\mathrm{H} 2$ at $95^{\circ} \mathrm{C}$ for $90 \mathrm{sec}$ on an Eppendorf Mastercycler and allowing to cool to room temperature in a dark drawer for $30 \mathrm{~min}$. Hairpins were resuspended in $100 \mu \mathrm{l}$ amplification buffer and tissues were incubated in this hairpin solution in the dark on a rotator at room temperature overnight. Tissues were washed 5 times for 10 min each in 5 X SSC $0.1 \%$ Tween-20 and mounted in SlowFade 
Diamond (Thermo Fisher S36972) on glass slides with coverslips for confocal imaging.

Whole mount antennal and maxillary palp dTomato visualization

7-14 day-old Ir25a-QF2, Orco-QF2, Ir25a-QF2AD, Orco-QFDBD, and Ir25a-QF2AD, Orco-QFDBD > 15XQUAS-dTomato-T2AGCaMP6s mosquitoes were cold anesthetized, manually decapitated with forceps and heads with antennae and maxillary palps were immediately fixed in $1 \mathrm{~mL} 4 \%$ paraformaldehyde, 1X PBS, $0.03 \%$ Triton $\mathrm{X}-100$, on a rotator in the dark at $4^{\circ} \mathrm{C}$ overnight. Heads were washed $3 \times 30$ min each in 1 X PBS, $0.03 \%$ Triton X100 at room temperature, then antennae and maxillary palps were carefully removed and placed in $1 \mathrm{X}$ PBS, $0.03 \%$ Triton X-100. Next, antennae and maxillary palps were placed in a solution of $1 \mathrm{X}$ PBS, $0.03 \%$ Triton $X-100,1 \%$ DMSO, and a $1: 400$ dilution of TO PRO 3 (Thermo Fisher T3605) for $24 \mathrm{hr}$ at $4^{\circ} \mathrm{C}$ in the dark. Antennae and maxillary palps were then washed $5 \mathrm{X} 30$ min each in $1 \mathrm{X}$ PBS, $0.03 \%$ Triton X-100 at room temperature in the dark, washed once with $1 \mathrm{X}$ PBS, transferred to a well of SlowFade diamond to remove excess PBS, and mounted in SlowFade Diamond for confocal imaging.

Antennal and maxillary palp confocal imaging and cell quantification

Images of peripheral tissues were acquired with a Zeiss Axio Observer Z1 Inverted LSM 880 NLO laser scanning confocal microscope (Zeiss) with a $25 x / 0.8$ NA or $63 x / 1.4$ NA immersion-corrected objective at a resolution of $3096 \times 3096$ pixels or $2048 \times$ 2048 pixels. When comparing dTomato fluorescence across genotypes, image acquisition parameters were kept consistent. When necessary, tiled images were stitched with $20 \%$ overlap. Confocal images were processed in Image $(\mathrm{NIH})$. Because the antenna is a cylindrical structure, when whole antennal segments are mounted on a slide and imaged on a confocal microscope, signal can be easily detected from the region closest to the coverslip and confocal objective, but signal is weaker when imaging the side further from the coverslip and objective. For the purposes of consistent quantification, we only quantified cell numbers from the region closest to the coverslip (orange region in Figure S9A). For quantifying expression in the maxillary palp, only the dorso-lateral region of the $4^{\text {th }}$ maxillary palp segment was analyzed. (yellow region in Figure S9B). Quantification of co-expression in antennae and maxillary palps was done in Image $(\mathrm{NIH})$ using the Cell Counter plugin. Cells in each channel were manually marked independently of the signal in the other channels. After cells in each channel are marked, and markers were then merged. Cells that were labeled with multiple markers (co-expressing cells) were then marked with a third marker (Figure S9C-H). Cell counts were then imported into Microsoft Excel and R for analysis.

In vivo 2-photon GCaMP calcium imaging preparation

Calcium imaging was performed on an Ultima IV two-photon laserscanning microscope (Bruker Nanosystems) equipped with galvanometers and illuminated by a Chameleon Ultra II Ti:Sapphire laser (Coherent). GaAsP photomultiplier tubes (Hamamatsu) were used to collect emitted fluorescence. Images were acquired with a 60X/1.0N.A. Long Working Distance Water-Immersion Objective (Olympus) at a resolution of 256 x 256 pixels. GCaMP6s was expressed via the Ir25a-QF2 knock-in which labels all three maxillary palp glomeruli. Preliminary imaging studies were conducted in animals that were wild-type at the Gr3 locus. In Figure 5 all $\mathrm{Gr} 3+$ and $\mathrm{Gr} 3-/-$ animals were reared and imaged in parallel. Because the Gr3 mutants were generated in the Orlando wild-type background and all Q-system lines were generated in the Liverpool wildtype background, care was taken to compensate for background effects in the following way. A single stock was created containing the 15x-QUAS-dTomato-T2A-GCamP6s-3xP3-ECFP transgene (Matthews et al., 2019), the Ir25a-QF2-3xP3-dsRed gene-sparing knock-in, and the Gr3 ECFP knock-out allele that is marked with
ECFP (McMeniman et al., 2014). This parental line was then crossed to either the unmarked $\mathrm{Gr} 3^{\Delta 4}$ mutant that is in the Orlando background (McMeniman et al., 2014) to generate Gr3-/- animals, or to wild-type Orlando to generate $\mathrm{Gr} 3+/-$ animals. The Gr3 mutation is recessive (McMeniman et al., 2014), so this comparison of heteroallelic and heterozygous animals both controls for genetic background and makes it possible to assay the Gr3 mutant phenotype.

Calcium imaging experiments were performed on 7-14 day-old female mosquitoes. Mosquitoes were fed on 10\% sucrose and switched to water overnight prior to imaging. Mosquitoes were anesthetized at $4^{\circ} \mathrm{C}$ for dissection. The mosquito was fixed to a custom Delrin plastic holder with UV-curable glue (Bondic). The mosquito was inserted into a hole in the holder, such that the head and thorax were exposed above the surface of the holder, with the rest of the mosquito below. The mosquito was secured with a few points of glue (Bondic) on the thorax and head. The antennae and maxillary palp remained below the plate and were kept free of saline to prevent damage to the tissue. The top of the dish was then filled with external saline, which is based on Drosophila melanogaster imaging saline (Fişek and Wilson, 2014) with the following composition: $103 \mathrm{mM} \mathrm{NaCl}, 3 \mathrm{mM} \mathrm{KCl}, 5 \mathrm{mM}$ 2-[Tris(hydroxymethyl)methyl]-2-aminoethanesulfonic acid (TES), $1.5 \mathrm{mM} \mathrm{CaCl}_{2}, 4$ $\mathrm{mM} \mathrm{MgCl}_{2}, 26 \mathrm{mM} \mathrm{NaHCO}_{3}, 1 \mathrm{mM} \mathrm{NaH}_{2} \mathrm{PO}_{4}, 10 \mathrm{mM}$ trehalose, 10 $\mathrm{mM}$ glucose, $\mathrm{pH} 7.3$, osmolality adjusted to $275 \mathrm{mOsm} / \mathrm{kg}$ ). A small window was gently opened in the head and the cuticle was removed anterior to the antennal pedicles and the tissue was secured with dental wax to expose the antennal lobes. Opaque nonneural tissue, primarily fat cells, was removed if they obstructed the antennal lobes. Great care was taken not to damage the antennal nerves. The preparation was placed on a custom laser cut acrylic holder that was secured to the stage and placed the mosquito in close proximity to the output port of the olfactometer. Plans for the fabrication of the imaging holder are available on Github: https://github.com/VosshallLab/Younger_Herre_Vosshall2020. On rare occasions mosquitoes showed no movement or odor responses and were discarded.

Image volumes were taken at higher resolution to identify glomeruli innervated by the maxillary palp, including the nerves that innervate these glomeruli. Glomerulus 1 was always easily identifiable by eye. A single plane through the center of each glomerulus was scanned at 4.22 frames per second with a $920 \mathrm{~nm}$ excitation wavelength imaged through a $680 \mathrm{~nm}$ shortpass infrared (IR) blocking filter, a $565 \mathrm{~nm}$ longpass dichroic and $595 / 50 \mathrm{~nm}$ or $525 / 70 \mathrm{~nm}$ bandpass filters. GCaMP6s and dTomato emission was collected simultaneously for at least 70 frames per trial.

In vivo 2-photon GCaMP calcium imaging stimulus delivery Odor stimulation was achieved by directing a continuous stream (400-800 $\mathrm{mL} / \mathrm{min}$ ) of clean air, originating from a breathing air tank (Praxair), through 0.125 inch inner diameter/0.250 inch outer diameter perfluoroalkoxy alkaline (PFA) tubing. The antenna and maxillary palp of the mosquitoes were positioned close to the tube such that they were exposed to constant air flow (carrier stream). 4-60\% of the total air stream was diverted through the headspace of a 20 $\mathrm{mL}$ borosilicate glass vial (EnviroWare \#03-339-14E) containing the odorant diluted in either paraffin oil or water (odor stream). At a trigger, a custom-built solenoid valve controller system redirected the odor stream from a blank vial to a vial containing various odorants diluted in paraffin oil or water to a final volume of $3 \mathrm{~mL}$. Unless otherwise noted, $40 \%$ of the air stream was used for odor delivery. Prior to conducting experiments, a mini-PID (Aurora Scientific, model 201A) was used to measure odorant waveforms and ensure the consistency of odor presentations across trials.

$\mathrm{CO}_{2}$ was introduced into this system from a tank of $5 \% \mathrm{CO}_{2}$ in a $20.9 \%$ oxygen/ $79.1 \%$ nitrogen balance (Praxair). At a trigger, $\mathrm{CO}_{2}$ was diverted through the headspace of a second clean $20 \mathrm{~mL}$ borosilicate glass vial $\left(\mathrm{CO}_{2}\right.$ stream) that was redirected from a bypass 
stream into the system. This was coupled to a clean air stream with a matched flow rate that was simultaneously removed from the system. In experiments where odor concentration of $\mathrm{CO}_{2}$ concentration was varied, the fraction of odor stream directed to the mosquito was adjusted. $\mathrm{CO}_{2}$ was delivered at $4-60 \%$ of the total air stream for total concentrations of $0.2-3.0 \% \mathrm{CO}_{2}$. In Figure 5, a final concentration of $2 \% \mathrm{CO} 2$ was used in all experiments. Prior to conducting experiments, a $\mathrm{CO}_{2}$ meter (Vaisala GM70) was used to measure $\mathrm{CO}_{2}$ concentration in the final air stream and we found that the expected concentration was delivered. Odor and $\mathrm{CO}_{2}$ delivery was controlled using custom software written in Matlab R2020a (MathWorks). The odor delivery system and software was based on a previously used system and updated for $\mathrm{CO}_{2}$ delivery (Cohn et al., 2015).

After the mosquito was transferred to the microscope and placed within the air stream, there was a 10-min acclimation period before any imaging began. For each trial, $5 \mathrm{sec}$ of GCaMP6s fluorescence at baseline was imaged and then a one second odor or $\mathrm{CO}_{2}$ pulse was delivered while imaging continued for at least 10 more sec (at least 70 frames total). There was a one-min delay between imaging trials so that the mosquito could reacclimate to the air stream after exposure to each odor. In an initial experiment we did not see any change in the amplitude of the $\mathrm{CO}_{2}$ response across multiple trials within an animal. Imaging remained stable during the duration of the imaging session in all animals that were included in this study. We did not notice a decrease in the response to stimuli over time. Odorants were selected for the highest purity available for purchase (greater than 98\%) and were either diluted in MilliQ ultrapure water (resistance 18 megaohm) or paraffin oil (EMD Millipore \#PX0045-3) depending on solubility. All odorants were diluted into a large stock solution that was used throughout each entire experiment to avoid variability in concentrations.

The odorants used in Figure 5 were: R-(-)-1-octen-3-ol (PubChem CID: 6992244, Penta Manufacturing 15-18900) diluted 1:10 in paraffin oil; 3-octanone (PubChem CID: 246782, Sigma 136913) diluted 1:10 in paraffin oil; acetone (PubChem CID: 180 Sigma A4206) diluted to $5 \% \mathrm{v} / \mathrm{v}$ in MilliQ ultrapure water; ammonia (PubChem CID: 222, Suprapur, Supelco 105428) diluted to $2.5 \% \mathrm{v} / \mathrm{v}$ in MilliQ ultrapure water; hexyl amine (PubChem CID: 8102, Sigma 219703) diluted to $1 \% \mathrm{v} / \mathrm{v}$ in MilliQ ultrapure water; triethyl amine (PubChem CID: 1146, Sigma T0886) diluted to $1 \%$ v/v in MilliQ ultrapure water.

In vivo 2-photon GCaMP calcium imaging data analysis

All image processing was done using FIJI/ImageJ (NIH). Data analysis used Matlab R2020a (MathWorks), Excel (Microsoft), and Prism (GraphPad). Regions of interest were selected based on the dTomato fluorescence intensity and GCaMP6s was normalized to dTomato intensity for analysis. A Gaussian blur with a sigma value of 1 was performed on the GCaMP6s signal. In the calculation of $\Delta F / F$, six frames were averaged before stimulus presentation to determine the baseline fluorescence. To determine maximum $\Delta F / F$, the average of the maximum 3 frames at the peak after stimulus delivery was determined for each sweep.

Quattroport olfactometer behavioral assays

Mosquitoes that were blood fed for behavior were fed on warmed defibrinated sheep's blood (Hemostat Laboratories DSB100) through a parafilm membrane. Animals were sorted by eye to determine if they were blood fed by looking at engorgement of the abdomen, and non-fed animals were not used in subsequent behavior assays. Blood-fed animals were returned to the same rearing conditions as their non-blood-fed counterparts, and behavior was assayed $\sim 48 \mathrm{hr}$ after they had consumed a blood meal. Quattroport olfactometer experiments were conducted as previously described (Basrur et al., 2020) with modifications to enable the delivery of monomolecular odorants. Details of fabrication and operation of the Quattroport are available at https://github.com/VosshallLab/Basrur_Vosshall2020.

All behavioral experiments were carried out in an environmental room set to $25-28^{\circ} \mathrm{C}, 70-80 \%$ relative humidity, and were carried out between ZT3-14. Trials with identical stimuli were interspersed throughout experimental days to control for circadian rhythm fluctuations. Mosquitoes in the Quattroport began each trial in a start canister, flew through a flight tube, and, if they were attracted to a stimulus, into a trap proximal to the stimulus. Filtered air, with or without additional $\mathrm{CO}_{2}$, was pumped through the stimulus box and into the flying tube. Mosquitoes were prevented from contacting the stimulus by a mesh barrier, and adjustable gates between each chamber allow the experimenter to count the number of mosquitoes in each compartment.

The night before each experiment, approximately 20 7-22 days old mosquitoes were cold-anesthetized and placed in each canister. They were sugar-starved with access to water overnight. The next day, at the start of each trial a set of 4 canisters was attached to the Quattroport and mosquitoes were given $10 \mathrm{~min}$ to acclimate with filtered air flowing at the $25 \mathrm{~mm}$ setting on the flowmeter throughout the assay (see https://github.com/VosshallLab/Basrur_Vosshall2020 for details on filtered air and $\mathrm{CO}_{2}$ flowmeter settings). They were then exposed to the stimulus with or without added $\mathrm{CO}_{2}$ flowing at the $50 \mathrm{~mm}$ flowmeter setting for $30 \mathrm{sec}$, after which they were given access to the flying tube and attraction trap for $5 \mathrm{~min}$ in the continued presence of filtered air with or without added $\mathrm{CO}_{2}$ and the stimulus. At the end of the trial, the gates enclosing the start canister and the attraction trap were closed, and mosquitoes that remained in the start canister, entered the flying tube, or flew into the attraction trap were counted.

For live human host-seeking assays, a single human volunteer placed their forearm in the stimulus box. For the delivery of lactic acid and triethyl amine, the odorant solutions were delivered using $35 \mathrm{~mm}$ Petri dishes (Fisher Scientific \#08-757-100A) placed within the air stream in the stimulus box. The odorants used in this assay were L-(+)-Lactic acid solution, 88-92\% (PubChem CID: 107689, Sigma-Aldrich \#27714-500mL) and Triethyl amine (PubChem CID: 1146, Sigma T0886) diluted to $1 \% \mathrm{v} / \mathrm{v}$ in MilliQ ultrapure water. In cases where both odorants were used as a stimulus, care was taken not to mix the liquids when they were placed in the stimulus box. Different volumes of each liquid odorant were delivered to generate the dose response curves in Figure 6F,H and Data File 1. Depending on the experiment, between $1 \mu \mathrm{L}$ and $2 \mathrm{~mL}$ of liquid odorant was used. When less than $1 \mathrm{~mL}$ of liquid was used, the lid of the Petri dish was inverted, and the liquid odorant was pipetted onto the center of the inverted lid. The inverted lid was then placed on the bottom of the Petri dish, which elevated it slightly, placing the odorants in the path of the air stream that ran through the stimulus box. When $1 \mathrm{~mL}$ or greater of liquid was used, the liquid odorant was pipetted into the base of the Petri dish, which was set atop the inverted lid of the Petri dish to elevate it. If the volume of odor was $1 \mathrm{~mL}$ or greater for either odorant, they were delivered using 2 separate Petri dishes to avoid possible mixing. If the volume of each liquid was less than $1 \mathrm{~mL}$, both liquid odorants were delivered as separated drops of liquid on a single inverted Petri dish lid, and the drops remained sperate because of surface tension. When neither lactic acid nor triethyl amine was delivered, an empty Petri dish was placed inside the stimulus box to serve as a control for any odors that might be emitted by the dish itself and/or any perturbations in air flow introduced by the presence of the Petri dish lid and base 
bioRxiv preprint doi: https://doi.org/10.1101/2020.11.07.368720; this version posted November 8, 2020. The copyright holder for this preprint (which was not certified by peer review) is the author/funder, who has granted bioRxiv a license to display the preprint in perpetuity. It is made available under aCC-BY 4.0 International license.

\section{SUPPLEMENTARY FIGURES}
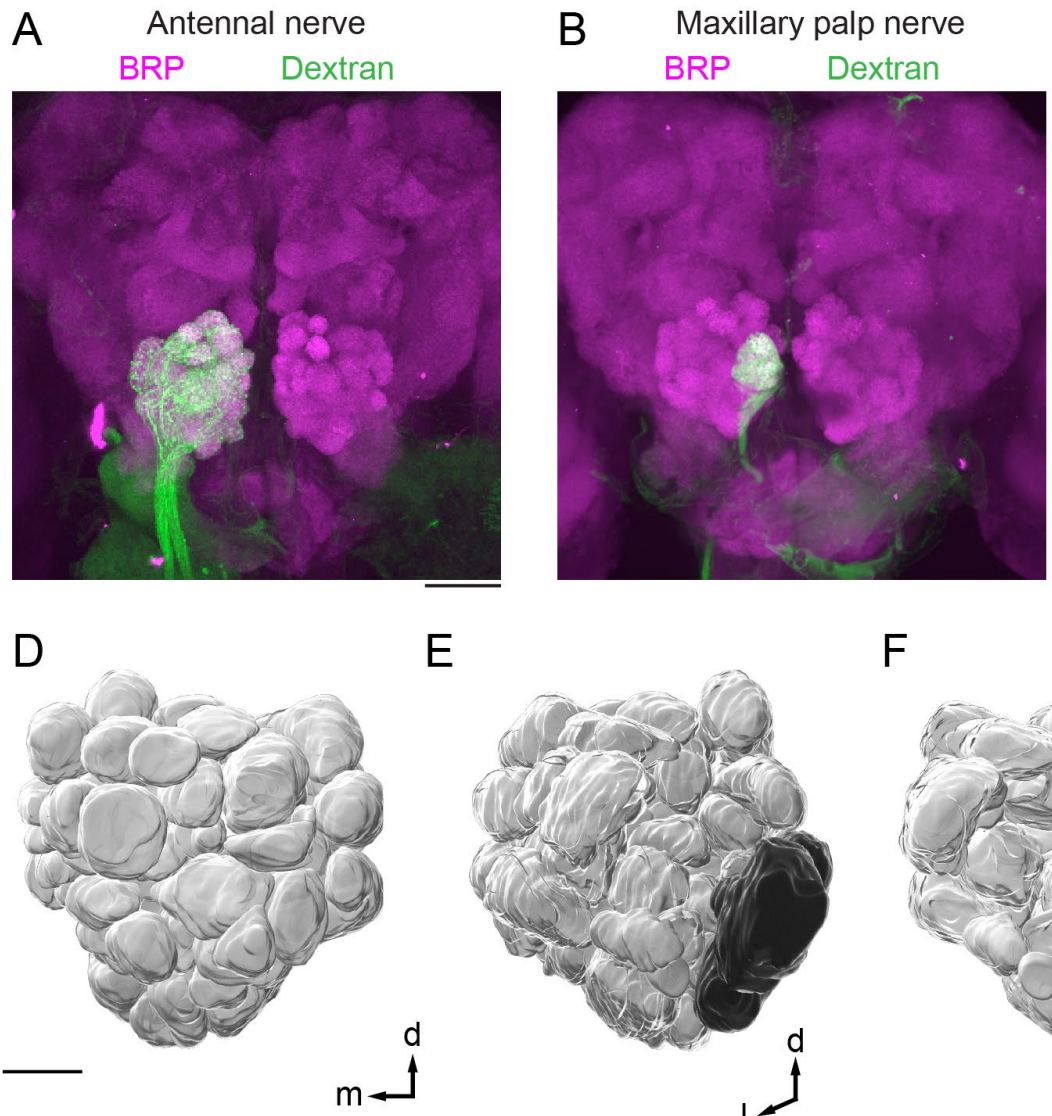

$\mathrm{H}$

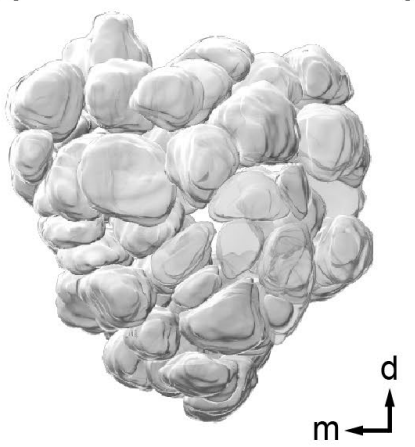

E
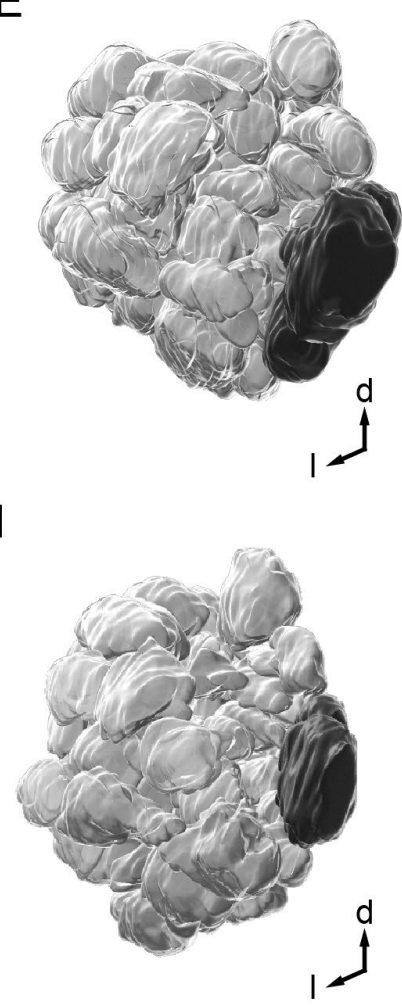

C

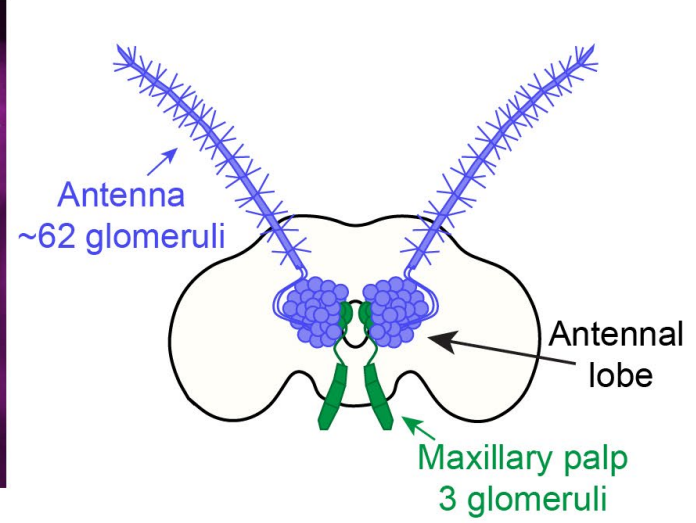

F

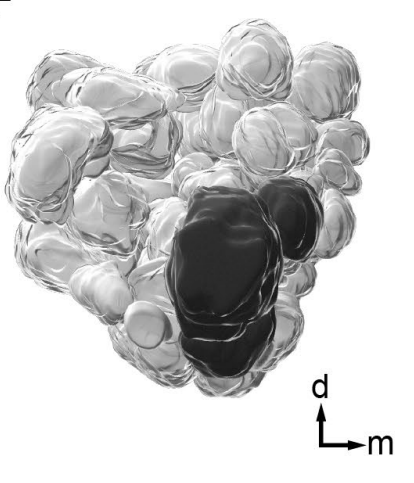

J

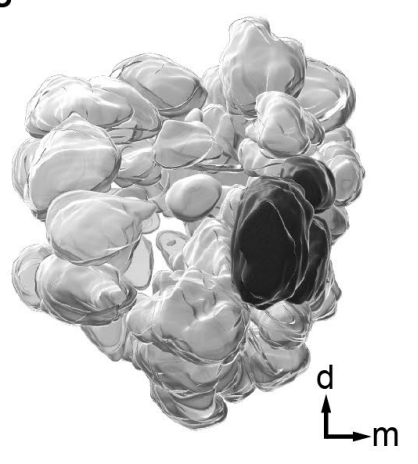

G

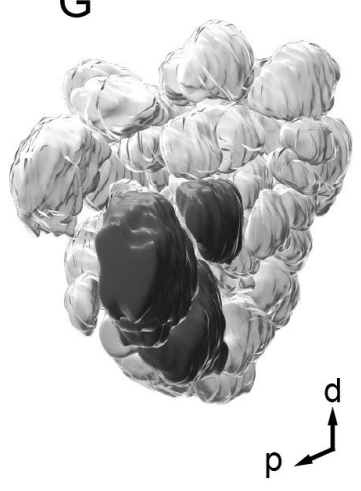

K

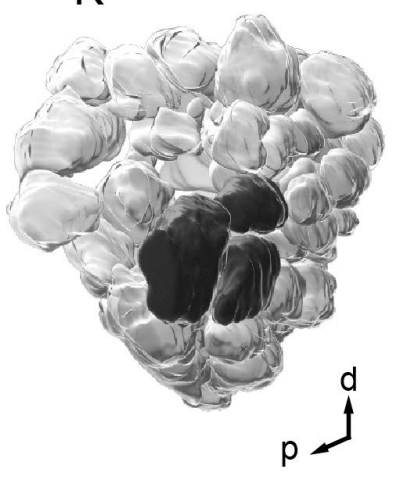

Maxillary palp innervation

Antennal innervation

Figure S1 Organization of Ae. aegypti antennal lobe glomeruli (Related to Figure 1)

(A-B) Maximum-intensity projections of confocal Z-stacks of a brain after anterograde dye fill of a single ipsilateral antenna (A) or ipsilateral maxillary palp (B) using a dextran-conjugated fluorophore (green) with immunofluorescent labeling of Brp (synaptic marker, magenta).

(C) Approximate number of antennal lobe glomeruli per brain hemisphere innervated by the indicated sensory structure, derived from quantification of the left antennal lobe in 12 brains presented in Figure 1I-J, S2-S5. (D-K) 3-D reconstruction of a single left antennal lobe with $61(\mathrm{D}-\mathrm{G})$ or $66(\mathrm{H}-\mathrm{K})$ glomeruli shown at 4 different angles. Glomeruli are colored according to innervation by the indicated sensory

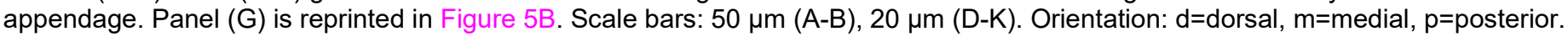


bioRxiv preprint doi: https://doi.org/10.1101/2020.11.07.368720; this version posted November 8, 2020. The copyright holder for this preprint (which was not certified by peer review) is the author/funder, who has granted bioRxiv a license to display the preprint in perpetuity. It is made available under aCC-BY 4.0 International license.

A
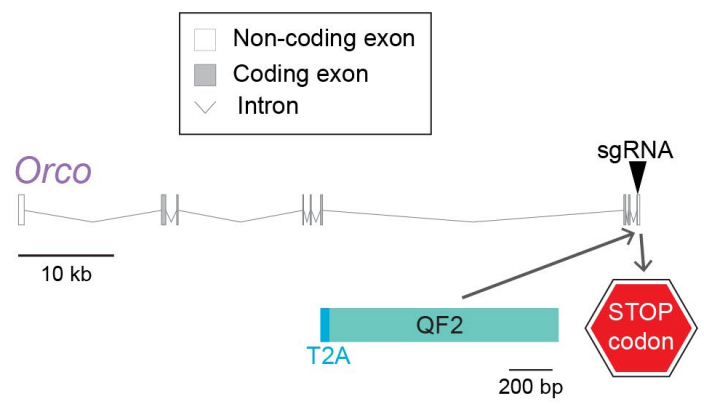

C
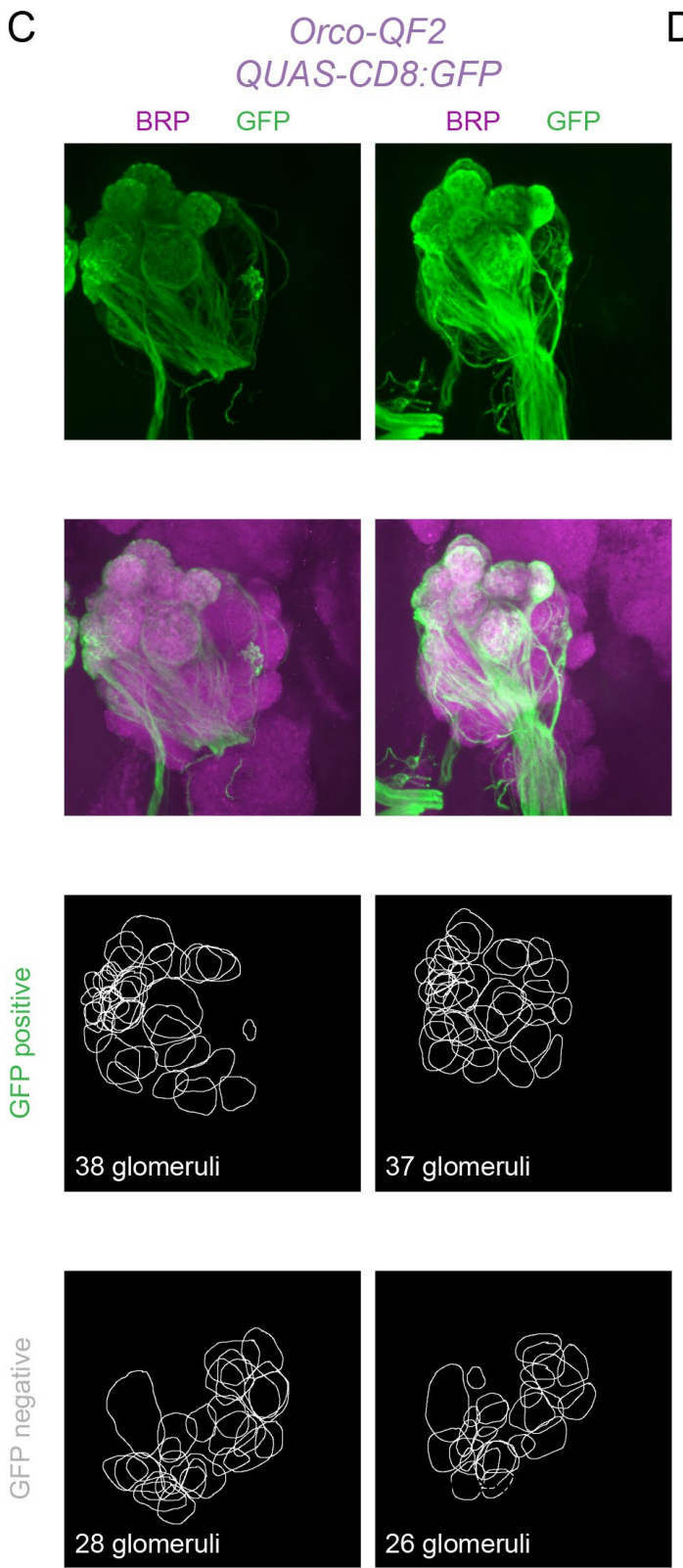
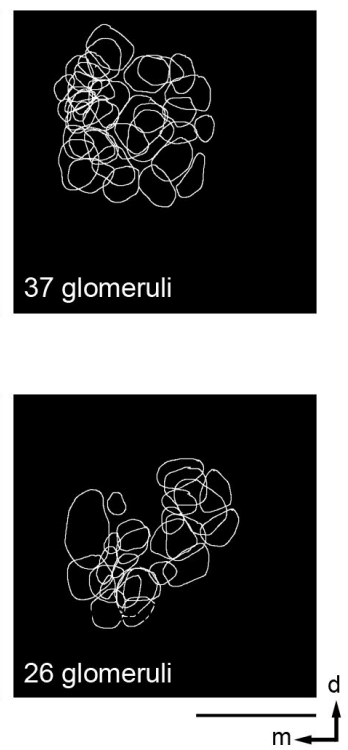

$\mathrm{B}$

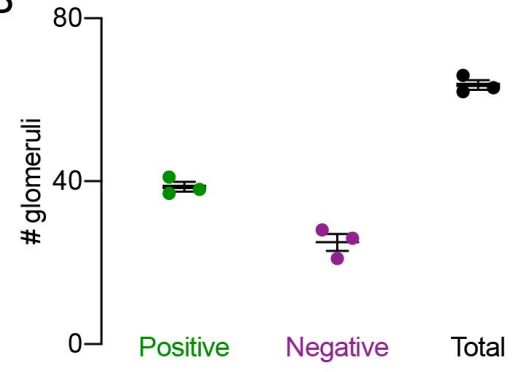

\section{Orco-QF2}

$\mu m$ from
anterior
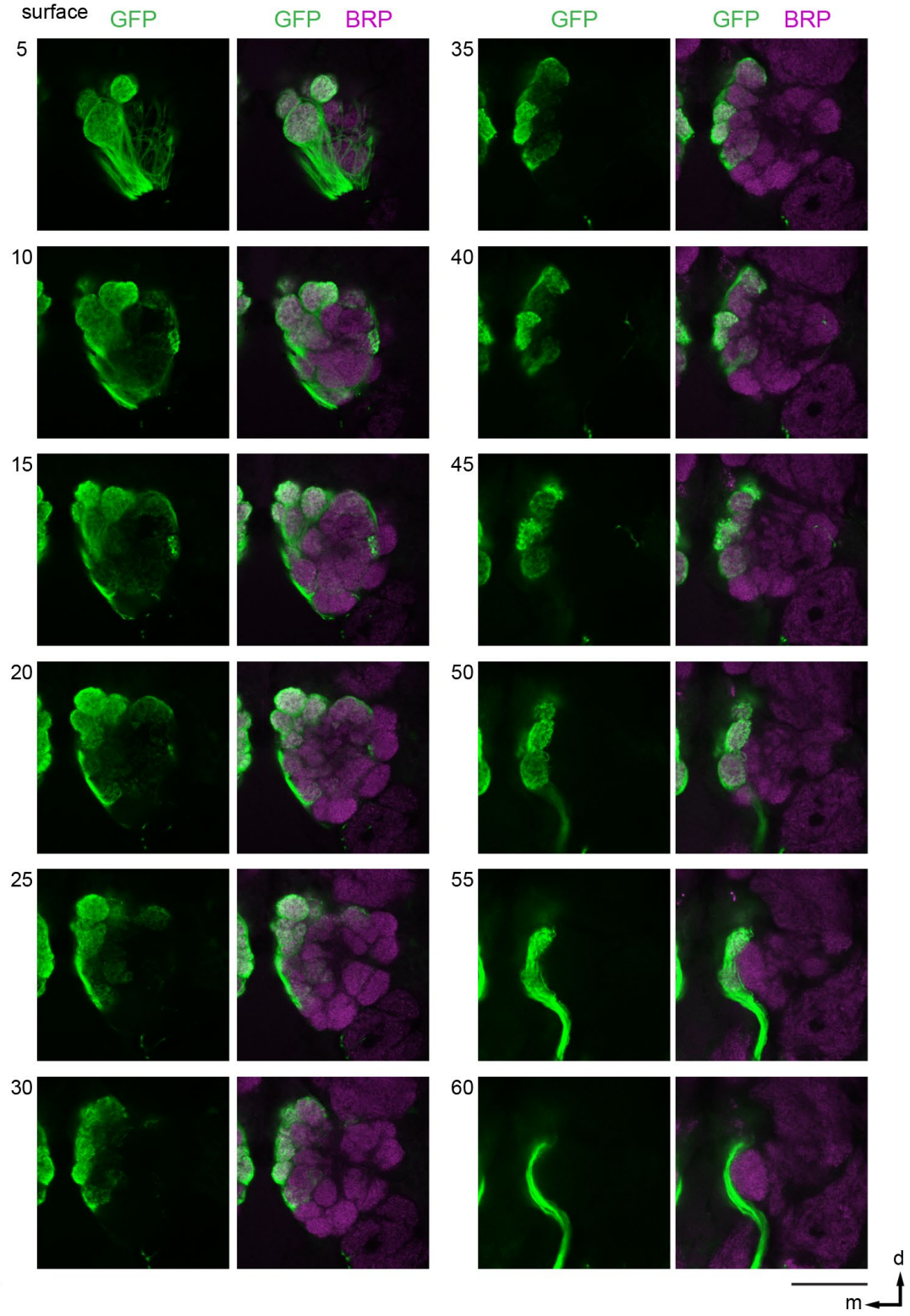

Figure S2. Projections of Orco-QF2-expressing neurons in the antennal lobe (Related to Figure 1)

(A) Orco locus with exons (grey boxes), introns (grey lines) and CRISPR-Cas9 gRNA site (arrowhead) used to insert T2A-QF2 (light blue). (B) Quantification of the number of glomeruli that are GFP positive (green), GFP negative (magenta), and total number of glomeruli (black). Analysis based on brains in (C-D) and Figure 1I,J. (C) Maximum-intensity projections of confocal Z-stacks of left antennal lobes from two different brains of the indicated genotype with immunofluorescent labeling of GFP (green) and Brp (synaptic marker, magenta) (top) and 2-D representation of the boundary of each glomerulus that is GFP positive and GFP negative (bottom). (D) Single confocal sections taken from the maximum-intensity projection confocal Z-stack of the left antennal lobe shown in Figure 1 I with immunofluorescent labeling of GFP (green) and Brp (synaptic marker, magenta). A single plane is shown every $5 \mu \mathrm{m}$ in Z to capture each glomerulus. Scale bar (C-D): $50 \mu \mathrm{m}$. Orientation: $d=d$ orsal, $m=$ medial. 
bioRxiv preprint doi: https://doi.org/10.1101/2020.11.07.368720; this version posted November 8, 2020. The copyright holder for this preprint (which was not certified by peer review) is the author/funder, who has granted bioRxiv a license to display the preprint in perpetuity. It is made available under aCC-BY 4.0 International license.

A
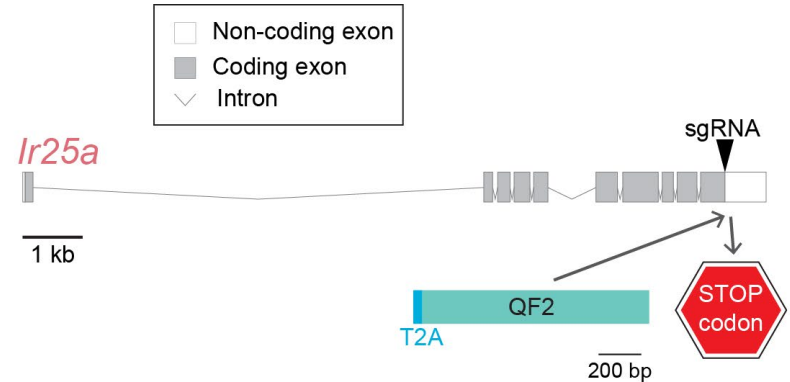

C
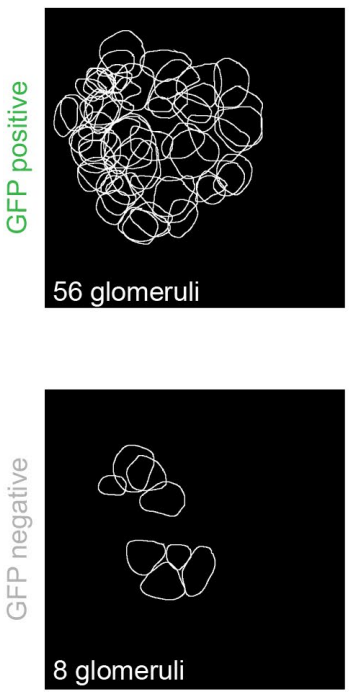

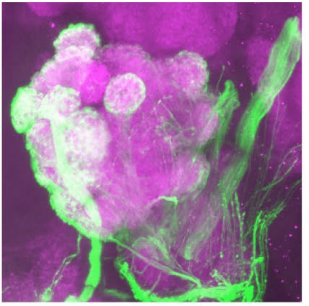

Ir25a-QF2 QUAS-CD8:GFP BRP GFP
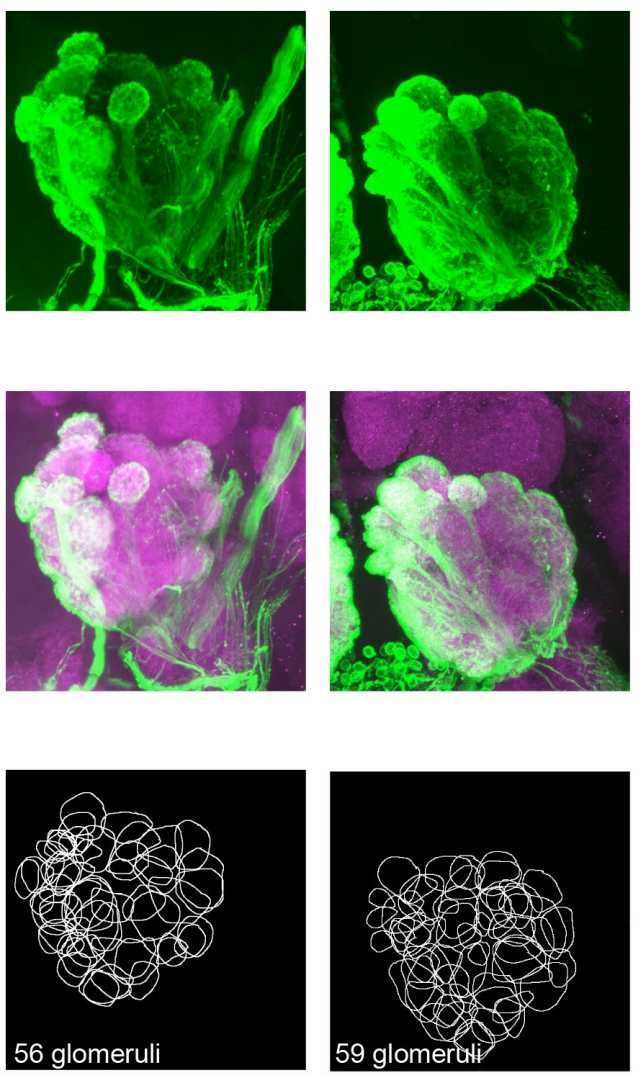

59 glomeruli

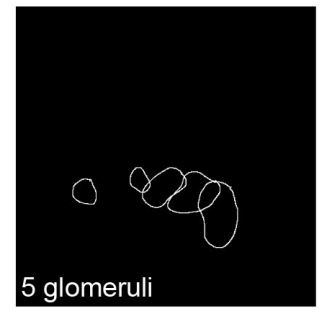

$-\mathrm{m}$
D

$\mu \mathrm{m}$ from anterior surface GFP
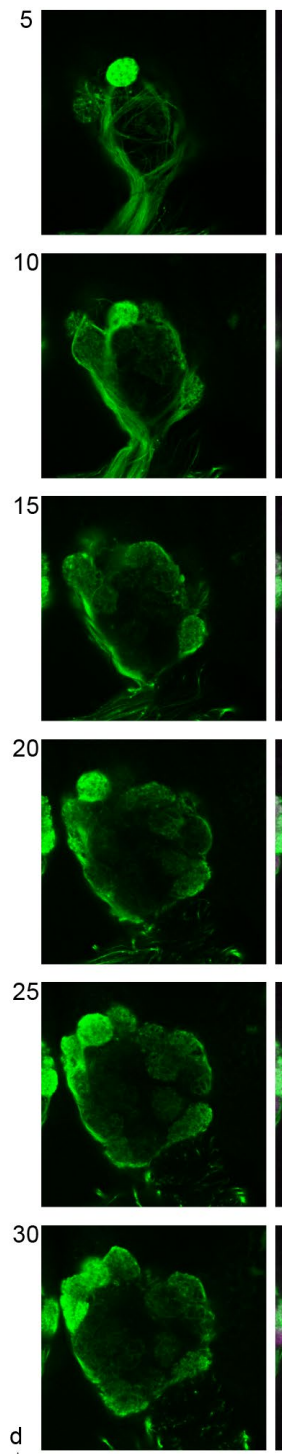

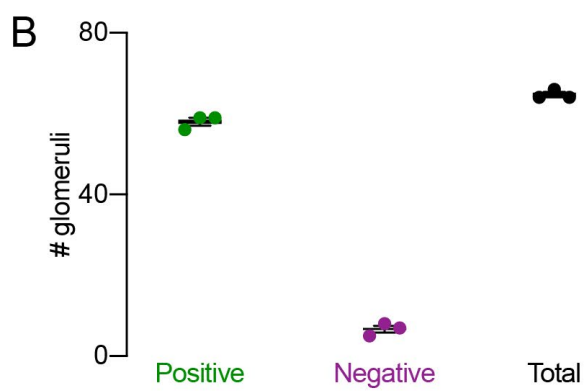

\section{Ir25a-QF2 \\ QUAS-CD8:GFP}
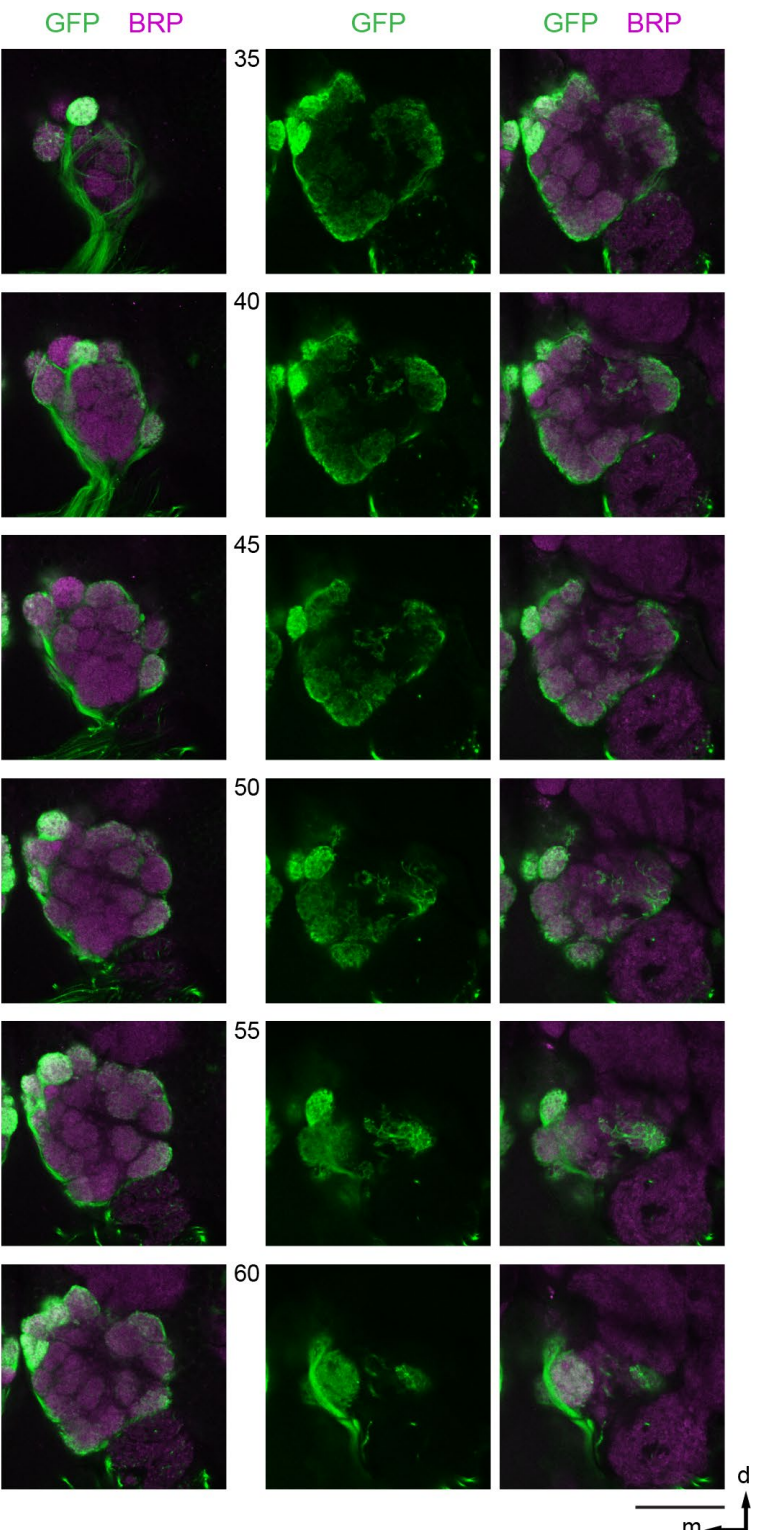

Figure S3. Projections of Ir25a-QF2-expressing neurons in the antennal lobe (Related to Figure 1)

(A) Ir25a locus with exons (grey boxes), introns (grey lines) and CRISPR-Cas9 gRNA site (arrowhead) used to insert T2A-QF2 (light blue). (B) Quantification of the number of glomeruli that are GFP positive (green), GFP negative (magenta), and total number of glomeruli (black). Analysis based on brains in (C-D) and Figure 1I,J. (C) Maximum-intensity projections of confocal Z-stacks of left antennal lobes from two different brains of the indicated genotype with immunofluorescent labeling of GFP (green) and Brp (synaptic marker, magenta) (top) and 2-D representation of the boundary of each glomerulus that is GFP positive and GFP negative (bottom)

(D) Single confocal sections taken from the maximum-intensity projection confocal Z-stack of the left antennal lobe shown in Figure 1 I with immunofluorescent labeling of GFP (green) and Brp (synaptic marker, magenta). A single plane is shown every $5 \mu \mathrm{m}$ in Z to capture each glomerulus. Scale bar (C-D): $50 \mu \mathrm{m}$. Orientation: $d=d o r s a l, m=m e d i a l$. 
bioRxiv preprint doi: https://doi.org/10.1101/2020.11.07.368720; this version posted November 8, 2020. The copyright holder for this preprint (which was not certified by peer review) is the author/funder, who has granted bioRxiv a license to display the preprint in perpetuity. It is made available under aCC-BY 4.0 International license.

A

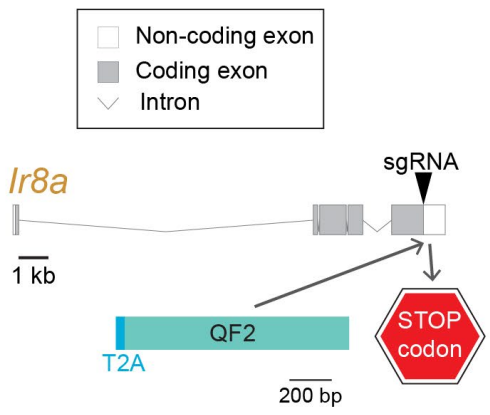

C
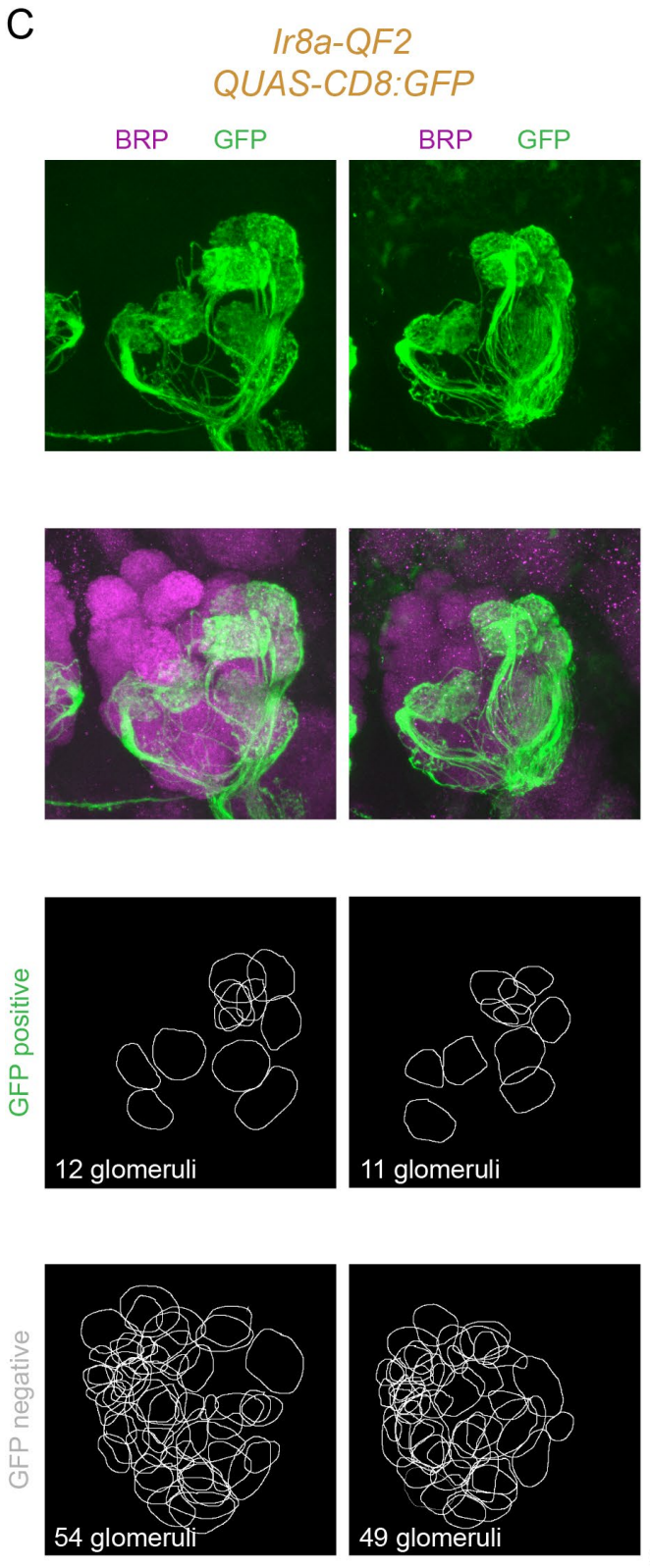
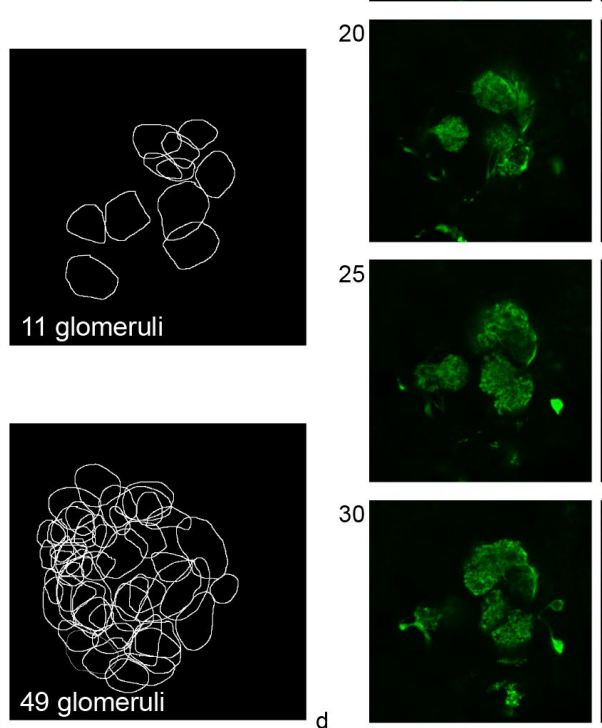

B

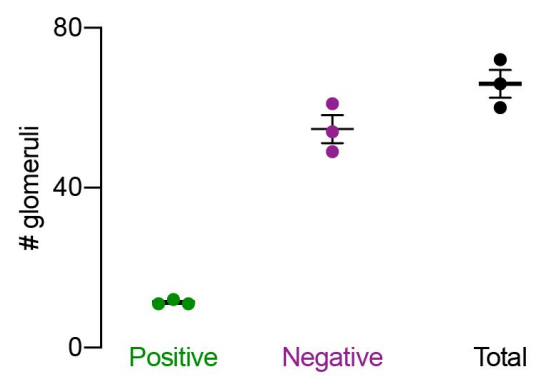

Ir8a-QF2

QUAS-CD8:GFP

GFP BRP
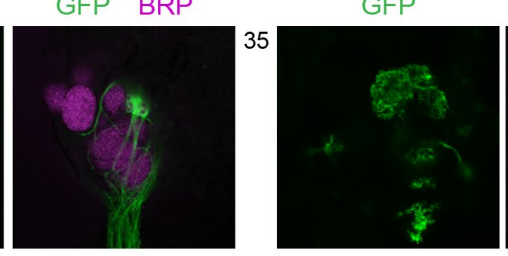

GFP BRP
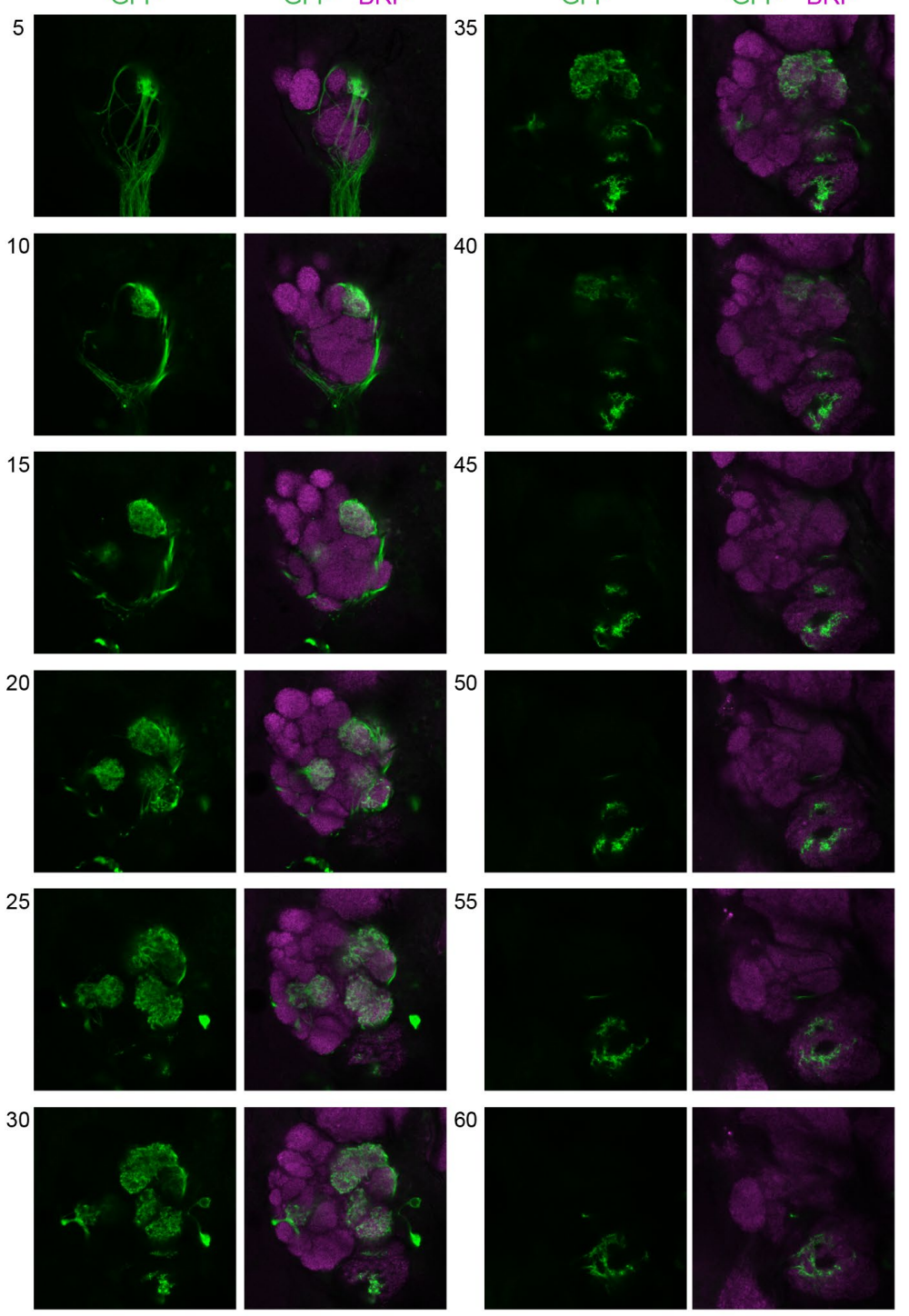

$\longrightarrow$

Figure S4. Projections of Ir8a-QF2-expressing neurons in the antennal lobe (Related to Figure 1)

(A) Ir8a locus with exons (grey boxes), introns (grey lines) and CRISPR-Cas9 gRNA site (arrowhead) used to insert T2A-QF2 (light blue). (B) Quantification of the number of glomeruli that are GFP positive (green), GFP negative (magenta), and total number of glomeruli (black). Analysis based on brains in (C-D) and Figure 1I,J. (C) Maximum-intensity projections of confocal Z-stacks of left antennal lobes from two different brains of the indicated genotype with immunofluorescent labeling of GFP (green) and Brp (synaptic marker, magenta) (top) and 2-D representation of the boundary of each glomerulus that is GFP positive and GFP negative (bottom). (D) Single confocal sections taken from the maximum-intensity projection confocal Z-stack of the left antennal lobe shown in Figure 1/ with immunofluorescent labeling of GFP (green) and Brp (synaptic marker, magenta). A single plane is shown every $5 \mu \mathrm{m}$ in Z to capture each glomerulus. Scale bar (C-D): $50 \mu \mathrm{m}$. Orientation: $d=d$ orsal, $m=$ medial. 
bioRxiv preprint doi: https://doi.org/10.1101/2020.11.07.368720; this version posted November 8, 2020. The copyright holder for this preprint (which was not certified by peer review) is the author/funder, who has granted bioRxiv a license to display the preprint in perpetuity. It is made available under aCC-BY 4.0 International license.

A

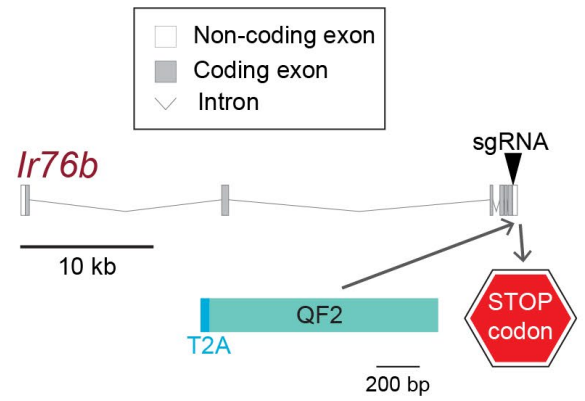

C
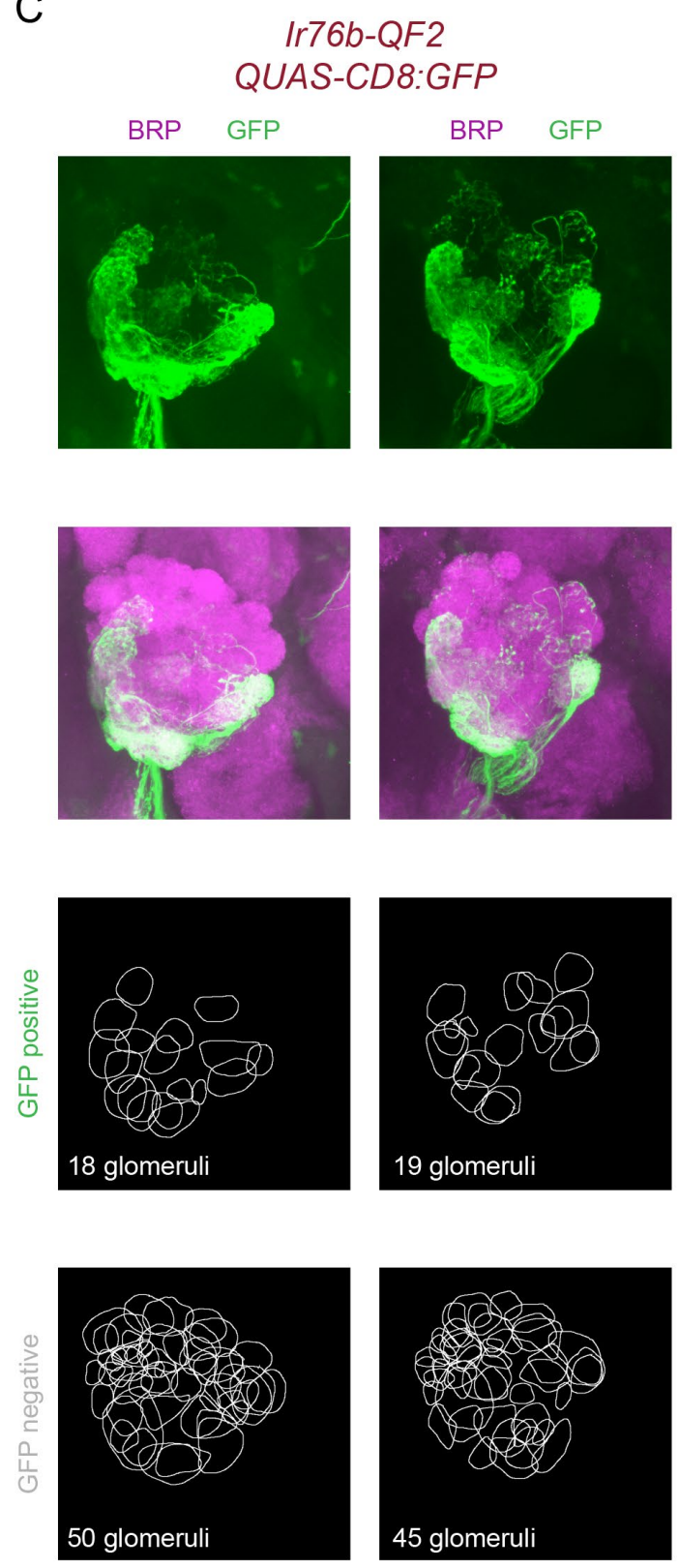

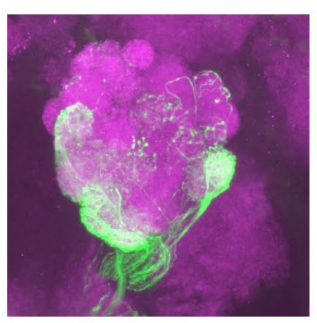

D

$\mu \mathrm{m}$ from anterior surface GFP
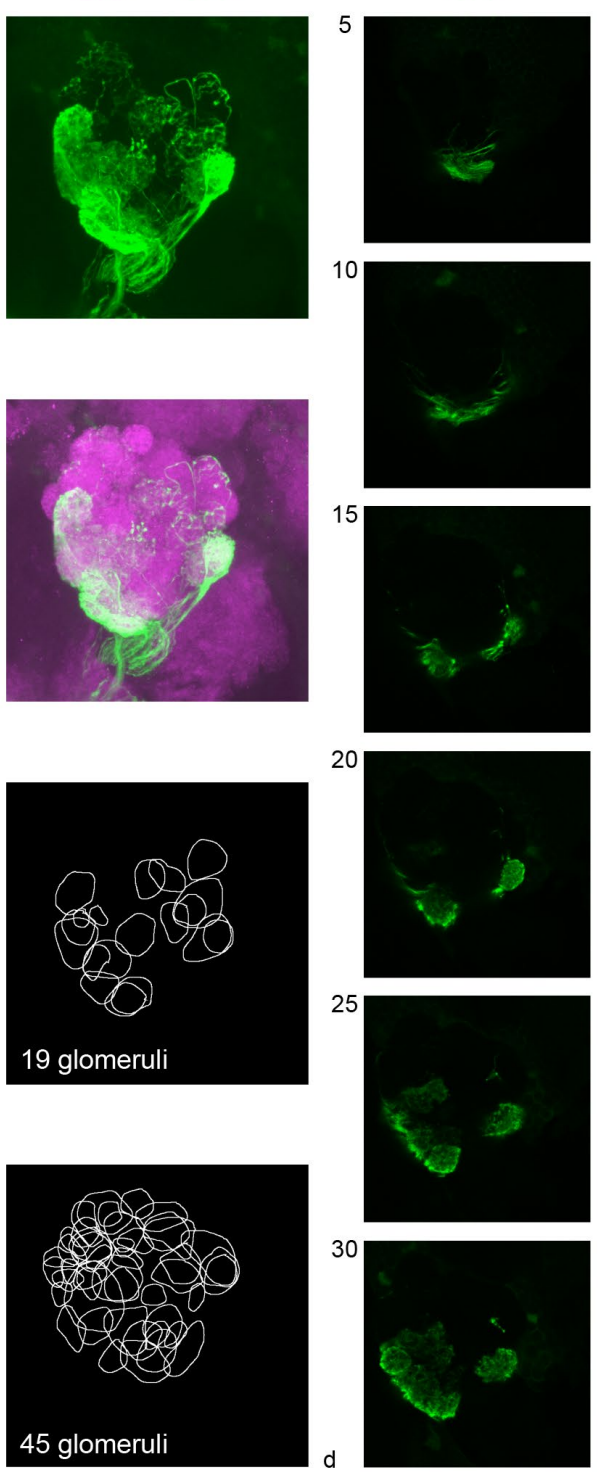

B

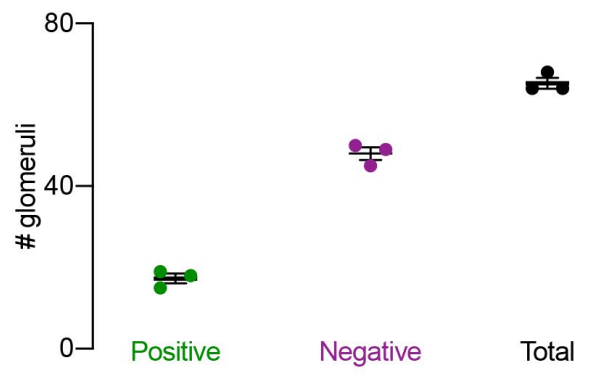


bioRxiv preprint doi: https://doi.org/10.1101/2020.11.07.368720; this version posted November 8, 2020. The copyright holder for this preprint (which was not certified by peer review) is the author/funder, who has granted bioRxiv a license to display the preprint in perpetuity. It is made available under aCC-BY 4.0 International license.

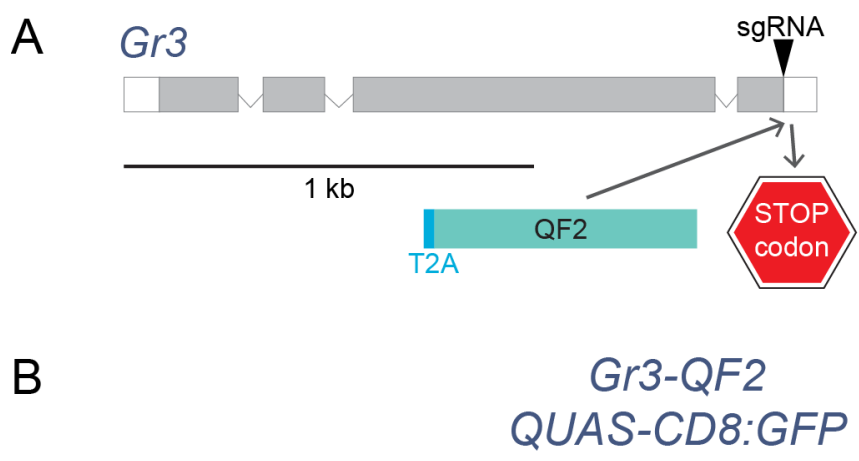

Brain 1
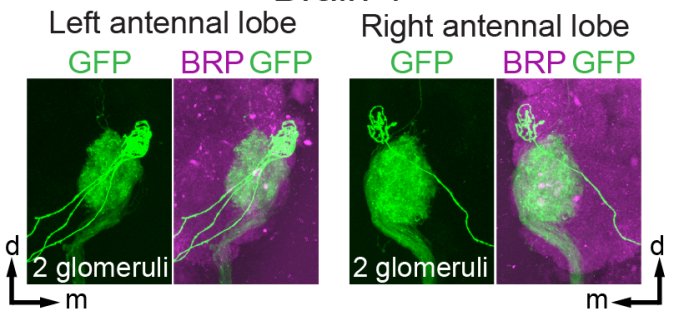

Brain 3

Left antennal lobe

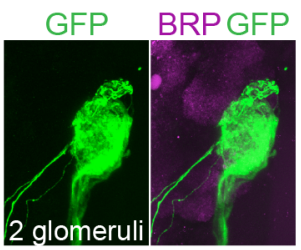

Right antennal lobe

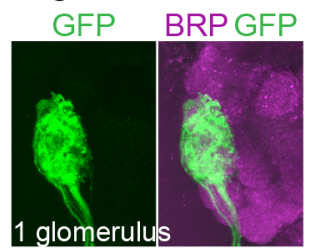

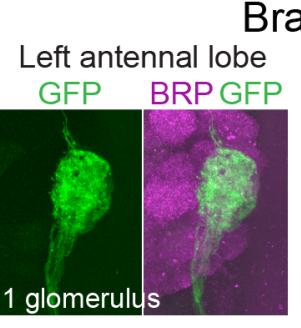

Brain 2

Right antennal lobe

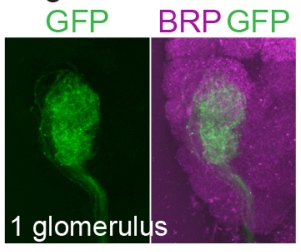

\section{Brain 4}

Left antennal lobe

Right antennal lobe
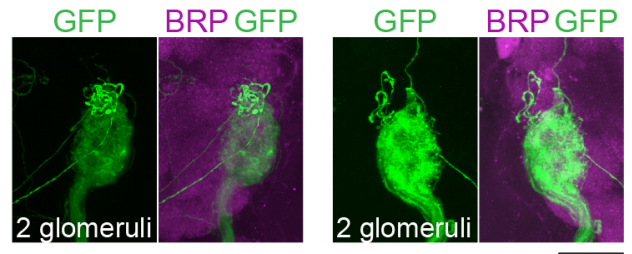

Figure S6. Projections of GR3-QF2-expressing neurons in the antennal lobe (Related to Figure 1)

(A) Gr3 locus with exons (grey boxes), introns (grey lines) and CRISPR-Cas9 gRNA site (arrowhead) used to insert T2A-QF2 (light blue). (B) Maximum-intensity projection confocal Z-stack through the medial antennal lobes of 4 brains with immunofluorescent labeling of GFP (green) and Brp (synaptic marker, magenta). Scale bar: $25 \mu \mathrm{m}$. Orientation: $\mathrm{d}=\mathrm{dorsal}$, $\mathrm{m}=$ medial. 
bioRxiv preprint doi: https://doi.org/10.1101/2020.11.07.368720; this version posted November 8, 2020. The copyright holder for this preprint (which was not certified by peer review) is the author/funder, who has granted bioRxiv a license to display the preprint in perpetuity. It is made available under aCC-BY 4.0 International license.

A

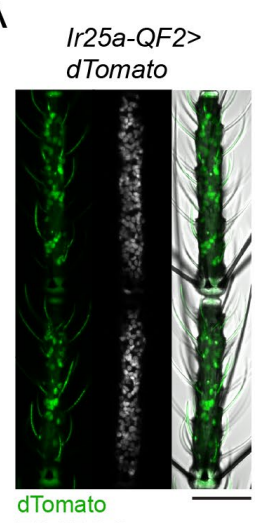

B

Ir25a-QF2> dTomato

Orco-QF2> dTomato

$\mid r 25 a-Q F 2-A D>$ dTomato

Orco-QF2-DBD> dTomato

Ir25a-QF2-AD, Orco-QF2-DBD> dTomato

C

Ir25a-QF2-AD Orco-QF2-DBD> dTomato

Ir25a-QF2-AD, Orco-QF2-DBD> dTomato
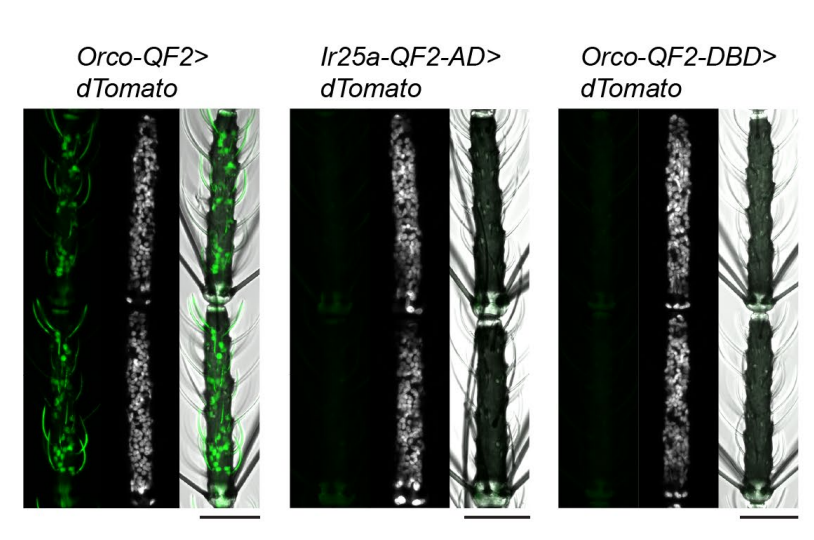

Ir25a-QF2-AD,

Orco-QF2-DBD> dTomato

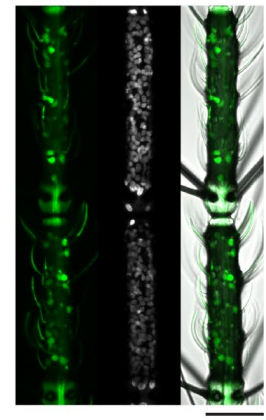

dTomato TO-PRO-3
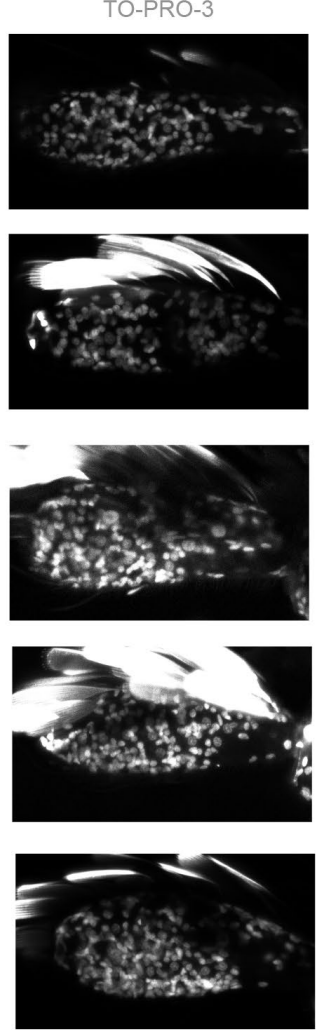

dTomato positive
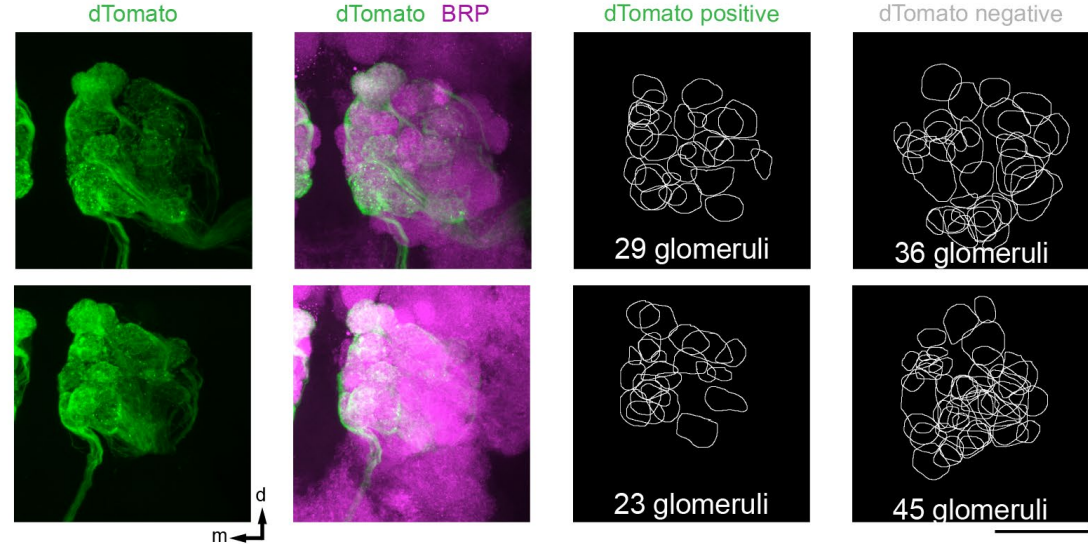

dTomato BRP
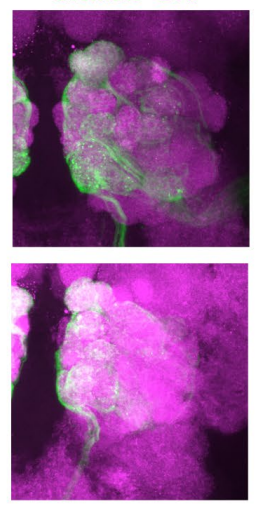
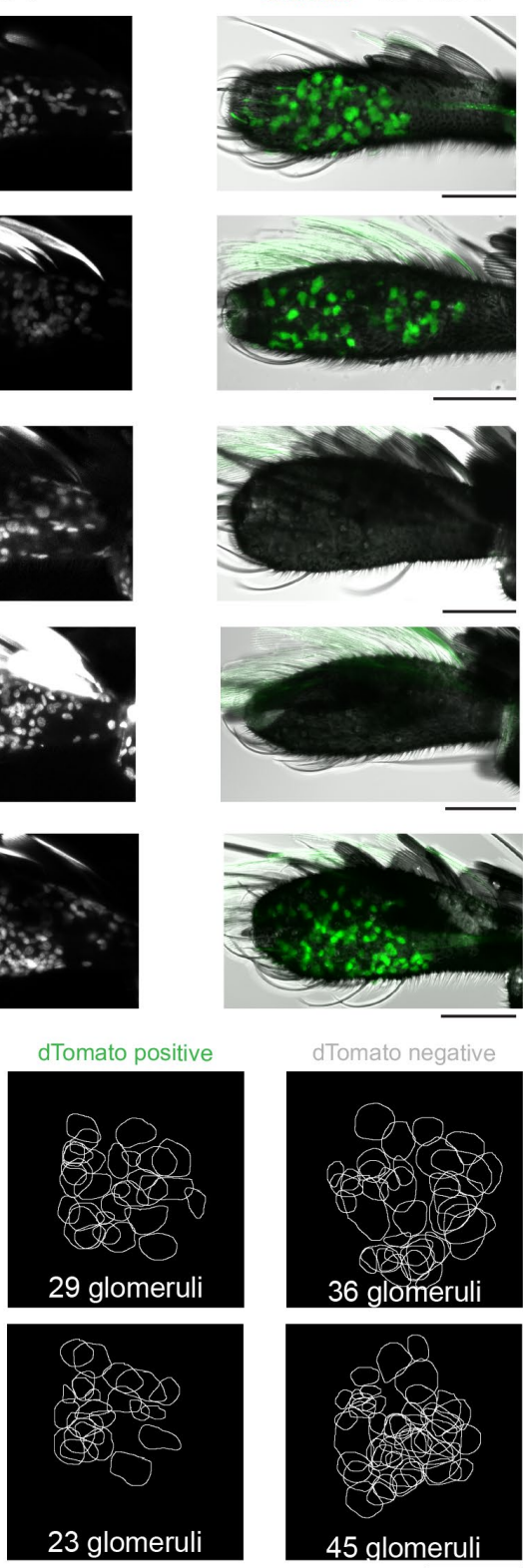

dTomato

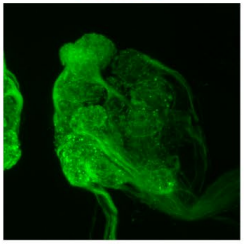

23 glomeruli

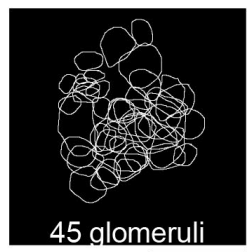

Figure S7. Specificity of Split-QF2 reagents (Related to Figure 2)

(A-B) Maximum-intensity projections of confocal Z-stacks of antennae (A) and maxillary palps (B) of the indicated genotypes showing intrinsic dTomato fluorescence and stained with the nuclear dye TO-PRO-3, with transmitted light overlay. (C) Maximum-intensity projections of confocal Z-stacks of left antennal lobes from two different brains of the indicated genotype with immunofluorescent labeling of dTomato (green) and Brp (synaptic marker, magenta) (top) and 2-D representation of the boundary of each glomerulus that is GFP positive and GFP negative (bottom). Scale bars: $50 \mu \mathrm{m}$. Orientation (C,D): $d=d o r s a l, m=m e d i a l$. 
bioRxiv preprint doi: https://doi.org/10.1101/2020.11.07.368720; this version posted November 8, 2020. The copyright holder for this preprint (which was not certified by peer review) is the author/funder, who has granted bioRxiv a license to display the preprint in perpetuity. It is made available under aCC-BY 4.0 International license.

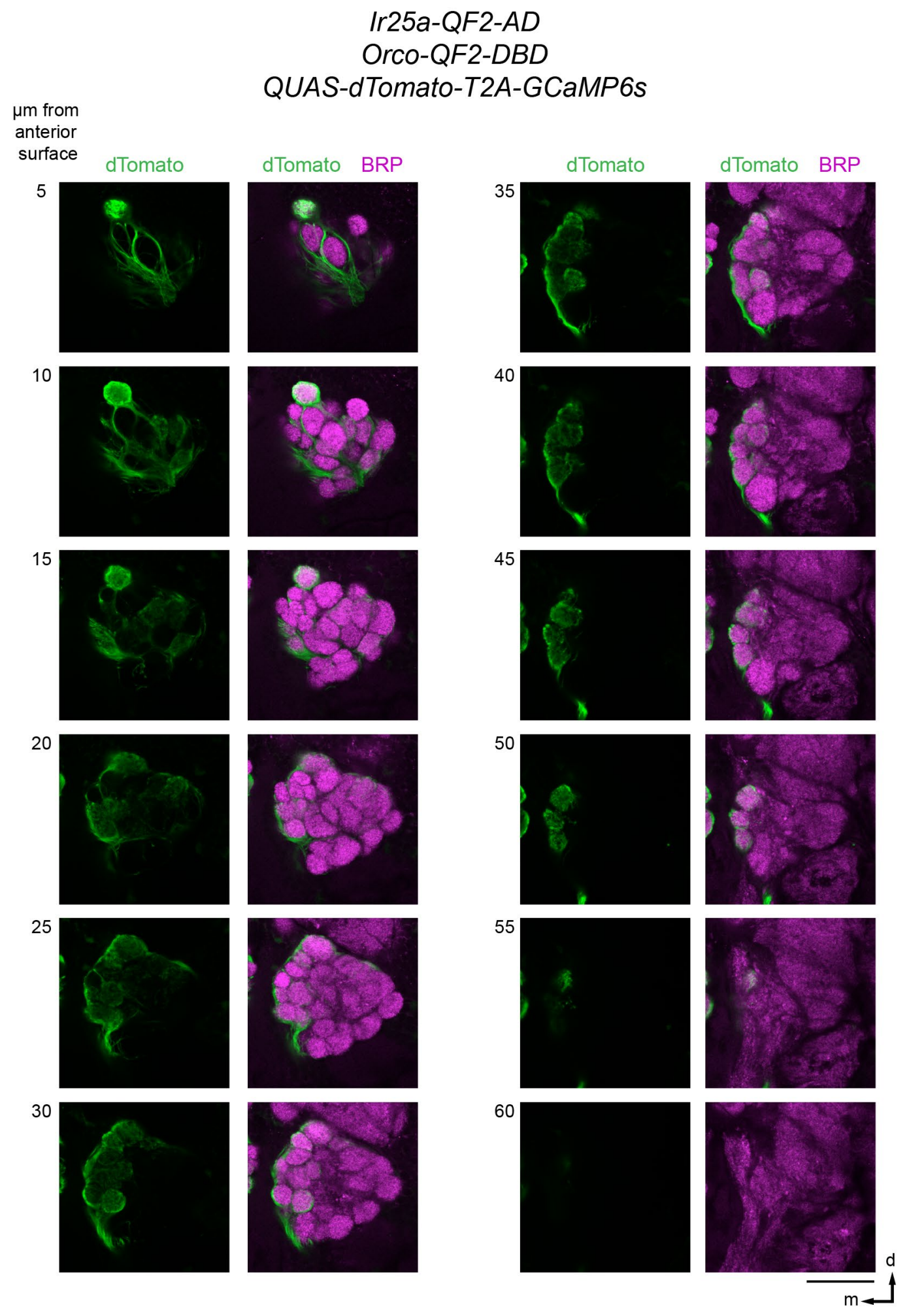

Figure S8. Projections of Orco-QF2-DBD; Ir25A-QF2-AD-expressing neurons in a single antennal lobe (Related to Figure 2)

Single confocal sections taken from the maximum-intensity projection confocal Z-stack of the left antennal lobe shown in Figure $2 \mathrm{G}$ with immunofluorescent labeling of dTomato (green) and Brp (synaptic marker, magenta). A single plane is shown every $5 \mu \mathrm{m}$ in $\mathrm{Z}$ to capture each glomerulus. Scale bar: $50 \mu \mathrm{m}$. Orientation: $d=d o r s a l, m=m e d i a l$. 
bioRxiv preprint doi: https://doi.org/10.1101/2020.11.07.368720; this version posted November 8, 2020. The copyright holder for this preprint (which was not certified by peer review) is the author/funder, who has granted bioRxiv a license to display the preprint in perpetuity. It is made available under aCC-BY 4.0 International license.

A

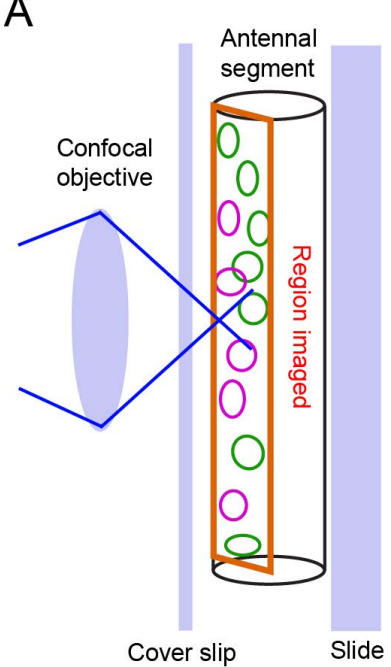

B Dorso-lateral 4th maxillary palp segment
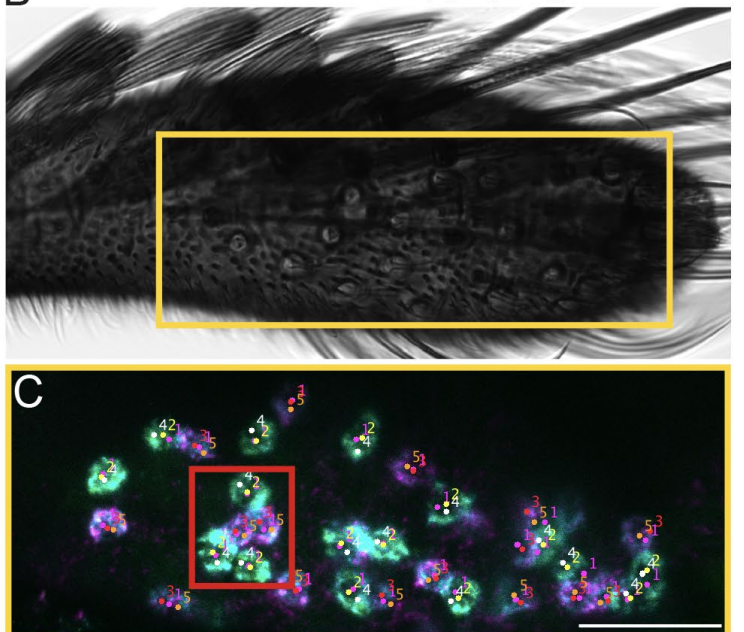

I
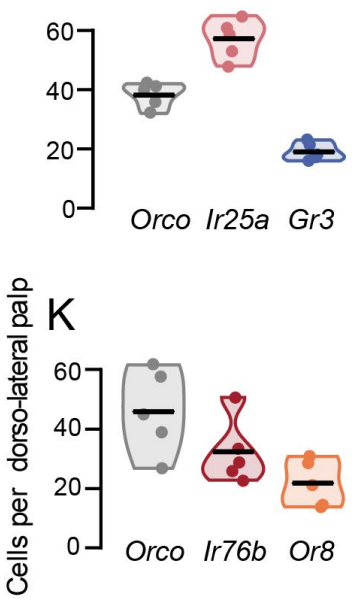

M

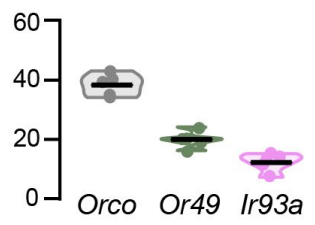

J

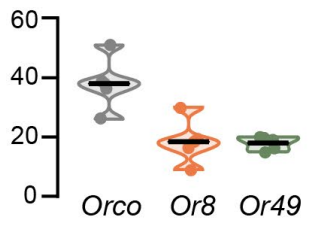

L

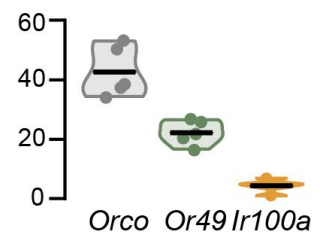

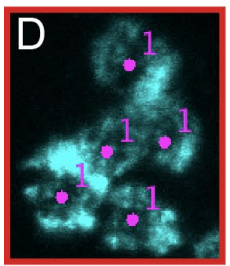
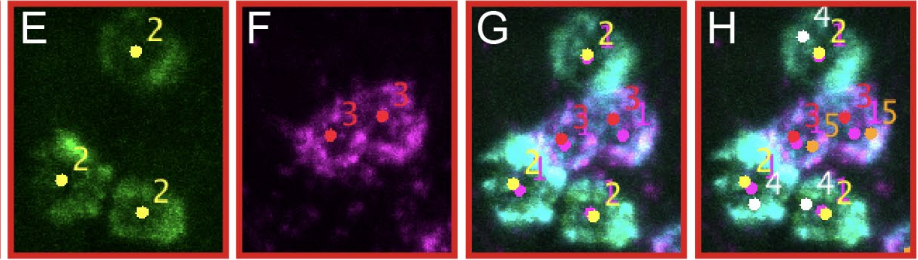

$\mathrm{N}$
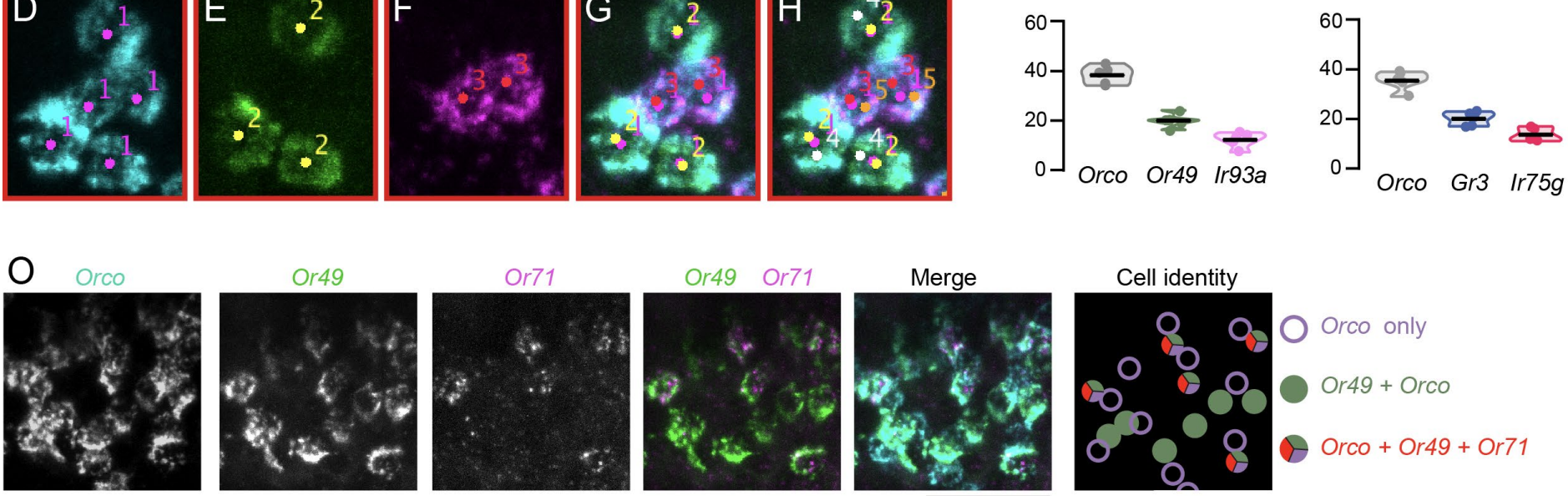

Q Gr3>GFP

P Ir25a>GFP
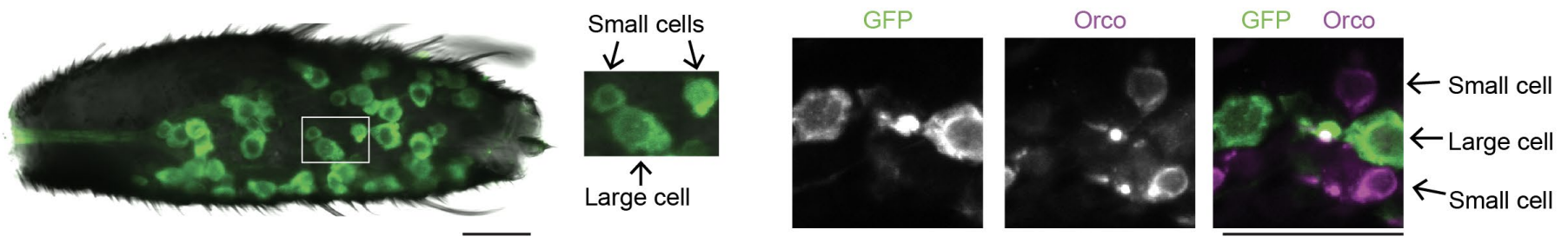

Figure S9. Quantification of antennal and maxillary palp cell populations (Related to Figure 3 and Figure 4)

(A-H) Workflow for cell quantification. Schematic of antennal region imaged on a confocal microscope (A) and image of maxillary palp with imaged area indicated with the yellow square (B). Whole-mount maxillary palp RNA in situ, yellow region from (C). Cells are manually marked independently as Orco+, Or49+, or Or8+ (red inset from B) using FIJI Cell Counter (D-F) and markers from each channel are merged (G). Cells with markers 1 and 2 are then scored as Orco+Or49+ with marker 4, and cells with markers 1 and 3 are then scored as Orco+Or8+ with marker $5(\mathrm{H})$. Counts from each marker for each image are exported into Excel and R for further analysis. (I-N) Total cell counts from whole mount maxillary palp RNA in situs in Figure 4. Mean with range, $n=5$. (O) RNA in situ of whole-mount maxillary palp with the indicated probe and cell identity schematic. (P-Q) Whole-mount maxillary palp immunostaining showing Ir25a expression in "small" and "large" cells (P) and Gr3 expression in "large" cells and Orco protein in "small" cells (Q). Scale bars: $25 \mu \mathrm{m}$ except (C): 50 $\mu \mathrm{m}$. Orientation $(\mathrm{B}, \mathrm{P})$ : distal right. 